\title{
Microphysical and Radiative Properties of Marine Stratocumulus from Tethered Balloon Measurements
}

\author{
By \\ David P. Duda and Graeme L. Stephens
}

Department of Atmospheric Science

Colorado State University

Fort Collins, Colorado

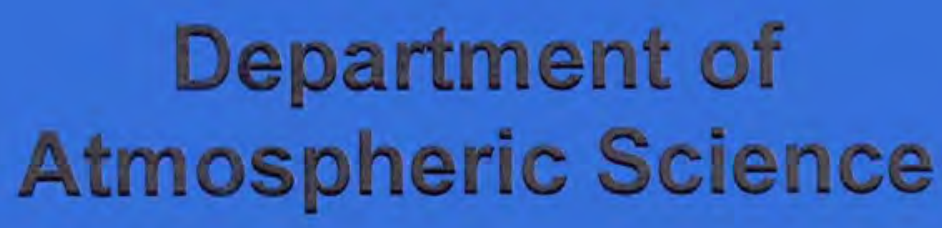

Paper No. 453 
MICROPHYSICAL AND RADIATIVE PROPERTIES OF MARINE STRATOCUMULUS FROM TETHERED BALLOON MEASUREMENTS

by

David P. Duda and Graeme L. Stephens

Research supported by NSF Grant ATM-8415127 and ONR Grant N0014- 87-K-0228

Principal Investigator: Graeme L. Stephens

Department of Atmospheric Science

Colorado State University

Ft. Collins, CO 80523

May 1989

Atmospheric Science Paper No. 453 


\begin{abstract}
FIRE is a research program which uses both field observations and numerical modeling to investigate the physical processes that govern large-scale cloud systems and the interactions between these clouds and climate. In this paper, microphysics and radiation measurements of subtropical marine stratocumulus clouds made from a tethered balloon during the FIRE intensive field observation program were analyzed.

Radiation data from two pairs of pyranometers were used to obtain vertical profiles of the net near-infrared and total solar fluxes through the boundary layer, while a pair of pyrgeometers supplied measurements of net longwave fluxes in the cloud layer. From the raw data collected from a FSSP probe, estimates of the droplet size distribution, total number density, mean and effective radius and liquid water content in the cloud were calculated. A sensitivity analysis of the data showed the computed number concentrations were sensitive to changes in the wind speed and the relative orientation between the wind and the probe. The radiation fields in the cloud layer were also mathematically simulated by a two-stream radiative transfer model.
\end{abstract}

The results of the microphysics analysis showed that when the air flow in the boundary layer was away from the continent, the droplet size distribution was dominated by small droplets and the LWC in the cloud was much less than the adiabatic LWC value. On days with onshore flow, the droplet size distribution was marine-like and the cloud LWC was near the adiabatic LWC.

Vertical profiles of the observed longwave cooling rates in the clouds were similar in shape and magnitude not only to previous measurements of marine stratocumulus, but also to the cooling rates computed by the two-stream radiative transfer model. However, the solar heating rates measured in the cloud were significantly larger than the rates calculated in the model and appeared more important to the radiative energy balance of the cloud than previously expected. Nearly equal contributions to the observed shortwave heating came from the visible and near IR portions of the spectrum, which contrasts greatly with the model results of heating. The computed solar reflectivities and absorptivities tended to be lower than the observed values, while the calculated transmissivities were much 
higher than the measured transmissivities. The discrepancy between the observed near IR to visible albedo ratio and the calculated values was less than the results reported by Hignett (1987).

This study showed that tethered balloon instrumentation can be an excellent method for the collection of high-resolution vertical microphysics and radiation data. Some suggestions are made on improving the quality of the data collected by the instrument platform. 


\section{ACKNOWLEDGEMENTS}

We wish to acknowledge various people who have contributed in different ways to this research. Among those are Dr. Wayne Schubert, and Dr. Allan Kirkpatrick for their evaluation of this paper.

We are also indebted to many others for their support during the preparation and writing of this paper. We would like to thank Paul Hein, Dr. Stephen Cox, and Chris Johnson-Pasqua for their assistance in obtaining and analyzing the data from the tethered balloon, and Thomas Guinn and Mike Mulloy for their help in the reduction of the meteorological and radiation data. Thanks is also given to Jack Snider for providing the microwave radiometer data, Paul Ciesielski for supplying the CLASS sounding data, and Judy Sorbie for her excellent drafts of several figures in this paper. We are particularly grateful to Paul Stackhouse for his helpful comments and for providing the use of his radiative transfer model in the analysis of the data. We also appreciate the efforts of Susan Lini, who helped in the preparation of this paper.

This research was supported by the Atmospheric Sciences Section of the National Science Foundation under Contract ATM-8415127 and Office of Naval Research under Contract N00014-87-K-0228 and computer calculations were carried out using the super computer facilities at Colorado State University Computer Center. 
1 Introduction 1

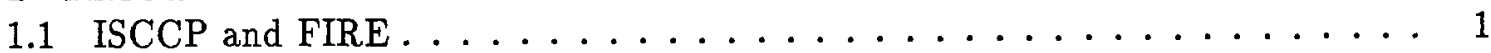

1.2 CSU Instrument Platform . . . . . . . . . . . . . . . . 3

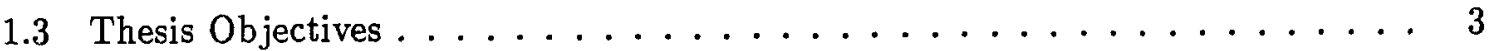

1.4 Thesis Outline ...................... 5

2 Radiation Instrumentation 6

2.1 Description of Tethered Balloon . . . . . . . . . . . . . 6

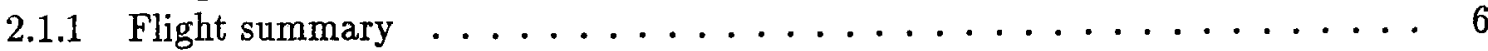

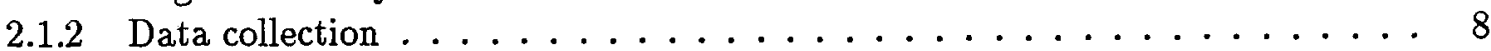

2.2 Description of Radiation Instruments . . . . . . . . . . . 8

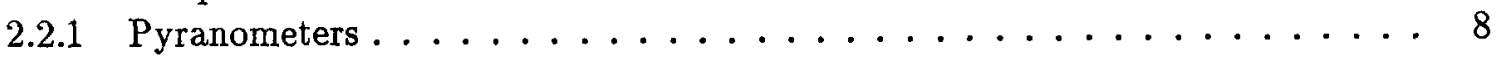

2.2 .2 Pyrgeometers . . . . . . . . . . . . . . . . . 8

2.2 .3 Pyrgeometer corrections . . . . . . . . . . . . . . . 11

3 Microphysics Instrumentation $\quad 15$

3.1 FSSP Probe . . . . . . . . . . . . . . . . . . . . 15

3.2 Data Reduction . . . . . . . . . . . . . . . . . . 17

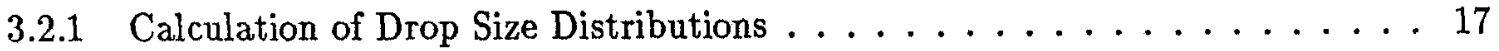

3.2.2 Calculation of other microphysical variables . . . . . . . . . . . 19

3.3 Circuitry Problems with FSSP Probe . . . . . . . . . . . . . . . 21

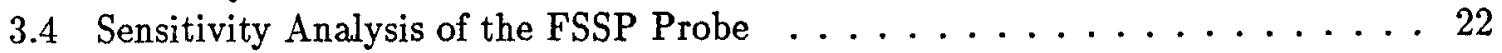

3.5 Summary . . . . . . . . . . . . . . . . . . . . 24

4 Results 25

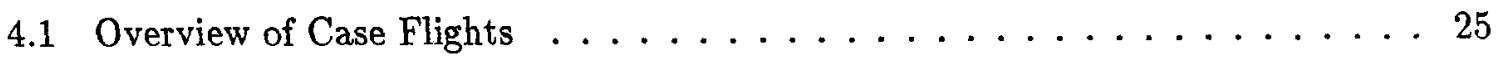

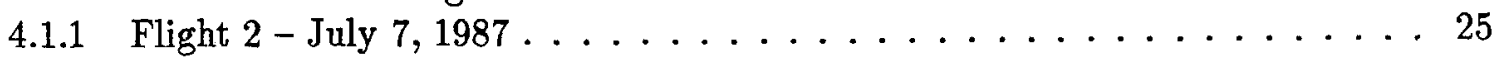

4.1 .2 Flight 3 - July $8,1987 \ldots \ldots \ldots \ldots \ldots \ldots$

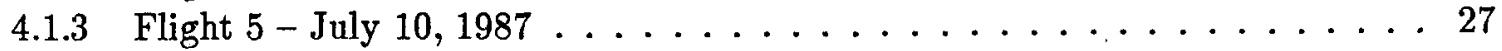

4.2 Microphysics Measurements . . . . . . . . . . . . . . . . 31

4.2 .1 Droplet size distributions . . . . . . . . . . . . . . . . 31

4.2 .2 Liquid water content . . . . . . . . . . . . . . . . . 32

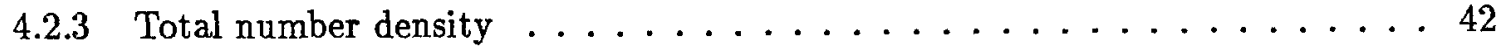

4.2 .4 Effective and mean radius . . . . . . . . . . . . . . . . . . . 42

4.2 .5 Comparison with other measurements . . . . . . . . . . . . 49

4.3 Radiation Measurements . . . . . . . . . . . . . . . . . . . 50

4.3 .1 Longwave radiative heating rates ................ 50

4.3 .2 Cloud top solar fluxes . . . . . . . . . . . . . . . . . 52

4.3 .3 Shortwave radiative heating rates . . . . . . . . . . . 57 


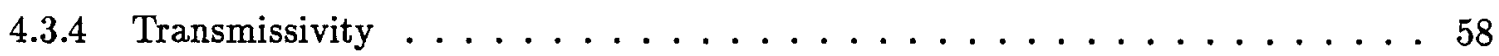

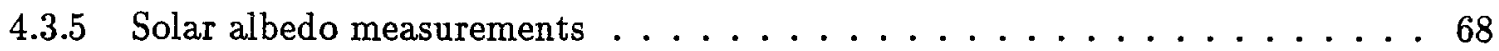

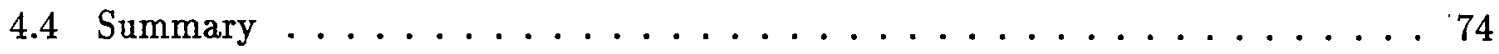

5 Two Stream Radiative Transfer Model ' 78

5.1 Introduction . . . . . . . . . . . . . . . . . 78

5.2 Formulation of the Two Stream Model . . . . . . . . . . . . . . . 79

5.3 Development of the Source Terms . . . . . . . . . . . . . . . . . . . . . . . . .

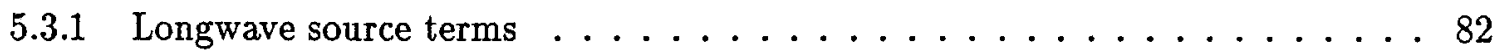

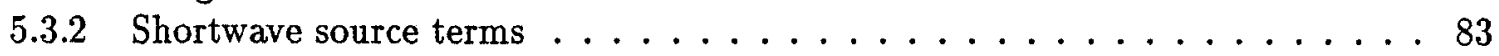

5.4 The Incorporation of Absorption and Scattering Processes of Both Gases and

Cloud Particles . . . . . . . . . . . . . . . . . 84

5.4.1 Calculation of optical depth . . . . . . . . . . . . . . 84

5.4.2 Scaling of the Single Scatter Albedo, Asymmetry Parameter and Direct

Backscattered Fraction . . . . . . . . . . . . . . 86

5.5 The Integration of Spectral Fluxes and the K-Distribution Method . . . . . . 86

5.6 Multi-layer Solution . . . . . . . . . . . . . . . . . 89

5.7 Computation of Heating Rates . . . . . . . . . . . . . . . 90

5.8 Comparison Between Simulated and Observed Radiation Fields . . . . . . . . 90

5.9 Implementation of the Two Stream Model . . . . . . . . . . . . . . . . . . . . . . . . . . .

5.10 Longwave Flux Results . . . . . . . . . . . . . . . . . 91

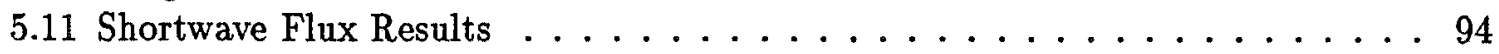

5.12 Radiative Energy Budget . . . . . . . . . . . . . . . . . . . . . . . . . . . . . . . .

5.13 Solar Albedo Calculations . . . . . . . . . . . . . . . . . . . . . . . . . . . . . . . . . .

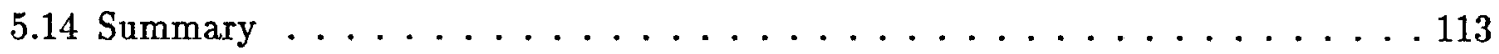

6 Summary, Conclusions and Recommendations 115

6.1 Analysis of Microphysical Data . . . . . . . . . . . . . 116

6.2 Analysis of Radiation Data . . . . . . . . . . . . . . 117

6.3 Comparison between Observed and Calculated Fluxes . . . . . . . . . . 117

6.4 Conclusions and Recommendations for Future Research . . . . . . . . . . 118

6.5 Suggestions for observational approaches used in marine stratocumulus . . . . . 119 


\section{LIST OF FIGURES}

2.1 CSU Instrument Platform . . . . . . . . . . . . . . . 7

3.1 FSSP Optical System (after Particle Measuring Systems, 1984) . . . . . . . 16

4.1 Pressure measured by the platform versus time from Flight 2 on July 7, 1987. . 26

4.2 Pressure measured by the platform versus time from Flight 3 on July 8, 1987. . 28

4.3 Wind direction versus time observed during Flight 3. . . . . . . . . . . . 29

4.4 Pressure measured by the platform versus time during Flight 5 on July 10, 1987. 30

4.5 Mean normalized droplet size distributions for the indicated flights. . . . . . . 33

4.6 Profile of mean LWC computed for all legs of Flight 2. . . . . . . . . . . . . . 34

4.7 Water vapor path and liquid water path measured by the NOAA/WPL microwave radiometer for July $7,1987 \ldots \ldots \ldots \ldots$

4.8 Profile of mean LWC computed for all legs of Flight 3. . . . . . . . . . . 36

4.9 Wind speed versus time observed during Flight $3 . \ldots \ldots \ldots$

4.10 Water vapor path and liquid water path measured by the NOAA/WPL microwave radiometer for July $8,1987 \ldots \ldots \ldots$. . . . . . . . . . 39

4.11 Profile of mean LWC computed for all legs of Flight 5. . . . . . . . . . . . 40

4.12 Water vapor path and liquid water path measured by the NOAA/WPL microwave radiometer for July $10,1987 . \ldots \ldots$. . . . . . . . . . . 41

4.13 Profile of the average total number density taken from the constant level legs of Flight 2. . . . . . . . . . . . . . . . . . . 43

4.14 Profile of the average total number density taken from the constant level legs of Flight 3. . . . . . . . . . . . . . . . . . . . . 44

4.15 Profiles of the average total number density taken from the constant level legs of Flight 5. . . . . . . . . . . . . . . . . 45

4.16 Profiles of the mean radius and the effective radius taken from the constant level legs of Flight 2. . . . . . . . . . . . . . . 46

4.17 Profiles of the mean radius and the effective radius taken from the constant level legs of Flight 3. . . . . . . . . . . . . . . . . . 47

4.18 Profiles of the mean radius and the effective radius taken from the constant level legs of Flight $5 \ldots \ldots \ldots . \ldots . \ldots . \ldots 48$

4.19 Longwave radiative fluxes and heating rates determined from the morning profile (1442-1554 GMT) taken during Flight 2 on July $7,1987, \ldots \ldots \ldots$. . 51

4.20 Same as Figure 4.19, except the profile was taken from 2038 to 2154 GMT. . . 53

4.21 Same as Figure 4.19, except the profile was taken from 2203 to 2315 GMT. . . 54

4.22 Same as Figure 4.19, except the profile was taken from 2320 to 0030 GMT. . . 55

4.23 Longwave radiative fluxes and radiative heating rates determined from the profile taken between 1434 and 1534 GMT during Flight 3 on July 8, 1987. 56 
4.24 Shortwave radiative fluxes and radiative heating rates determined from the morning (1442-1554 GMT) profile taken during Flight 2. The fluxes and the heating rates were normalized to the time midway through the profile $(1518 \mathrm{GMT}) . \ldots \ldots \ldots \ldots \ldots \ldots \ldots$

4.25 Shortwave radiative fluxes and radiative heating rates determined from the afternoon (2038-2154 GMT) profile taken during Flight 2. The fluxes and the heating rates were normalized to the time midway through the profile

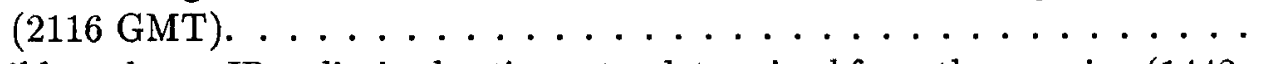

4.26 Visible and near IR radiative heating rates determined from the morning (14421554 GMT) profile taken during Flight 2 . The fluxes and heating rates were normalized to 1518 GMT. . . . . . . . . . . . . . . . . .

4.27 Visible and near IR radiative heating rates determined from the afternoon (2038-2154 GMT) profile taken during Flight 2. The fluxes and heating rates were normalized to 2116 GMT. . . . . . . . . . . . . . .

4.28 Shortwave radiative fluxes and radiative heating rates determined from the (1434-1534 GMT) profile taken during Flight 3. The fluxes and the heating rates were normalized to the time midway through the profile (1504 GMT).

4.29 Visible and near IR radiative heating rates determined from the profile taken from 1434 to 1534 GMT during Flight 3. The fluxes and heating rates were normalized to 1504 GMT. . . . . . . . . . . . . . . . . .

4.30 Time series of solar albedo measurements taken above the boundary layer during Flight 2. . . . . . . . . . . . . . . . . 70

4.31 Time series of near IR albedo/visible albedo measurements taken above the boundary layer during Flight 2. . . . . . . . . . . . . . . 71

4.32 Time series of the total, near IR, and visible albedos above the cloud observed

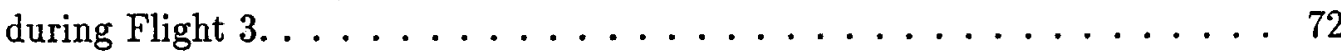

4.33 Time series of near IR albedo/visible albedo measurements taken above the boundary layer during Flight 3. . . . . . . . . . . . . 73

4.34 Time series of the total, near IR, and visible albedos above the cloud observed during Flight 5. . . . . . . . . . . . . . . . . 75

4.35 Time series of near IR albedo/visible albedo measurements taken above the boundary layer during Flight $5 \ldots \ldots \ldots$. . . . . . . . 76

5.1 Droplet size distributions used in the radiative transfer model cases. . . . . . . 92

5.2 Calculated net longwave irradiances for Case 1. . . . . . . . . . . . . 95

5.3 Calculated net longwave irradiances for Case $2 \ldots \ldots \ldots \ldots$

5.4 Calculated net longwave irradiances for Case 3. . . . . . . . . . . . . . 97

5.5 Calculated longwave heating rates for Case $1 \ldots \ldots \ldots \ldots$. . . . . . . . . . . . . . . . . . .

5.6 Calculated longwave heating rates for Case $2 \ldots \ldots \ldots$. . . . . . . . 99

5.7 Calculated longwave heating rates for Case 3. . . . . . . . . . . . . . 100

5.8 Calculated net shortwave irradiances for Case $1 . \ldots \ldots$. . . . . . . . . . . . . . . . . . . . . . .

5.9 Calculated net shortwave irradiances for Case 2. . . . . . . . . . . . 103

5.10 Calculated net shortwave irradiances for Case 3. . . . . . . . . . . . . 104

5.11 Calculated shortwave heating rates for Case $1 . \ldots \ldots \ldots$

5.12 Calculated shortwave heating rates for Case $2 \ldots \ldots \ldots$. . . . . . . . . . . . . . . . . . . . . .

5.13 Calculated shortwave heating rates for Case $3 . \ldots \ldots 10 . \ldots \ldots$ 
5.14 Observed (Flight 3) and calculated (Case 3) radiative energy balance inside the cloud on July $8,1987 \ldots \ldots \ldots$. . . . . . . . . . . . 110 


\section{LIST OF TABLES}

2.1 CSU Tethered Balloon Instrumentation $\ldots \ldots \ldots \ldots \ldots \ldots$

2.2 CSU Tethered Balloon Research Summary . . . . . . . . . . . . 9

2.3 CSU Tethered Balloon Research Summary . . . . . . . . . . . . . 10

2.4 FIRE - CSU Tethered Balloon Platform - RAD Output . . . . . . . . . 11

2.5 Radiation Output Interval . . . . . . . . . . . . . . . 14

2.6 Pyrgeometer Coefficients . . . . . . . . . . . . . . . . . 14

3.1 FSSP Size Ranges . . . . . . . . . . . . . . . 18

3.2 FIRE - CSU Tethered Balloon Platform - FSSP Output . . . . . . . 18

3.3 FIRE - CSU Tethered Balloon Platform - MET Output . . . . . . . . . 20

4.1 Mean and standard deviation of the solar transmissivity at each level from Flight 2 on July $7,1987 . \ldots \ldots \ldots \ldots \ldots 6$

4.2 Mean and standard deviation of the solar transmissivity at each level from Flight 3 on July $8,1987 . \ldots \ldots \ldots \ldots \ldots$. . . . . . . . 67

4.3 Mean and standard deviation of the solar transmissivity at each level from Flight 5 on July $10,1987 . \ldots \ldots \ldots \ldots 68$

4.4 Mean shortwave fluxes (in $\mathrm{W} \cdot \mathrm{m}^{-2}$ ) from constant level legs measured during flights on July 7 and July $10 \ldots \ldots \ldots \ldots \ldots \ldots$

5.1 Bandwidths of Absorbing Gases . . . . . . . . . . . . . . 88

5.2 Location of cloud in model atmosphere and the LWC profile for Cases 1 and 2. 93

5.3 Location of cloud in model atmosphere and the LWC profile for Case 3. . . . 93

5.4 Flight legs used to calculate the optical properties of the simulated clouds in

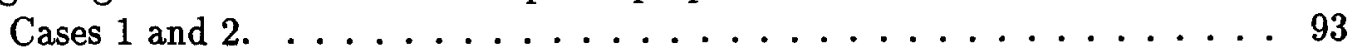

5.5 Flight legs used to calculate the optical properties of the simulated clouds in Case 3. . . . . . . . . . . . . . . . . . . . . . 109

5.6 Calculated shortwave fluxes and the near IR, visible and total solar albedos for Case 1. . . . . . . . . . . . . . . . . . . . 109

5.7 Calculated shortwave fluxes and the near IR, visible and total solar albedos for Case 2. . . . . . . . . . . . . . . . . . . . . . 109

5.8 Calculated shortwave fluxes and the near IR, visible and total solar albedos for Case $3 . \ldots \ldots \ldots \ldots \ldots \ldots \ldots 112$

5.9 Cloud radiative properties of the total solar spectrum. . . . . . . . . . . 112

5.10 Cloud radiative properties of the near infrared spectrum. . . . . . . . . 112

5.11 Cloud radiative properties of the visible spectrum. . . . . . . . . . 112

5.12 Near IR to visible albedo ratios for the model results and the tethered balloon observations. . . . . . . . . . . . . . . . . 114 


\section{Chapter 1}

\section{INTRODUCTION}

Earth's cloudiness is composed of many types of cloud systems. Some systems such as extratropical cyclones, hurricanes, and mesoscale squall lines have been studied in detail due to their immediate effects on mankind. Although these systems have provided much interest for atmospheric scientists, they make up only a small fraction of the global cloud cover. Cirrus and maritime stratocumulus clouds cover large areas of the planet, but until the past two decades they have been largely ignored by researchers. It appears that these cloud systems have several important and interesting effects on the global atmospheric circulation and climate. For example, during the summer extensive marine stratocumulus cloud sheets form off the western coasts of the continents in the subtropics. These clouds help to control the amount of moisture which is transported from the ocean surface into the downward branch of the Hadley cell circulation, which is a source of water vapor for the intertropical convergence zone. The cloud systems can greatly affect the flow of solar and infrared radiation into the atmosphere-ocean system due to the different radiative properties of the stratocumulus clouds compared to those of the ocean. Atmospheric scientists interested in the factors which influence climatic change have recognized that changes in the size, composition and location of these cloud systems may significantly alter the global climate.

\subsection{ISCCP and FIRE}

Recently, two research programs have been started to study cloudiness and how it interacts with climate. The International Satellite Cloud Climatology Project (ISCCP) is a program designed to develop a climatological data base of global cloud cover from satellite photographs. Both cirrus and stratocumulus cloud systems, however, create difficulties 
in the algorithms used to compile the global cloud climatologies in ISCCP. Project FIRE (First ISCCP Regional Experiment) is a U. S. research program created to develop a basic understanding of cirrus and marine stratocumulus systems and to improve ISCCP data products.

FIRE has three components which include a modeling program and two data gathering operations involving Extended Time Observations (ETO) and Intensive Field Observations (IFO). The Intensive Field Observations are separate field programs developed to investigate cirrus and marine stratocumulus cloud systems in detail. The cirrus IFO occurred in October 1986 in Wisconsin, while the marine stratocumulus mission was completed in June-July 1987 near San Nicholas Island (SNI), an island off the southern California coast. The Extended Time Observations are a set of satellite data, meteorological analyses, and surface data over a large area where cirrus and marine stratocumulus cloud systems develop. The data from the ETO will be used to extend the information gathered in the IFOs to larger time and space scales. Both the ETO and IFO provide observational data for use in the modeling component of FIRE. The modeling part consists of radiative transfer models (RTM), models of cirrus and the marine bound ary layer and general circulation models. The models will be used to compare current understanding of these cloud systems with observations and to improve present parameterizations of these systems in GCMs.

Despite much theoretical work on stratocumulus convection and several measurements by aircraft-based instruments, many processes in the cloud are still not completely understood. One of the specific goals of FIRE is to seek a basic understanding of the roles played by physical processes in determining the life cycles of marine stratocumulus systems. Toward this goal, FIRE was designed to produce an improved set of observations of the clouds. During the stratocumulus IFO, several satellite, airborne, and surface instruments measured the physical properties of the clouds. Some of the aircraft, ship and surface measurements were coordinated with satellite passes in order to obtain some intercomparisons between the various instruments. 


\subsection{CSU Instrument Platform}

A NASA tethered balloon was included with the surface-based instruments on San Nicholas Island. Colorado State University participated in the FIRE stratocumulus IFO by adding an instrument platform to the NASA balloon. The instrument platform was attached to the tethered balloon cable and carried several instruments to measure the thermodynamic, radiative and microphysical characteristics of the cloud layer. Eppley pyranometers and pyrgeometers were used to measure the solar and infrared fluxes respectively, and a Forward Scattering Spectrometer (FSSP) was used to measure droplet size distributions and liquid water contents inside the cloud.

The use of tethered balloon instruments to study stratocumulus cloud systems is almost new. Instrumented tethered balloons have been used to study nocturnal stratocumulus over Great Britain (Slingo et al., 1982) and subtropical stratocumulus (Gerber, 1986), but the data collected from SNI are believed to be the first combination measurements of both solar and terrestrial radiation, and microphysics made inside a subtropical marine stratocumulus cloud by a tethered balloon instrument system.

Marine stratocumulus clouds are maintained by a balance between entrainment and radiative cooling/heating at cloud top, and fluxes of heat and moisture from the surface. Tethered balloon platforms may be one of the best ways to study these clouds because they offer several advantages over other instrument systems in the measurement of these energy balance components. The tethered balloon can probe the entire depth of the marine boundary layer more easily than aircraft and thus provide complete vertical profiles of several meteorological variables.

Unlike aircraft, the balloon platform can remain in one location over a long period of time and therefore can measure local time series of cloud properties. The instrument platform can also obtain high-resolution vertical data, which is essential for the study of radiative fluxes since they can vary dramatically through the $10-50 \mathrm{~m}$ below cloud top.

\subsection{Thesis Objectives}

One purpose of this thesis is to examine the usefulness of the balloon platform in studying stratocumulus clouds. An important aspect of this analysis is the development 
of better sampling techniques for the balloon. What kind of profiles should be made by the balloon in order to make proper measurements of radiative fluxes and microphysical properties?

The instrumentation aboard the platform is primarily designed to study the radiative part of the energy budget of the cloud. Several scientific issues concerning the radiative transfer through the cloud are addressed in this thesis. Some of these issues have not been explored extensively by the atmospheric science community, but they may have a profound impact on the evolution of the total energy balance in the stratocumulus clouds during the day. These include:

1. What is the depth and intensity of the longwave cooling and shortwave heating at cloud top?

2. How do these fields vary during the day?

3. What is the spectral distribution of shortwave heating in the cloud?

4. How do inhomogeneities in the cloud and changes in the microphysical properties affect the transfer of radiation through the boundary layer, especially in the near infrared and visible regions of the spectrum?

The analysis of the radiation and microphysical data from the tethered balloon may provide a better understanding of these questions, and result in new suggestions for future research.

Another topic which can be examined through the use of tethered balloons is the variability of the radiative budget in the cloud from day to day. More specifically, several balloon flights launched over a period of days provide an opportunity to study the influence of different air masses on the radiative properties of the cloud, especially through the effects of different air masses on the microphysical characteristics of the stratocumulus. Large areas of the stratocumulus sheets off the California coast are often influenced by continental air masses and its relatively large concentration of cloud condensation nuclei (CCN), and it is probable that the changes in the air mass significantly affect the radiative transfer 
over these areas. Since the tethered balloon is located in a region where both continental and maritime air masses are often present, this experiment provides an excellent setting to study the influences of air mass changes on the radiative transfer through stratocumulus.

Finally, the questions mentioned above can also be examined through the use of radiative transfer models (RTM). A RTM can numerically simulate the radiative transfer through the clouds observed by the instrument platform. The models create a simplified version of the real clouds which can be modified to study how a change in one variable may affect the whole system. A two stream radiative transfer model is used in this thesis to determine the changes in the radiation fields caused by a change in the microphysical properties of the cloud. The model results will supplement the observed data and may help distinguish between the relative importance of cloud inhomogeneities or microphysical properties on the radiative transfer through the marine boundary layer.

In order to study the questions mentioned above, the analysis of the data was divided into several flights which examine either a pure marine or continentally influenced cloud. Simulations of the radiative transfer through both types of clouds were made in order to compare current understanding of these clouds with the tethered balloon observations.

\subsection{Thesis Outline}

The following two chapters describe the radiation and microphysics instruments carried aboard the tethered balloon platform and the procedures used to reduce the raw data from the instruments into a usable form for each flight. Chapters 4 and 5 contain most of the original research of this thesis. Chapter 4 presents some results from three flights, which include measurements of the observed fluxes and solar and infrared heating rates inside the clouds. Sensitivity test results are also included in this chapter. Chapter 5 describes the two-stream radiative transfer model used to compute radiation fields above, below, and inside a simulated cloud. A comparison between the model and the observed radiation fields is also shown in Chapter 5, and Chapter 6 gives a brief summary and a discussion of the results. 


\section{Chapter 2}

\section{RADIATION INSTRUMENTATION}

A description of some of the instruments on the CSU platform are presented in this chapter and in Chapter 3. This chapter describes the flight patterns taken by the tethered balloon and the meteorological data collected during each flight. The Eppley pyranometers and pyrgeometers are described and the procedure used to correct the effects of differential heating on the pyrgeometers is also presented.

\subsection{Description of Tethered Balloon}

The tethered balloon used to carry the CSU instrument package was developed by the Wallops Flight Facility of the NASA/Goddard Space Flight Center. The balloon is $31.6 \mathrm{~m}$ long with a volume of $1275 \mathrm{~m}^{3}$ and is capable of lifting a $400 \mathrm{~kg}$ payload up to an altitude of $1 \mathrm{~km}$. A photograph of the balloon and the instrument platform is shown in Figure 2.1. The platform was attached to the tether line approximately 60 meters below the balloon and measured radiation, microphysical and thermodynamic properties in the cloud. Table 2.1 provides a list of the CSU instrumentation placed on the platform.

\subsubsection{Flight summary}

A total of nine research flights were made using the CSU package. Information on the vertical structure of the boundary layer was collected two ways. The first was a continuous profile through the boundary layer (the rise rate of the balloon was approximately 20 $\left.\mathrm{m} \cdot \mathrm{minute} \mathrm{e}^{-1}\right)$. The second method involved making a sounding in a series of steps; the balloon would be raised or lowered a set distance (usually $100 \mathrm{~m}$ ) and remained at a constant level for five to twenty minutes. This stepping method allows one to compute the mean and the range of the radiative and microphysical variables at several levels, while 

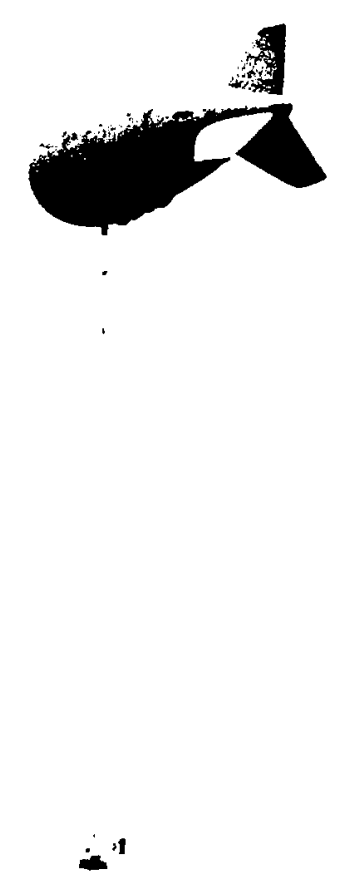

Figure 2.1: CSU Instrument Platform

Table 2.1: CSU Tethered Balloon Instrumentation

\begin{tabular}{|l|l|}
\hline Measurement Type & Instrumentation \\
\hline Meteorology & AIR Inc. barometer \\
Meteorology & Campbell resistance thermometer \\
Meteorology & Campbell hygristor \\
Meteorology & Campbell anemometer \\
Meteorology & AIR Inc. compass \\
Meteorology & Cambridge dew point hygrometer \\
Meteorology & MRL psychrometer \\
Cloud physics & FSSP PMS probe \\
Radiation & 4 Eppley pyranometers \\
Radiation & 2 Eppley pyrgeometers \\
Radiation & 2 CSU - (bugeye) radiometers \\
Radiation & CSU - photodiode \\
Radiation & Funk type net radiometer \\
Platform data system & 3 Campbell CR-21X Data Loggers \\
Photography & Color video \\
\hline
\end{tabular}


the continuous profile provides a vertical profile of data over a short time interval. The length of the flights varied from 1-10 hours. Tables 2.2 and 2.3 provide a summary of each flight.

\subsubsection{Data collection}

The information collected from the instrument platform was logged onto cassette tapes by three Campbell CR-21X Scientific Data Loggers and stored in three separate tapes for each flight. One tape contained the meteorological data (MET), while the second stored the data from radiation instruments and the anemometer (RAD), and the third contained information from the FSSP probe (FSSP). The data loggers converted much of the data from volts to engineering units $\left({ }^{\circ} \mathrm{C}, \mathrm{W} \cdot \mathrm{m}^{-2}\right.$, etc.). The data were later transferred to streaming tape and read onto a floppy disk.

\subsection{Description of Radiation Instruments}

\subsubsection{Pyranometers}

The tethered balloon instrument platform carried several different types of radiation instruments to measure both solar and infrared radiation. Two sets of Eppley pyranometers (upward and downward facing) were used to obtain measurements of the visible and near IR parts of the shortwave spectrum. One set of pyranometers measured the total shortwave spectrum (from $.3-2.8 \mu \mathrm{m}$ ), while the other set filtered by dark red Schott glass domes measured the near IR spectrum $(.7-2.8 \mu \mathrm{m})$. The pyranometers essentially consist of circular multi-junction thermopiles surrounded by a hemisphere of precision ground optical glass and are capable of measuring hemispheric solar fluxes within an accuracy of $5 \mathrm{~W} \cdot \mathrm{m}^{-2}$.

\subsubsection{Pyrgeometers}

Eppley pyrgeometers were used to measure the upward and downward infrared fluxes in the range from approximately $4-50 \mu \mathrm{m}$. The detectors used in these instruments are 100 junction thermopiles and have an accuracy of $30 \mathrm{~W} \cdot \mathrm{m}^{-2}$. Both the pyranometers and the pyrgeometers were calibrated before the start of the balloon flights. 
Table 2.2: CSU Tethered Balloon Research Summary

\begin{tabular}{|c|c|c|}
\hline DATE: & REMARKS: & LENGTH OF FLIGHT \\
\hline $\begin{array}{l}5 \text { July } 1987 \\
\text { JD } 186\end{array}$ & $\begin{array}{c}\text { First Flight (test flight) - daytime } \\
\text { PROBLEMS: FSSP missing least significant } \\
\text { bit (LSB) }\end{array}$ & 2 HOURS \\
\hline $\begin{array}{l}7 \text { July } 1987 \\
\text { JD } 188\end{array}$ & $\begin{array}{l}\text { Second Research Flight - daytime } \\
\text { Balloon launch at } 7: 45 \text { PDT. At } 13: 25 \\
\text { PDT the balloon starts two soundings } \\
\text { with } 5 \text { minute legs at each } 300 \mathrm{ft} \text { level } \\
\text { PROBLEMS: FSSP missing LSB, problem } \\
\text { with wet bulb wicks. Wicks } \\
\text { replaced after flight. }\end{array}$ & $\begin{array}{c}9 \text { HOURS } \\
52 \text { MINUTES }\end{array}$ \\
\hline $\begin{array}{l}8 \text { July } 1987 \\
\text { JD } 189\end{array}$ & $\begin{array}{l}\text { Third Research Flight - daytime } \\
\text { Four } 20 \text { minute constant level runs made } \\
\text { near cloud top. Balloon brought down } \\
\text { in } 200 \mathrm{ft} \text { steps with } 20 \text { minutes at each } \\
\text { level. } \\
\text { PROBLEMS: FSSP missing LSB }\end{array}$ & 6.5 HOURS \\
\hline $\begin{array}{l}9 \text { July } 1987 \\
\text { JD } 190\end{array}$ & $\begin{array}{l}\text { Fourth Research Flight - daytime } \\
\text { Deep cloud with top near } 950 \text { meters and } \\
\text { some drizzle. } \\
\text { PROBLEMS: FSSP missing LSB, thermistor } \\
\quad \text { psychrometer was not } \\
\text { operating due to broken } \\
\text { wire. }\end{array}$ & 4 HOURS \\
\hline $\begin{array}{l}\text { 10 July } 1987 \\
\text { JD } 191\end{array}$ & $\begin{array}{l}\text { Fifth Research Flight - daytime } \\
\text { Deep boundary layer (1000 m). Balloon } \\
\text { stepped upward in } 300 \mathrm{ft} \text { intervals with } \\
20 \text { minutes at each level. Several } 15 \\
\text { minute legs at } 50 \mathrm{ft} \text { intervals taken } \\
\text { near cloud top on descent. } \\
\text { PROBLEMS: FSSP and psychrometer were } \\
\text { fixed and working properly. }\end{array}$ & 10 HOURS \\
\hline
\end{tabular}


Table 2.3: CSU Tethered Balloon Research Summary

\begin{tabular}{|l|l|c|}
\hline DATE: & REMARKS: & LENGTH OF FLIGHT \\
\hline 11 July 1987 & $\begin{array}{l}\text { Sixth Research Flight - evening } \\
\text { Balloon launch at 13:35 PDT. Balloon } \\
\text { brought down in eleven 20 minute legs } \\
\text { after two hours near cloud top. } \\
\text { PROBLEMS: Instruments working properly. }\end{array}$ & 9.5 HOURS \\
\hline $\begin{array}{l}\text { 12 July 1987 } \\
\text { JD 193 }\end{array}$ & $\begin{array}{l}\text { Seventh Research Flight - morning } \\
\text { Balloon launch at 3:40 PDT. } \\
\text { PROBLEMS: Instruments working properly. } \\
\text { Flight was terminated due to } \\
\text { a sudden drop in the altitude } \\
\text { of the balloon. }\end{array}$ & \\
\hline $\begin{array}{l}\text { 13 July 1987 } \\
\text { JD 194 }\end{array}$ & $\begin{array}{l}\text { Eighth Research Flight - daytime } \\
\text { Sixteen 20 minute legs taken in the cloud } \\
\text { layer and nine in the subcloud layer. } \\
\text { PROBLEMS: FSSP missing every other } \\
\text { pair of channels. }\end{array}$ & 11.5 HOURS \\
\hline $\begin{array}{l}\text { 13-14 July 1987 } \\
\text { JD 194-195 }\end{array}$ & $\begin{array}{l}\text { Ninth Research Flight - nighttime } \\
\text { Balloon launch at 21:45 PDT. Cloud top } \\
\text { was low. Twenty constant level legs } \\
\text { made in the boundary layer. } \\
\text { PROBLEMS: FSSP shifted output to } \\
\text { lower end of spectrum. }\end{array}$ & 6.5 HOURS \\
\hline
\end{tabular}


The radiation data from each instrument was logged at an interval from 4-8 seconds. The format for the stored radiation variables is shown in Table 2.4. The output interval for each flight is shown in Table 2.5.

Table 2.4: FIRE - CSU Tethered Balloon Platform - RAD Output

\begin{tabular}{|c|c|c|c|c|c|c|}
\hline 01 ID-207 & $02 \mathrm{JD}$ & 03 HHMM & 04 SEC & 05 UPB1 & $06 \mathrm{UPB} 2$ & 07 UPB3 \\
\hline 08 UPB4 & 09 UPB5 & 10 UPB6 & 11 UPB7 & 12 UPB8 & 13 UPB 9 & 14 UPB10 \\
\hline 15 UPB11 & 16 UPB12 & 17 UPB13 & 18 DNB1 & 19 DNB2 & 20 DNB3 & 21 DNB4 \\
\hline 22 DNB5 & 23 DNB6 & 24 DNB7 & 25 DNB8 & 26 DNB9 & 27 DNB10 & 28 DNB11 \\
\hline 29 DNB12 & 30 DNB13 & 31 FIRUP & 32 FIRDN & 33 TOTUF & 34 NIRUP & 35 TOTDN \\
\hline 36 NIRDN & 37 ST-UP & 38 ST-DN & 39 DT-UP & 40 DT-DN & 41 FUNK & 42 BGTTE \\
\hline $43 \mathrm{LU}$ & $44 \mathrm{LD}$ & 45 WNDSP & & & & \\
\hline & ID & Identification $n$ & amber - 0207 & & & \\
\hline & JD & Julian date & & & & \\
\hline & HHMM & Hours minutes & 24 hour clo & $\mathrm{k}-\mathrm{GMT}$ & & \\
\hline & SEC & Seconds & & & & \\
\hline & UPB\# & Upfacing buge & e channel nu & nber & Millivolts & \\
\hline & DNB\# & Downfacing bu & geye channel & number & Millivolts & \\
\hline & FIRUP & Far IR upfacin & pyrgeomete & & Millivolts & \\
\hline & FIRDN & Far IR downfa & ing pyrgeom & ter & Millivolts & \\
\hline & TOTUP & Total upfacing & pyranometer & & $\mathrm{W} \cdot \mathrm{m}^{2}$ & \\
\hline & NIRUP & Near IR upfaci & g pyranome & & $\mathrm{W} \cdot \mathrm{m}^{2}$ & \\
\hline & TOTDN & Total downfaci & g pyranome & & $\mathrm{W} \cdot \mathrm{m}^{2}$ & \\
\hline & NIRDN & Near IR downf & cing pyranor & neter & $\mathrm{W} \cdot \mathrm{m}^{2}$ & \\
\hline & ST-UP & Sink temp upfa & cing pyrgeom & eter & Volts & \\
\hline & ST-DN & Sink temp dow & facing pyrge & ometer & Volts & \\
\hline & DT-UP & Dome temp up & acing pyrgeo & meter & Volts & \\
\hline & DT-DN & Dome temp do & vnfacing pyr & eometer & Volts & \\
\hline & FUNK & Funk net radio & neter & & Millivolts & \\
\hline & BGTTE & Upfacing diode & & & Millivolts & \\
\hline & $\mathrm{LU}$ & Longwave upfa & ing pyrgeom & eter & $W \cdot m^{2}$ & \\
\hline & LD & Longwave dow & facing pyrge & meter & $W \cdot m^{2}$ & \\
\hline & WNDSP & Wind speed & & & $\mathrm{m} \cdot \mathrm{s}^{-1}$ & \\
\hline
\end{tabular}

\subsubsection{Pyrgeometer corrections}

Although both the measured shortwave and longwave irradiances were converted directly from the radiation instruments and logged into the data platform system, the output voltages from the pyrgeometers were also recorded so a more accurate calculation of the 
longwave fluxes could be made. Albrecht and Cox (1977) have identified a few systematic errors with the pyrgeometers which are corrected during the data analysis in order to obtain accurate values of infrared fluxes. These errors include battery voltage uncertainties, the nonlinearity of the circuitry at extreme temperatures and differential heating of the instrument. The instrument operated at moderate temperatures $\left(5^{\circ} \mathrm{C}\right.$ to $\left.20^{\circ} \mathrm{C}\right)$ so that the circuitry nonlinearity with temperature would produce an error less than $5 \mathrm{~W} \cdot \mathrm{m}^{-2}$. Since the battery voltage was nearly constant, only the differential heating produced a significant error.

The error produced by the differential heating of the instrument is apparent when the energy budget of the pyrgeometer is considered:

$$
F=E\left(c_{1}+c_{2} T_{s}^{3}\right)+\epsilon_{0} \sigma T_{s}^{4}-k \sigma\left(T_{d}^{4}-T_{s}^{4}\right)
$$

where $F$ is is incident irradiance, $E$ the thermopile output, $T_{s}$ the temperature of the thermopile cold junctions (referred to as the sink temperature) and $T_{d}$ the temperature of the pyrgeometer dome; $\epsilon_{0}$ is the emissivity of the thermopile surface (assumed to be 1 ), $\sigma$ the Stefan-Boltzman constant and $k, c_{1}$ and $c_{2}$ are constants which may be determined during calibration of the instrument.

Thermistor-resistor networks are used in the pyrgeometer to account for the first two terms on the right-hand side of the above equation. The third term considers the increase (or decrease) in longwave flux on the thermopile resulting from the temperature difference between the sink and the dome. This difference often becomes significant due to solar heating of the dome, but it is not automatically corrected by the pyrgeometer. In order to make the proper adjustments, the dome and sink temperatures must be known. The instruments used to measure the dome and sink temperatures on the pyrgeometers were Yellow Springs Instruments precision bead thermistors. The following equation was used to convert thermistor output voltages to temperature:

$$
T=\frac{\beta}{\ln \frac{80\left(E_{R}-E\right)}{K \times E}}
$$

where $T$ is the thermistor temperature in ${ }^{\circ} \mathrm{C}, E_{R}$ the positive reference voltage (2 volts), $E$ the voltage across the thermistor and $\beta, K$ are constants given below 


$$
\begin{array}{cll}
0<E \leq .74 & \beta=3209.61 & K=2.503063 \times 10^{-4} \\
.74<E \leq 1.26 & \beta=3344.06 & K=1.4399 \times 10^{-4} \\
1.26<E \leq 1.9 & \beta=3458.48 & K=9.322 \times 10^{-5} \\
1.9<E<2 & \beta=3562.14 & K=6.4643 \times 10^{-5}
\end{array}
$$

An alternate but less general formula was also formulated to calculate the temperatures of the thermistors used in this experiment

$$
T=\frac{220 E+3130}{\ln \frac{E_{R}-E}{E}+1.1 E+11.9}
$$

This equation computed temperatures within one ${ }^{\circ} \mathrm{C}$ of the previous formula and a difference in the calculated fluxes of less than $5 \mathrm{~W} \cdot \mathrm{m}^{-2}$.

Once the dome and sink temperatures were calculated, the voltages from the instruments were converted into irradiances. The conversion equation is a simplified version of the above pyrgeometer energy budget equation,

$$
F=c E+\epsilon_{0} \sigma T_{s}^{4}-k \sigma\left(T_{d}^{4}-T_{s}^{4}\right)
$$

where $F, E, \epsilon_{0}, \sigma, T_{s}, T_{d}$, and $k$ are the same as above, and $c \approx c_{1}$ since for all temperatures $c_{1} \gg c_{2} T_{s}^{3}$.

The calibration procedures for obtaining $c$ and $k$ have been described by Albrecht and Cox (1977). The values of $c$ and $k$ for the tethered balloon instruments are shown in Table 2.6.

The results from the radiation instruments, including the profiles of the measured solar and infrared fluxes and the accuracy of the fluxes are presented in Chapter 4. The next chapter describes the FSSP probe and the procedures used to compute droplet size distribution and other microphysical parameters. 
Table 2.5: Radiation Output Interval

\begin{tabular}{|c|c|}
\hline FLIGHT & OUTPUT INTERVAL \\
\hline 1 & 4 seconds \\
2 & 8 seconds \\
3 & 7 seconds \\
4 & 8 seconds \\
5 & 8 seconds \\
6 & 8 seconds \\
7 & 8 seconds \\
8 & 7 seconds \\
9 & 4 seconds \\
\hline
\end{tabular}

Table 2.6: Pyrgeometer Coefficients

\begin{tabular}{|l|c|c|}
\hline & $\mathrm{c}$ & $\mathrm{k}$ \\
\hline upfacing pyrgeometer & -220.66 & 3.17 \\
downfacing pyrgeometer & -211.51 & 2.58 \\
\hline
\end{tabular}




\section{Chapter 3}

\section{MICROPHYSICS INSTRUMENTATION}

Along with the radiation data collected by the Eppley instruments, information on the size and the number density of water droplets inside the cloud was measured by a PMS FSSP probe attached to the instrument platform. The information gathered by the probe were used with Mie scattering calculations and a radiative transfer model to mathematically simulate the radiation fields measured by the radiation instruments. This chapter gives an outline of the operation of the FSSP probe and the procedures used to reduce the raw data into droplet size distributions, total number densities, liquid water contents and other microphysical variables. A discussion of some of the problems encountered with the probe and an analysis of the sensitivity of the results is also presented.

\subsection{FSSP Probe}

The instrument on the platform used to obtain microphysical information was a Forward Scattering Spectrometer Probe (FSSP), developed by Particle Measuring Systems, Inc. (PMS). The probe was mounted on the front end of the platform and it was used to make in situ particle size measurements of the cloud droplets. The instrument estimates particle diameters by measuring the amount of light which is forward-scattered by a droplet passing through a focused laser beam. Figure 3.1 shows a diagram of the optical system in the FSSP. The scattered light is collected by another set of optics and separated by a $50 \%$ beam splitter. One half of the beam is gathered by a masked photodetector which only accepts light that is scattered from a particle outside a predescribed depthof-field in the laser beam. The signal from this detector is amplified and compared to the signal from an unmasked detector. If the masked signal exceeds the unmasked signal, the particle is rejected as passing outside the depth-of-field. The probe also measures the 
transit times of the particles in order to reject those which pass through the edge of the laser beam. A running average of approximately 1000 particle transit times is stored in an up-down counter. A percentage of the particles with the longest transit times (and probably those which pass through the center part of the beam) are accepted. The depthof-field and edge limitations produce a sampling volume much smaller than the average volume per particle so that coincidence errors (two or more particles crossing the laser beam at the same time) are rare.

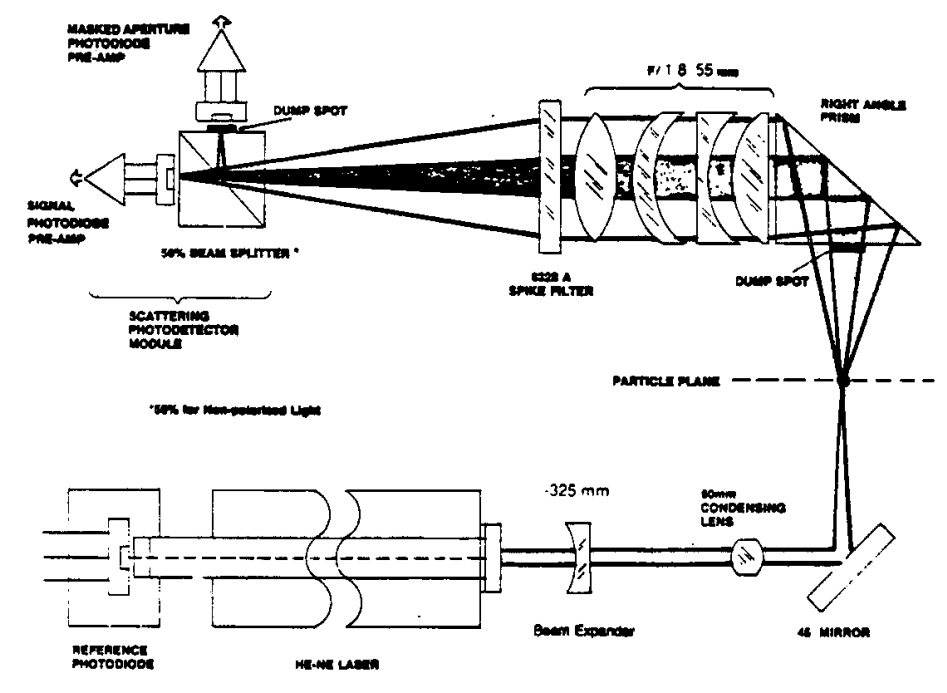

Figure 3.1: FSSP Optical System (after Particle Measuring Systems, 1984)

The pulses from those particles which are accepted by the probe as passing through the sampling area are sent to a 16-channel pulse height analyzer in order to size them. The bin width of each size channel depends on the size range selected on the probe. The size range may vary from $0.5-8 \mu \mathrm{m}$ or from $2-47 \mu \mathrm{m}$ in diameter. For all flights, the probe was set to range 0 . Information on the size ranges is given in Table 3.1. The pulse height analyzer is composed of four 4-channel pulse height analyzers connected in series. (The sixteenth channel is left empty.) The analyzer sizes the droplets by comparing the voltages from the pulses with threshold voltages derived from Mie scattering theory. 
The information recorded from the FSSP is shown in Table 3.2. The data from the FSSP probe contained information on the time, the number of counts in each of the 15 bins, the number of accepted particles (STRBS) and the total number of particles (accepted + rejected) counted by the probe (TSTBS). Finally, a range number was given to indicate which size range of particles the probe was sensing.

\subsection{Data Reduction}

\subsubsection{Calculation of Drop Size Distributions}

From the raw FSSP data, droplet size distributions were calculated for each leg of the flight. Additional variables, such as the liquid water content (LWC), effective droplet radius $\left(r_{e}\right)$, mean droplet radius $\left(r_{m}\right)$ and total number density $\left(N_{0}\right)$ were computed from the droplet size distributions. These quantities provide information on the microphysical structure of the clouds, and with the use of Mie scattering theory, an estimate of the optical properties of the clouds.

The droplet size distributions were found by computing the droplet concentrations for each size interval of the FSSP. The droplet concentration is the number of accepted droplets during the sampling interval divided by the sampling volume. The sampling volume is obtained as the product

sampling volume $=$ effective cross-sectional area $\times$ particle velocity.

In order to determine these quantities, several factors had to be considered. As indicated above, the sampling volume is determined by the depth-of-field of the laser beam and the percentage of particles accepted by the velocity averaging circuitry. The percentage of accepted particles is usually set at $50 \%$, although in some cases (such as this experiment) the probe may be set to count a variable percentage of particles. Thus, for this experiment it was appropriate to use a dynamic correction factor to calculate the effective cross-sectional area for each sample interval. The effective cross-sectional area of the laser beam was determined by multiplying the measured cross-section by the ratio between the accepted counts and the total counts.

$$
A_{e}=A \times A C \div T C
$$


Table 3.1: FSSP Size Ranges

\begin{tabular}{|c|c|c|}
\hline RANGE NUMBER & SIZE RANGE & WIDTH OF EACH CHANNEL \\
\hline 0 & $2-47 \mu \mathrm{m}$ & $3 \mu \mathrm{m}$ \\
1 & $2-32 \mu \mathrm{m}$ & $2 \mu \mathrm{m}$ \\
2 & $1-16 \mu \mathrm{m}$ & $1 \mu \mathrm{m}$ \\
3 & $0.5-8 \mu \mathrm{m}$ & $0.5 \mu \mathrm{m}$ \\
\hline
\end{tabular}

Table 3.2: FIRE - CSU Tethered Balloon Platform - FSSP Output

$\begin{array}{lllllll}01 \text { ID-102 } & \text { 02 JD } & \text { 03 HHMM } & \text { 04 SEC } & \text { 05 BIN0 } & 06 \text { BIN1 } & \text { 07 BIN2 } \\ \text { 08 BIN3 } & \text { 09 BIN4 } & \text { 10 BIN5 } & 11 \text { BIN6 } & 12 \text { BIN7 } & 13 \text { BIN8 } & 14 \text { BIN9 } \\ \text { 15 BIN10 } & \text { 16 BIN11 } & 17 \text { BIN12 } & 18 \text { BIN13 } & 19 \text { BIN14 } & 20 \text { BIN15 } & \text { 21 STRBS } \\ \text { 22 TSTBS } & \text { 23 RANGE } & & & & & \end{array}$

ID Identification number - 0102

JD Julian date

HHMM Hours minutes - 24 hour clock - GMT

SEC Seconds

BIN\# FSSP channel size number

STRBS Number of particles accepted during scan

TSTBS Total strobes - Total number of particles sensed by FSSP

RANGE Range code 
where $A$ is the measured cross-section $\left(4.6 \times 10^{-7} \mathrm{~m}^{2}\right), A C$ the total accepted counts, and $T C$ the total counts.

Since the wind in the boundary layer was generally strong $\left(5-10 \mathrm{~m} \cdot \mathrm{s}^{-1}\right)$, it was the only agent used to blow particles through the probe. Although the balloon was designed so it would constantly point into the wind, the drag on the instrument platform was such that it would twist the tether cable and the probe would not face directly into the wind. The angle between the wind and the probe (WINDIR) was measured along with the other meteorological variables and recorded on the meteorology (MET) file. An estimate of the speed of the particles through the tube was then made by multiplying the wind speed by the cosine of this angle. The information recorded on the MET file during each flight is shown in Table 3.3. Inadvertently, only 21 of the 26 variables were logged during the last five flights. The missing variables from these flights were: BVOLT, BAMPS, PTEMP, B2TMP, and VCRT.

Thus, the sampling volume is

$$
V=A_{e} v \cos \theta
$$

where $v$ is the airspeed, $\theta$ is the angle WINDIR, and the concentration of particles in one channel is

$$
n_{j}=\frac{C_{j}}{V \delta t}
$$

where $C_{j}$ is the number of droplets counted in the $j^{\text {th }}$ channel and $\delta t$ is the sampling interval ( 5 seconds). In order to prevent the estimates of the particle concentrations from being erroneously large, the calculations were not made when $\theta$ became large $\left(>60^{\circ}\right)$ or the particle speed became small $\left(<4 \mathrm{~m} \cdot \mathrm{s}^{-1}\right)$.

\subsubsection{Calculation of other microphysical variables}

Several other microphysical variables were derived from the droplet size distributions. The total number density is the summation of the particle concentrations in each channel,

$$
N_{0}=\sum_{j=1}^{15} n_{j} .
$$


Table 3.3: FIRE - CSU Tethered Balloon Platform - MET Output

$\begin{array}{lllllll}\text { 01 ID-138 } & \text { 02 JD } & \text { 03 HHMM } & \text { 04 SEC } & \text { 05 WINDIR } & \text { 06 PITCH } & \text { 07 ROLL } \\ \text { 08 P1DRY } & \text { 09 P1DT } & \text { 10 BVOLT } & \text { 11 BAMPS } & \text { 12 PTEMP } & \text { 13 P2WET } & 14 \text { P2DRY } \\ \text { 15 B1TMP } & \text { 16 B2TMP } & \text { 17 ATEMP } & \text { 18 \% R/H } & \text { 19 COMP1 } & \text { 20 COMP2 } & 21 \text { VCRF } \\ \text { 22 VCRT } & \text { 23 PR-FQ } & \text { 24 T-FQ } & \text { 25 PR-MB } & \text { 26 T-DEGC } & & \end{array}$

$\begin{array}{lll}\text { ID } & \text { Identification number - } 0138 & \\ \text { JD } & \text { Julian date } & \\ \text { HHMM } & \text { Hours minutes - 24 hour clock - GMT } & \\ \text { SEC } & \text { Seconds } & \pm 180^{\circ} \\ \text { WINDIR } & \text { Wind direction } & \pm 45^{\circ} \\ \text { PITCH } & \text { Platform pitch } & \pm 45^{\circ} \\ \text { ROLL } & \text { Platform roll } & \text { millivolts } \\ \text { P1DRY } & \text { Thermistor psychrometer dry bulb } & \text { millivolts } \\ \text { P1DT } & \text { Thermistor psychrometer dry bulb minus wet bulb } & \text { volts } \\ \text { BVOLT } & \text { Platform battery voltage } & \text { amperes } \\ \text { BAMPS } & \text { Platform battery current - not used } & { }^{\circ} \mathrm{C} \\ \text { PTEMP } & \text { Internal CR-21X temperature } & { }^{\circ} \mathrm{C} \\ \text { P2WET } & \text { Thermocouple psycrometer wet bulb temperature } & { }^{\circ} \\ \text { P2DRY } & \text { Thermocouple psycrometer dry bulb temperature } & { }^{\circ} \mathrm{C} \\ \text { B1TMP } & \text { Data logger electronics box internal temperature } & { }^{\circ} \mathrm{C} \\ \text { B2TMP } & \text { VCR electronics box internal temperature } & { }^{\circ} \mathrm{C} \\ \text { ATEMP } & \text { AM-32 MUX. temperature } & { }^{\circ} \mathrm{C} \\ \text { R/H } & \text { Logger electronics box internal relative humidity } & \text { percent } \\ \text { COMP1 } & \text { Platform direction compass \#1 } & \pm 180^{\circ} \\ \text { COMP2 } & \text { Platform direction compass \#2 } & \pm 180^{\circ} \\ \text { VCRF } & \text { VCR record on/off flag } & \\ \text { VCRT } & \text { VCR recording time } & \text { hours } \\ \text { PR-FQ } & \text { Digiquartz pressure transducer pressure } & \mathrm{KHz} \\ \text { T-FQ } & \text { Digiquartz pressure transducer internal temp } & \mathrm{KHz} \\ \text { PR-MB } & \text { Pressure } & \mathrm{mb} \\ \text { T-DEGC } & \text { Pressure transducer internal temperature } & { }^{\circ} \mathrm{C}\end{array}$


Once the total number density was found, the particle concentrations were normalized to that value in order to determine the percentage of the total droplets contained in each size range.

The average droplet radius in each channel depends on the size range set for the instrument. The radius of the droplets in each channel were assumed to be the midpoint value of each channel. Since the instrument was always set on range 0 , the average droplet radius in each channel was

$$
r_{j}=(3 j+0.5) / 2
$$

where $r_{j}$ is expressed in microns. The mean radius of the particles was computed from

$$
\tau_{m}=\frac{1}{N} \sum_{j=1}^{15} n_{j} r_{j},
$$

the effective radius was computed from

$$
r_{e}=\frac{\sum_{j=1}^{15} n_{j} r_{j}^{3}}{\sum_{j=1}^{15} n_{j} r_{j}^{2}}
$$

and the liquid water content was calculated from

$$
L W C=\frac{4 \pi}{3} \rho_{L} \sum_{j=1}^{15} n_{j} r_{j}^{3},
$$

where $\rho_{L}$ is the density of water.

The raw data from all three files were needed to calculate the droplet size distributions measured by the FSSP probe. However, the data in each file was stored at different time intervals. In order to synchronize the files, the variables in the MET and RAD files were linearly interpolated to the times in the FSSP files, and the droplet size distributions and other microphysical variables were calculated for five second time intervals. A filter was included in the data reduction program to reject spurious and incomplete data.

\subsection{Circuitry Problems with FSSP Probe}

The FSSP probe developed some problems in its circuitry which sometimes limited the performance of the instrument. During flights 1-4, the least significant bit was missing from the output of the pulse height analyzer. The loss of this bit resulted in the information 
from each pair of bins $(0-1,2-3,4-5, \ldots)$ being placed in the lower bin, and consequently there was a loss of some resolution in the bin size data. Other problems occurred in later flights. In flight 8 the information from every other pair of channels was missing. This was due to the second least significant bit (3rd bit) being stuck on 1. Later in the flight the second bit stuck on 0 and the counts were stored only on two pairs of channels. In flight 9 dirty optics in the probe made the output shift to the two lowest channels in the spectrum.

\subsection{Sensitivity Analysis of the FSSP Probe}

As stated earlier, the total number densities measured by the FSSP probe are a function of the wind speed and relative direction between the probe and the wind:

$$
n_{j}=\frac{C_{j} \times T C}{A \times A C \times v \cos \theta \delta t}
$$

where variables are the same as above.

The measured cross-sectional area $(A)$ and the sampling time $(\delta t)$ are constant throughout the flights, and thus may be substituted by a constant.

$$
K=A \delta t
$$

The other variables change throughout the flight. If it is assumed that the probe accurately counts the number of particles flowing through it, then only errors in wind speed $(v)$ and the relative direction between the wind and the probe $(\cos \theta)$ will affect $n_{j}$.

The change produced in the number density per unit error (radian) in the wind direction is

$$
\frac{\partial n_{j}}{\partial \theta}=\frac{C_{j} \times T C}{K \times A C \times v} \tan \theta \sec \theta
$$

From this equation it is evident that

- An increase in $\theta$ and thus $\cos \theta$ will lead to an increase in $n_{j}$.

- The sensitivity of $n_{j}$ to changes in $\theta$ is less for large wind speeds. 
- The sensitivity of $n_{j}$ to changes in $\theta$ increases greatly for large values of $\theta$.

A measure of the relative sensitivity of $n_{j}$ to $\theta$ can be made by dividing equation (3.2) by $(3.1)$,

$$
\frac{\frac{\partial n_{i}}{\partial \theta}}{n_{j}}=\tan \theta \text { in units of } \mathrm{rad}^{-1} \text {. }
$$

Thus for a $5^{\circ}$ error $\left(\partial \theta=5^{\circ}\right)$ in measurement, which is the accuracy of the instrument,

$$
\begin{array}{|r|l|}
\hline \text { when } \theta=10^{\circ}, & \text { relative error } \approx 1.5 \% \\
\theta=40^{\circ}, & \text { relative error } \approx 7.3 \% \\
\theta=60^{\circ}, & \text { relative error } \approx 15.1 \% \\
\hline
\end{array}
$$

The relative error would be less if the measured angle is less than the actual measurement and greater if the measured angle is greater than the actual measurement. For most of the flights, the average value of $\theta$ is below $40^{\circ}$.

The sensitivity of $n_{j}$ to a unit error $\left(\mathrm{m} \cdot \mathrm{s}^{-1}\right)$ in wind velocity is

$$
\frac{\partial n_{j}}{\partial v}=-\frac{C_{j} \times T C}{K \times A C \times v^{2} \cos \theta}
$$

Thus, increasing $v$ would reduce the number density, but the sensitivity would decrease as $v$ becomes larger. A measure of the relative sensitivity of $n_{j}$ to wind speed can be made by dividing equation (3.4) by (3.1),

$$
\frac{\frac{\partial n_{j}}{\partial v}}{n_{j}}=-\frac{1}{v} \text { in units of } \mathrm{m}^{-1} \cdot \mathrm{s}
$$

For a $1 \mathrm{~m} \cdot \mathrm{s}^{-1}$ error $\left(\partial v=1 \mathrm{~m} \cdot \mathrm{s}^{-1}\right)$ in measurement,

\begin{tabular}{|r|r|}
\hline when $v=4 \mathrm{~m} \cdot \mathrm{s}^{-1}$, & relative error $\approx 25 \%$ \\
$v=7 \mathrm{~m} \cdot \mathrm{s}^{-1}$, & relative error $\approx 14 \%$ \\
$v=10 \mathrm{~m} \cdot \mathrm{s}^{-1}$, & relative error $\approx 10 \%$ \\
\hline
\end{tabular}

Further numerical tests on the sensitivity of the data are presented in Chapter 4. 


\subsection{Summary}

This chapter described the FSSP probe and the data reduction procedures necessary to obtain several microphysical variables. Some of the circuitry problems with the probe were briefly discussed. An analysis of the sensitivity of the calculated number density to $\theta$ (the relative angle between the wind and the platform) shows that the errors in the number density due to errors in measuring $\theta$ is proportional to the tangent of this angle. A $5^{\circ}$ error in $\theta$ will result in a $7.3 \%$ relative error when the value of this angle is $40^{\circ}$. The sensitivity of the calculated number density to the wind speed is inversely proportional to the magnitude of the wind speed. A $1 \mathrm{~m} \cdot \mathrm{s}^{-1}$ error in the wind speed will result in a $10 \%$ relative error when the true wind speed is $10 \mathrm{~m} \cdot \mathrm{s}^{-1}$. 


\section{Chapter 4}

\section{RESULTS}

As mentioned in Chapter 1, the use of tethered balloons to collect meteorological data inside a boundary layer is relatively new. The series of tethered balloon flights taken during the FIRE IFO was the one of the first times both radiation and microphysics data were collected by balloon inside the marine stratocumulus boundary layer. Radiation and microphysical computations were made for most of the cases, except during flights (such as flights 8 and 9) which had incomplete or inaccurate microphysical data. After a review of the flight plans and synoptic conditions for each flight, the data from four flights will be presented in detail, examining the microphysical and radiative structure of the clouds observed during each flight. The second section of this chapter focuses on the microphysical data from the flights while the third section examines the radiation data.

\subsection{Overview of Case Flights}

\subsubsection{Flight 2 - July 7, 1987}

Flight 2 was made on July 7, 1987 through a boundary layer approximately $650 \mathrm{~m}$ deep. The balloon was flown throughout the day from 1445 to 0030 GMT (745 to 1730 PDT). A plot of the measured pressure versus time is shown in Figure 4.1. The flight started with a profile leg through the boundary layer and followed with a long time series of constant level legs above the cloud top. Finally, three stepped profiles with several five minute legs were made through the boundary layer.

The $850 \mathrm{mb}$ analysis of the eastern Pacific showed that the area around SNI was under the southeastern edge of a large subtropical high. This high pressure system coupled with a low centered over northern New Mexico provided a north westerly flow over the 


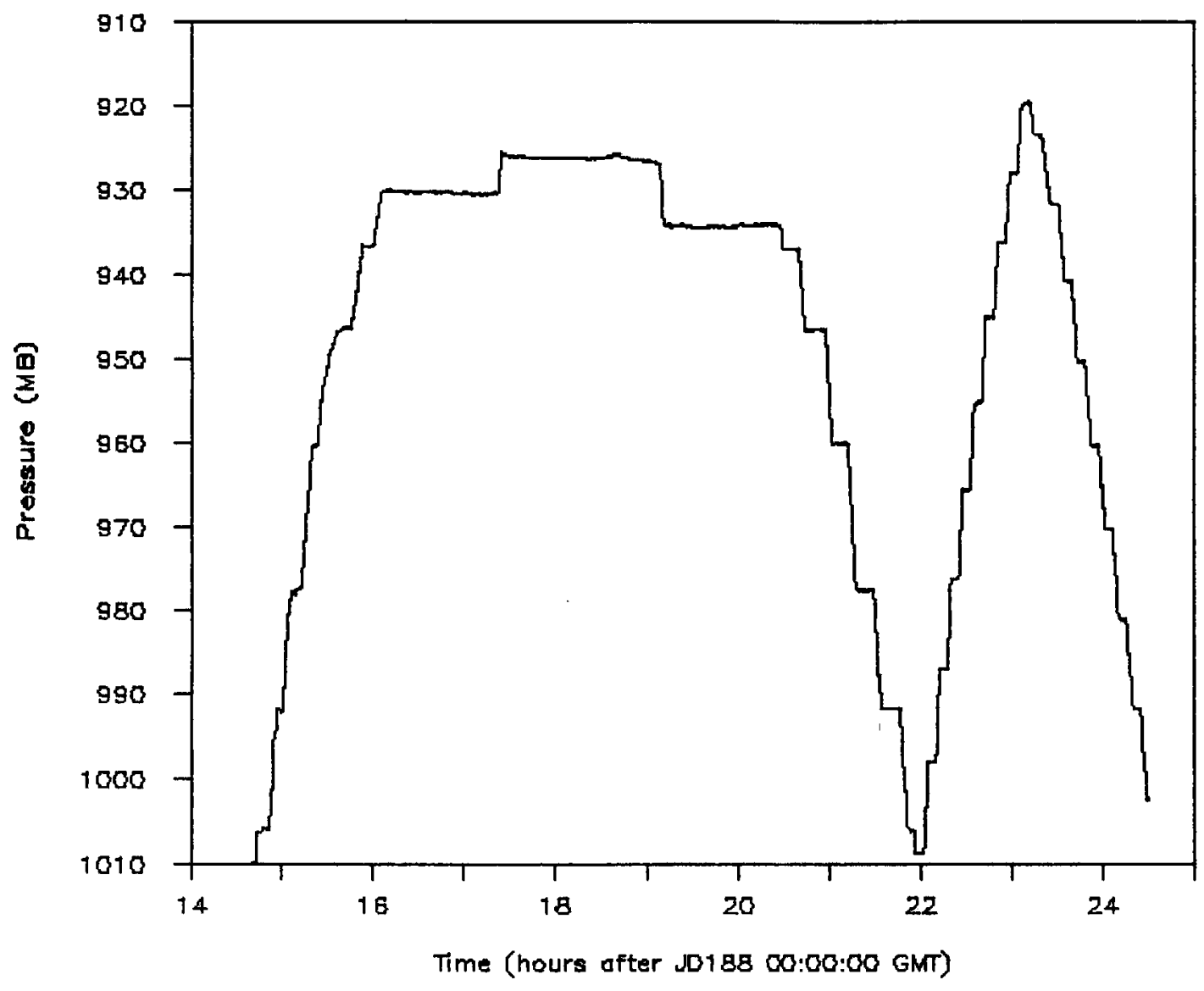

Figure 4.1: Pressure measured by the platform versus time from Flight 2 on July 7, 1987. 
island region at $850 \mathrm{mb}$. From the $850 \mathrm{mb}$ and surface maps it appears that the air flow throughout the boundary layer probably came from the western US. An offshore air flow would supply CCN for the production of many small droplets in the cloud layer and tend to give the clouds over SNI a more continental character.

\subsubsection{Flight $3-$ July 8,1987}

Figure 4.2 shows a plot of the measured pressure versus time for Flight 3 . The balloon was flown in the morning from 1430 to 2100 GMT (730 to 1400 PDT), through a boundary layer approximately 700-750 m deep. The flight was made in three parts, with the first

being a rapid ascent profile (profile leg), followed by several constant height legs near or above the cloud top. During the final part of the flight the balloon was lowered in steps through the boundary layer with a fifteen minute sampling interval at each level.

The $850 \mathrm{mb}$ analysis showed that the stratocumulus IFO area was still under the influence of a large subtropical high. The high pressure system continued to provide a northerly, offshore flow over the island. This is supported by measurements of the wind direction observed from the instrument platform during Flight 3 (Figure 4.3), which was generally from $350^{\circ}$, that is, from offshore.

\subsubsection{Flight 5 - July 10, 1987}

Flight 5 was made on July 10, 1987, under a high but shallow cloud deck approximately $200 \mathrm{~m}$ deep. The flight was made from 1530 GMT (830 PDT) to 100 GMT (1800 PDT). A plot of the measured pressure versus time is shown in Figure 4.4. The flight was made in three parts with the first being a set of twenty minute constant height legs taken at approximately $10 \mathrm{mb}$ increments from $1000 \mathrm{mb}$ to $890 \mathrm{mb}$. Then from above the cloud layer a series of ten minute legs taken at 1-6 mb intervals descending through the cloud was made. A descending profile through the sub-cloud layer to the surface was made at the end of the flight.

The time series of the wind direction measured on the platform shows that by July 10, the synoptic flow had changed and the winds came from the south. This resulted in the air mass over the island being more marine-like in nature. 


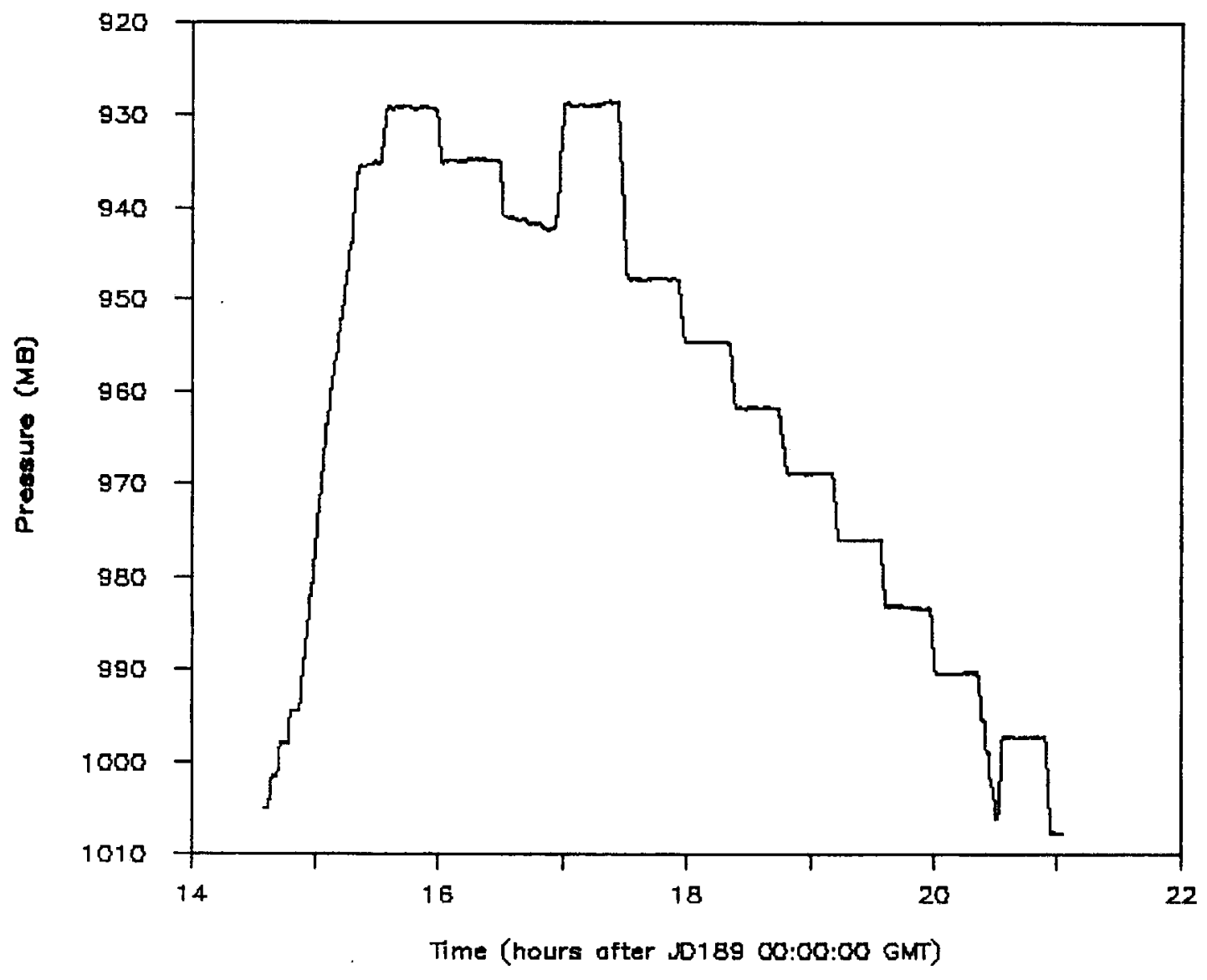

Figure 4.2: Pressure measured by the platform versus time from Flight 3 on July 8, 1987. 


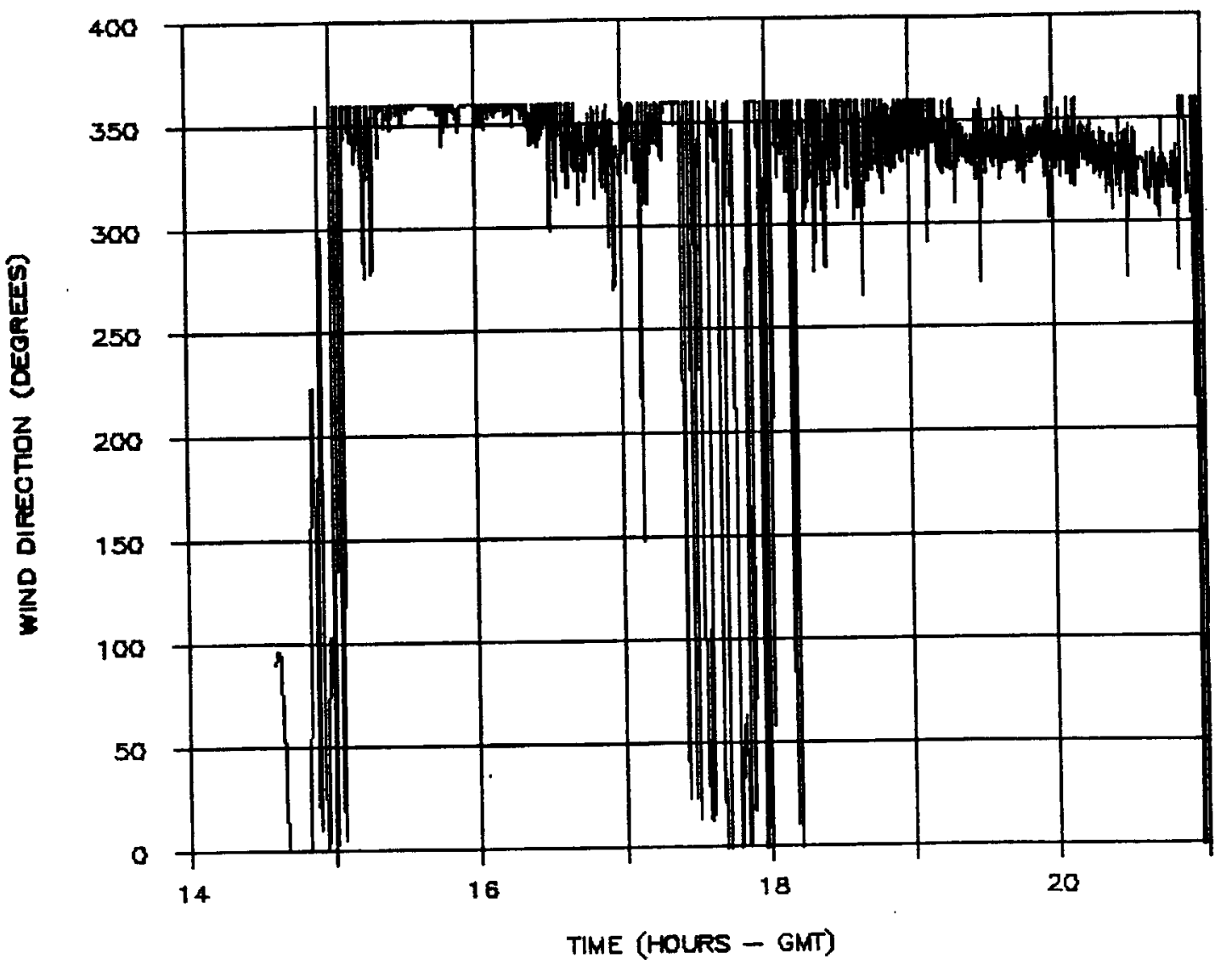

Figure 4.3: Wind direction versus time observed during Flight 3. 


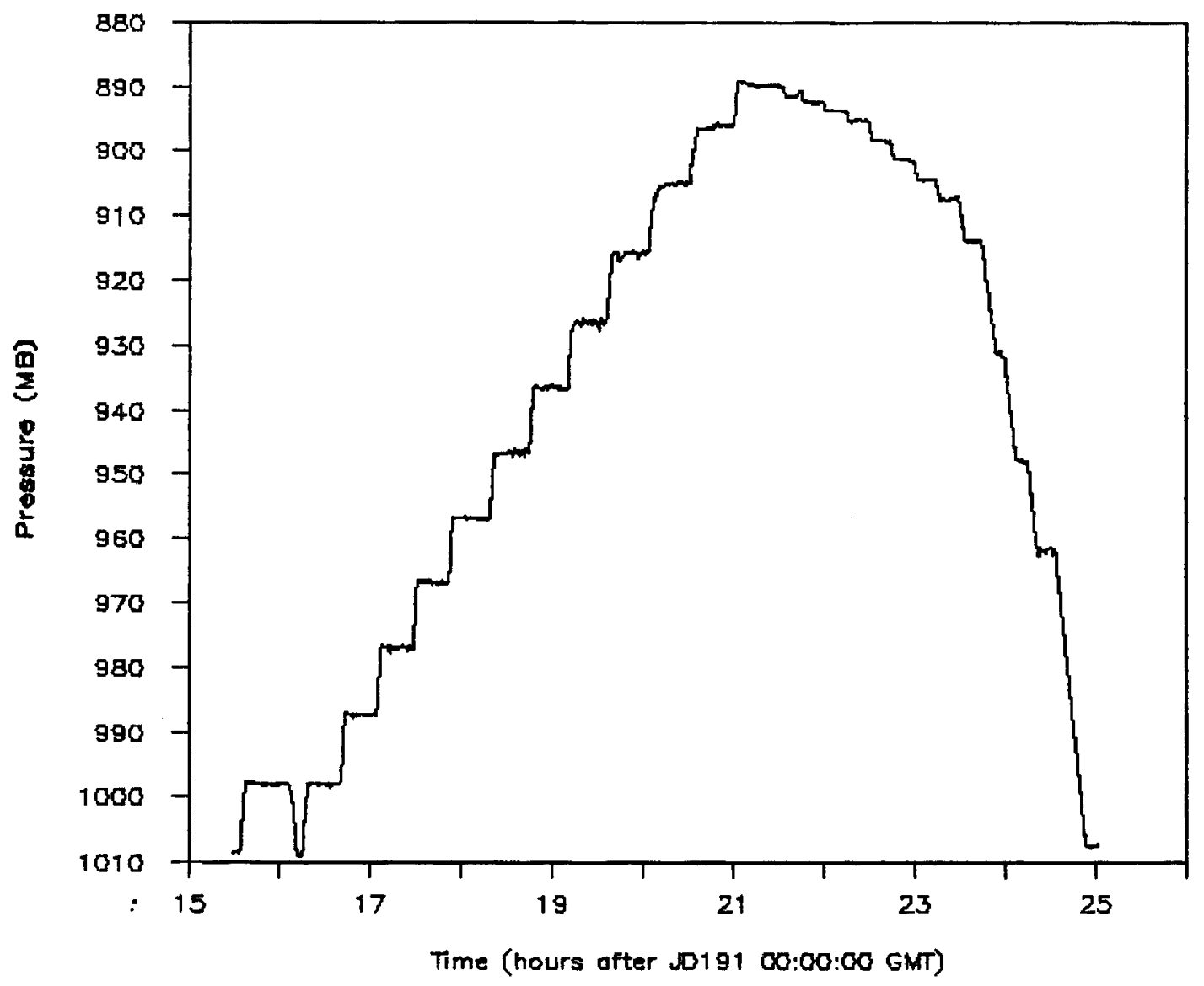

Figure 4.4: Pressure measured by the platform versus time during Flight 5 on July 10, 1987. 


\subsection{Microphysics Measurements}

From the raw data set, all of the microphysical variables described in Chapter 3 were calculated for each 5 second data interval, and the average and standard deviation of each variable were computed for every horizontal leg of the flight. The statistics from the flight legs provide a description of the composite microphysical properties obtained during the flight. The microphysical variables measured during Flights 2, 3, and 5 are presented below, as well as the droplet size distribution and effective radius data from Flight 6.

Along with the data collected by the FSSP probe, estimates of the cloud liquid water path (LWP), which is the vertically integrated liquid water content, were derived from observations by a NOAA/WPL microwave radiometer stationed on SNI (Hogg et al., 1983; Snider, 1988). The radiometer data were used as a measure of the variability of the liquid water path during the flight.

\subsubsection{Droplet size distributions}

The droplet size distributions were normalized to the total number density and thus the concentration of the droplets in each channel is given as the percentage of the total concentration. The normalized droplet size distributions were averaged over each leg and since the shape of the distributions was generally the same throughout the cloud, each leg inside the cloud was then averaged together to obtain the mean droplet size distribution throughout the cloud. Figure 4.5 shows the mean droplet size distributions for all flights with available microphysical data. In order to compare all flights, the distributions from Flights 5 and 6 were condensed into eight size intervals. The droplet size distributions from the flights can be divided into two regimes. The distributions from Flights 2 and 3 are dominated by particles in the two smallest FSSP bins from $2-8 \mu \mathrm{m}$ in diameter, while Flights 5 and 6 have distributions which are more marine-like in appearance, with a peak in the 14-20 $\mu \mathrm{m}$ range. The high concentrations of smaller droplets in Flights 2 and 3 suggest the clouds during those flights were formed in a boundary layer influenced by continental air. The offshore winds generally contain many more cloud condensation nuclei (CCN) than maritime air, which may have produced the larger proportion of small 
droplets in the clouds. The distributions from the second regime were created when the air flow was from the ocean, and thus resemble typical marine cloud droplet distributions.

\subsubsection{Liquid water content}

\section{Profiles}

A profile of the average LWC computed from each leg of Flight 2 is shown in Figure 4.6. The data collected from the ascending profile taken during the morning show that the cloud extended from $980 \mathrm{mb}$ to $945 \mathrm{mb}$. The height of the cloud top decreased during the afternoon, and was near $950 \mathrm{mb}$ at $2300 \mathrm{GMT}$. The mean LWC generally increased throughout the cloud layer and reached a maximum value of $0.14 \mathrm{~g} \cdot \mathrm{m}^{-3}$ at cloud top. The standard deviation of the liquid water content is approximately $36 \%$ of the mean value. Assuming the LWC increased linearly from cloud base to cloud top, the mean liquid water path in the cloud during the flight would be approximately $25 \mathrm{~g} \cdot \mathrm{m}^{-2}$. Figure 4.7 shows the radiometer measurements for July 7,1987 . The measured LWP remained near 90 $\mathrm{g} \cdot \mathrm{m}^{-2}$ throughout most of the flight until $2000 \mathrm{GMT}$ when the LWP reduced to $30 \mathrm{~g} \cdot \mathrm{m}^{-2}$. The LWP estimated from the FSSP is considerably smaller than the LWP measured by the radiometer, and the computed LWC profile much less than the adiabatic liquid water content. It is not certain why the FSSP would measure such low liquid water contents inside the cloud, although the probe is very sensitive to errors in sampling the number of accepted to total counts by the probe.

Figure 4.8 presents the mean LWC data for Flight 3. The cloud layer extended from roughly $970 \mathrm{mb}$ to $935 \mathrm{mb}$ at the start of the flight, although during the day the cloud top grew above $930 \mathrm{mb}$. The mean LWC profile increased with height from cloud base to a peak value of $0.19 \mathrm{~g} \cdot \mathrm{m}^{-3}$ at $947 \mathrm{mb}$. The standard deviation of LWC varies considerably between each level, from $30 \%$ to $75 \%$ of the mean value of the LWC. The variability of the data is partially due to changes in the magnitude of the wind speed throughout the flight (see Figure 4.9), which controls the sampling volume of the instrument. The standard deviation is especially large when the relative angle between the wind and the platform is large. 


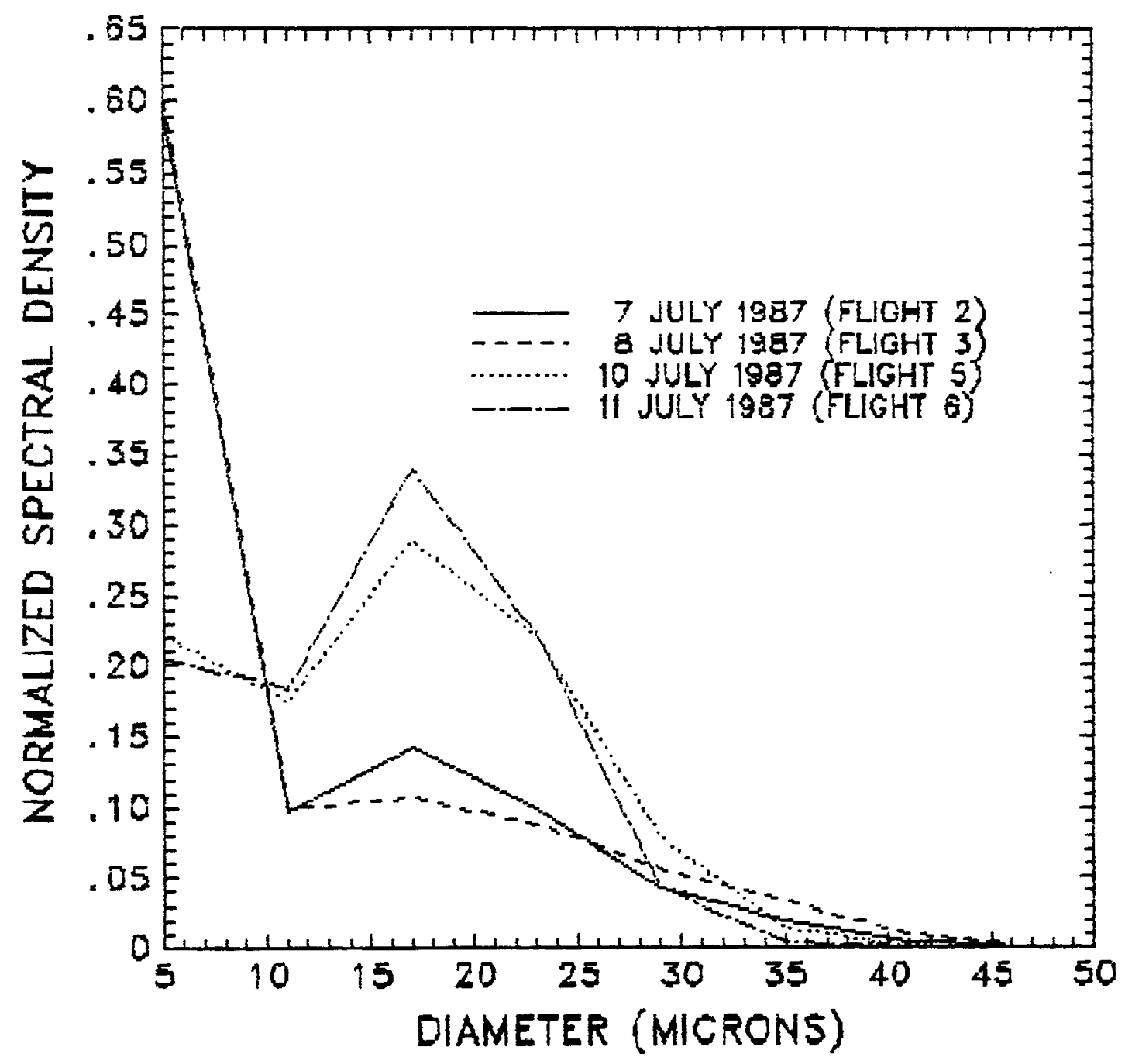

Figure 4.5: Mean normalized droplet size distributions for the indicated flights. 


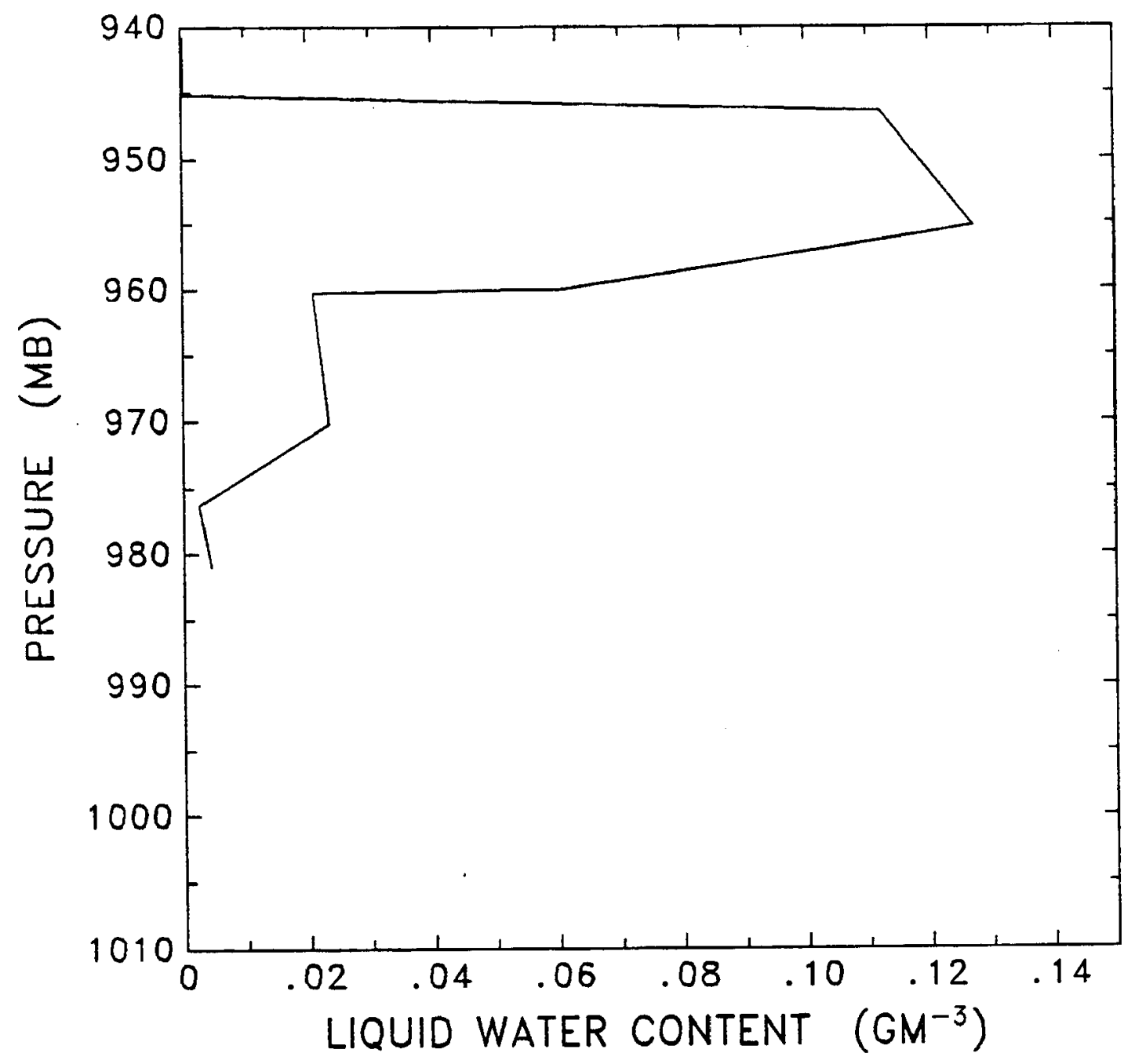

Figure 4.6: Profile of mean LWC computed for all legs of Flight 2. 


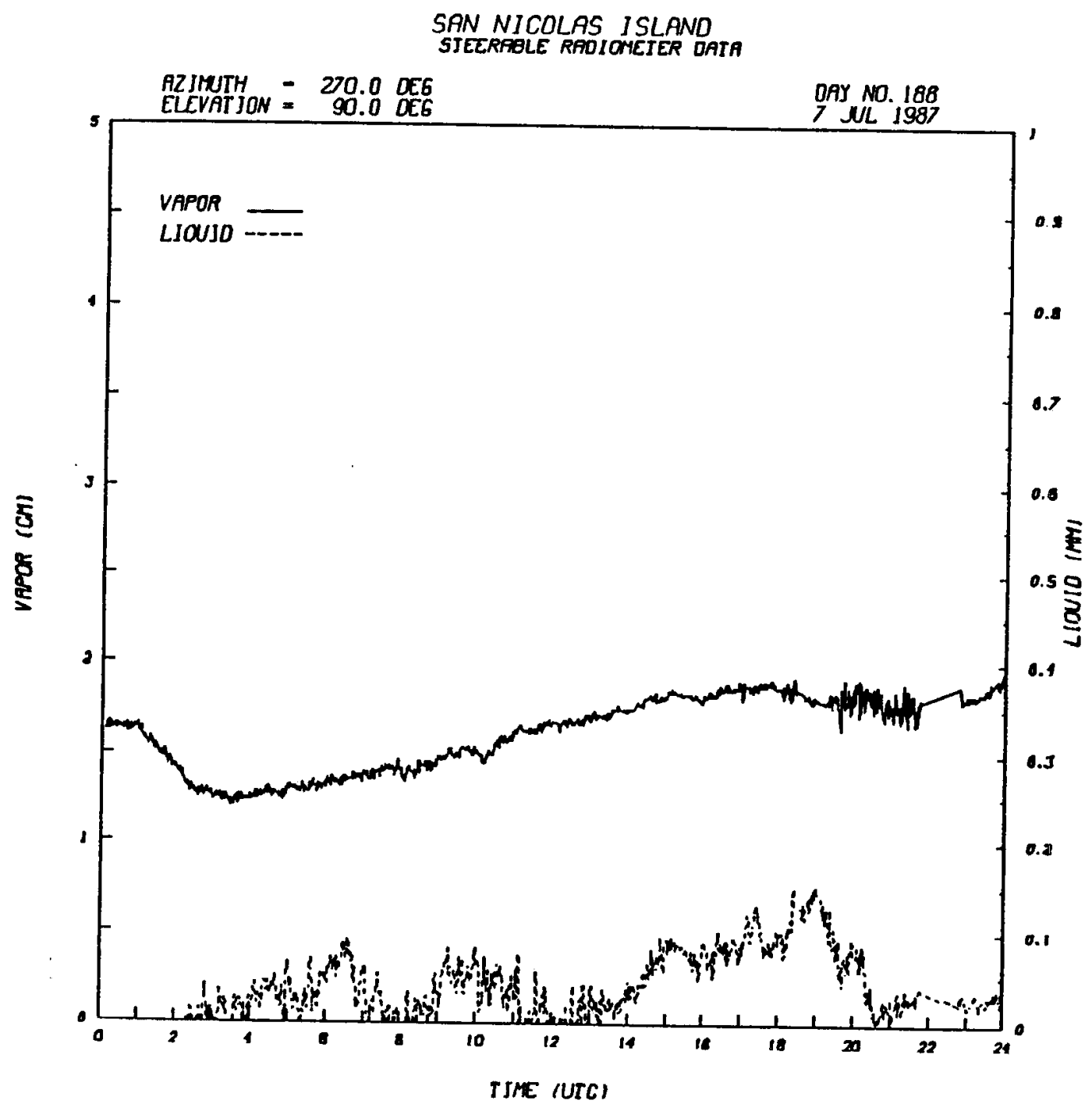

Figure 4.7: Water vapor path and liquid water path measured by the NOAA/WPL microwave radiometer for July $7,1987$. 


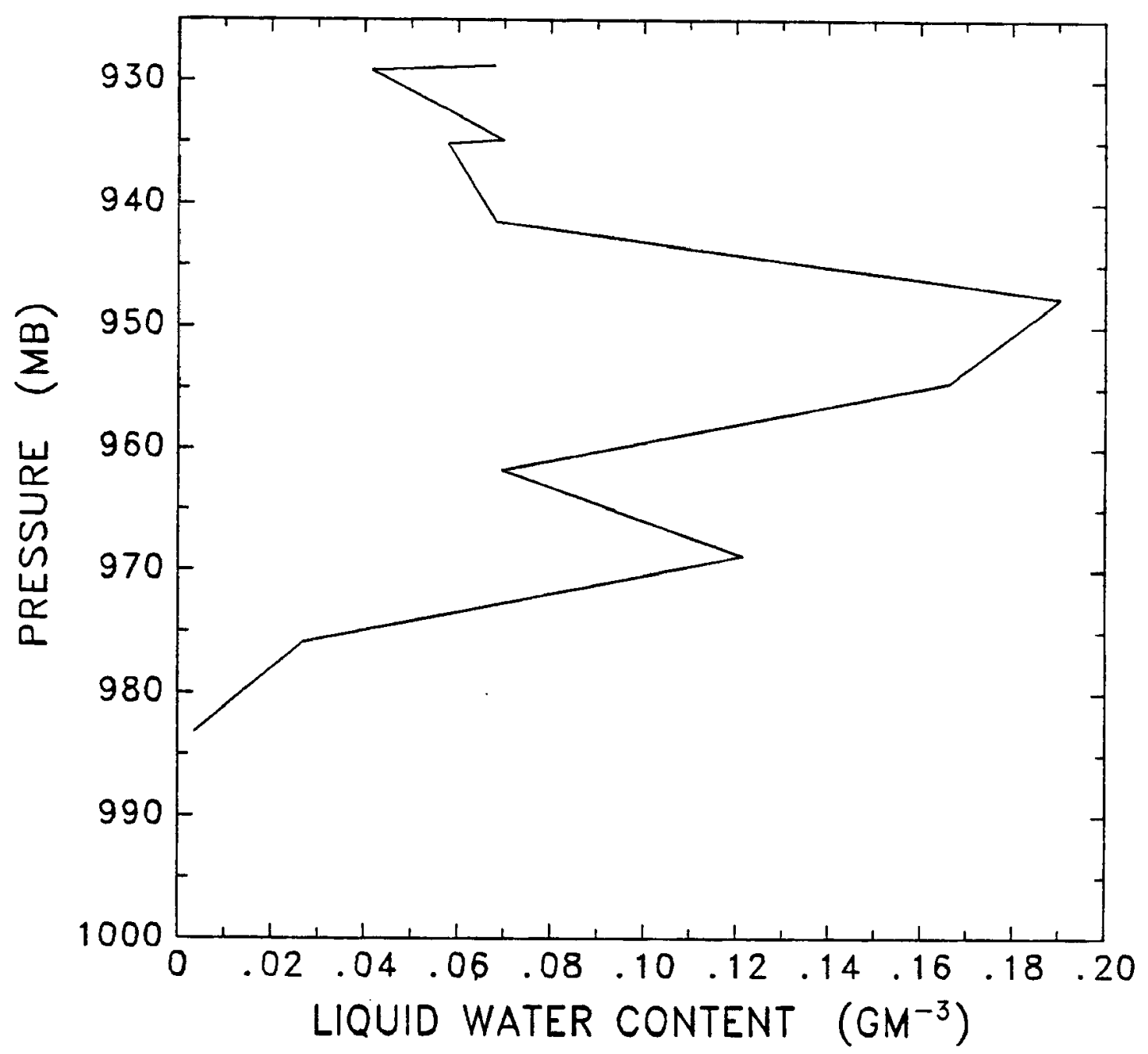

Figure 4.8: Profile of mean LWC computed for all legs of Flight 3. 


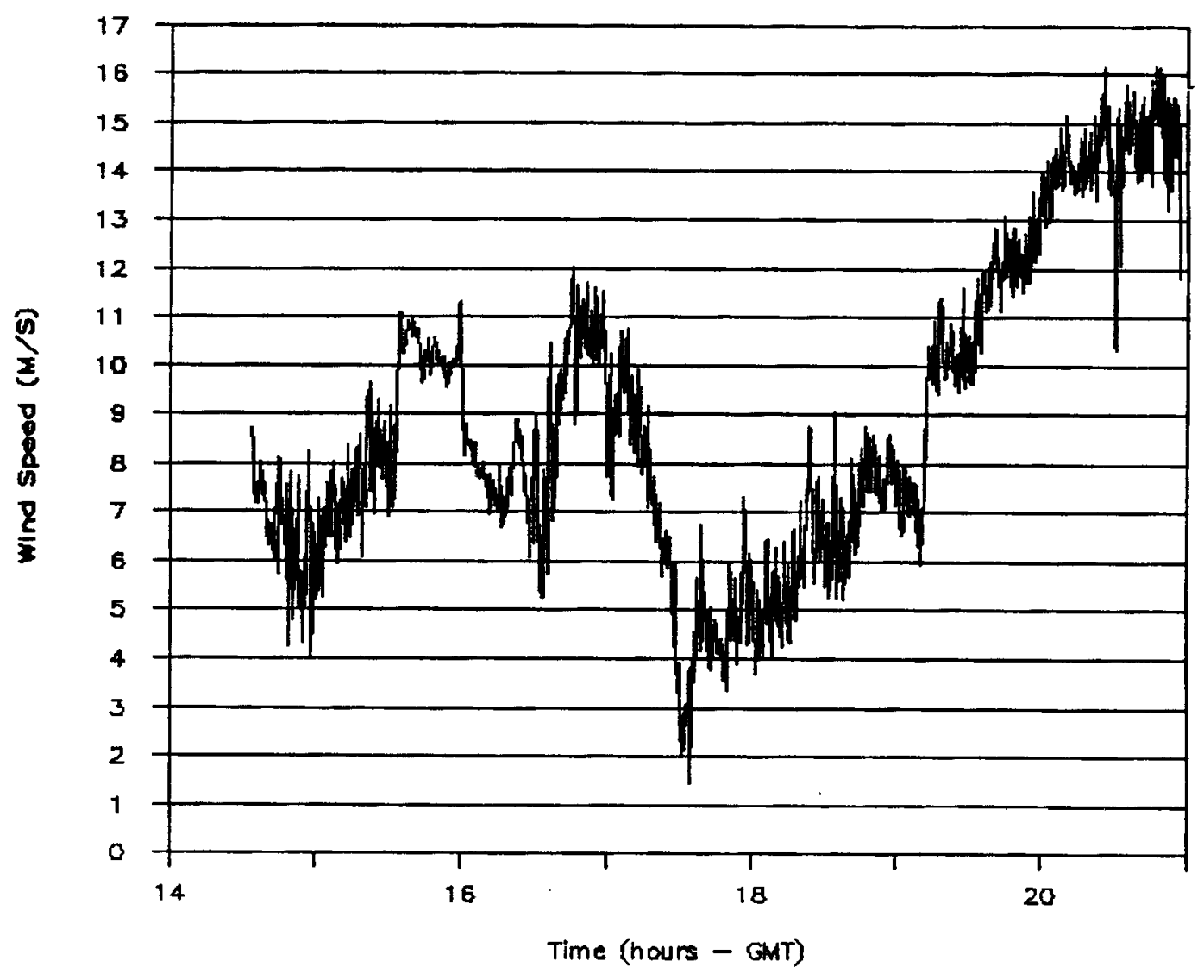

Figure 4.9: Wind speed versus time observed during Flight 3. 
The estimated mean LWP during Flight 3 was $35 \mathrm{~g} \cdot \mathrm{m}^{-2}$. This value is also smaller than the LWP measured by the radiometer on July 8, shown in Figure 4.10. The radiometer estimated LWP was extremely variable with several peaks in the LWP up to 300 $\mathrm{g} \cdot \mathrm{m}^{-2}$.

The liquid water content measured during Flight 5 is presented in Figure 4.11. The cloud layer extends from roughly 915 to $895 \mathrm{mb}$. The radiometer data and the radiation data shown below indicate that the clouds in the boundary layer varied considerably during the day and the cloud cover probably was not homogeneous. In order to compensate for the possibility of sampling clear air, a filter was added to screen the microphysical data. All data points with liquid water contents less than $0.04 \mathrm{~g} \cdot \mathrm{m}^{-3}$ and a wet bulb temperature depressions greater than $0.1^{\circ} \mathrm{C}$ were considered to be taken "outside" of the cloud. The liquid water contents are much larger from this flight, and are near the adiabatic value throughout the cloud layer. The cloud top value is nearly $0.50 \mathrm{~g} \cdot \mathrm{m}^{-3}$. The LWP estimated from the FSSP data is $65 \mathrm{~g} \cdot \mathrm{m}^{-2}$, which compares favorably to the LWP measurements from the radiometer, shown in Figure 4.12. The filtering of the data reduced the average standard deviation of the LWC value from $65 \%$ to $45 \%$ of the mean value at each level.

\section{Sensitivity tests}

Sensitivity tests were run on the LWC for Flights 3 and 5 . In the first test, the value of $\theta$ was increased by $10^{\circ}$ at each sampling interval. The second test increased the measured wind speed by $1 \mathrm{~m} \cdot \mathrm{s}^{-1}$ at each sample point. The averaged liquid water contents at each level generally increased by $5 \%$ for the direction test, and decreased by 10 to $15 \%$ for the wind speed test. This indicates that the average value of $\theta$ was relatively small $\left(<30^{\circ}\right)$ and the average wind speed was 7 to $8 \mathrm{~m} \cdot \mathrm{s}^{-1}$.

The results of the sensitivity tests from Flight 5 show that the measured LWC was more strongly affected by changes in the values of $\theta$. The averaged liquid water contents at each level generally increased by 10 to $25 \%$ for the direction test, and decreased by $10 \%$ for the wind speed test. This indicates that the average value of $\theta$ was larger than in flight 3 . 


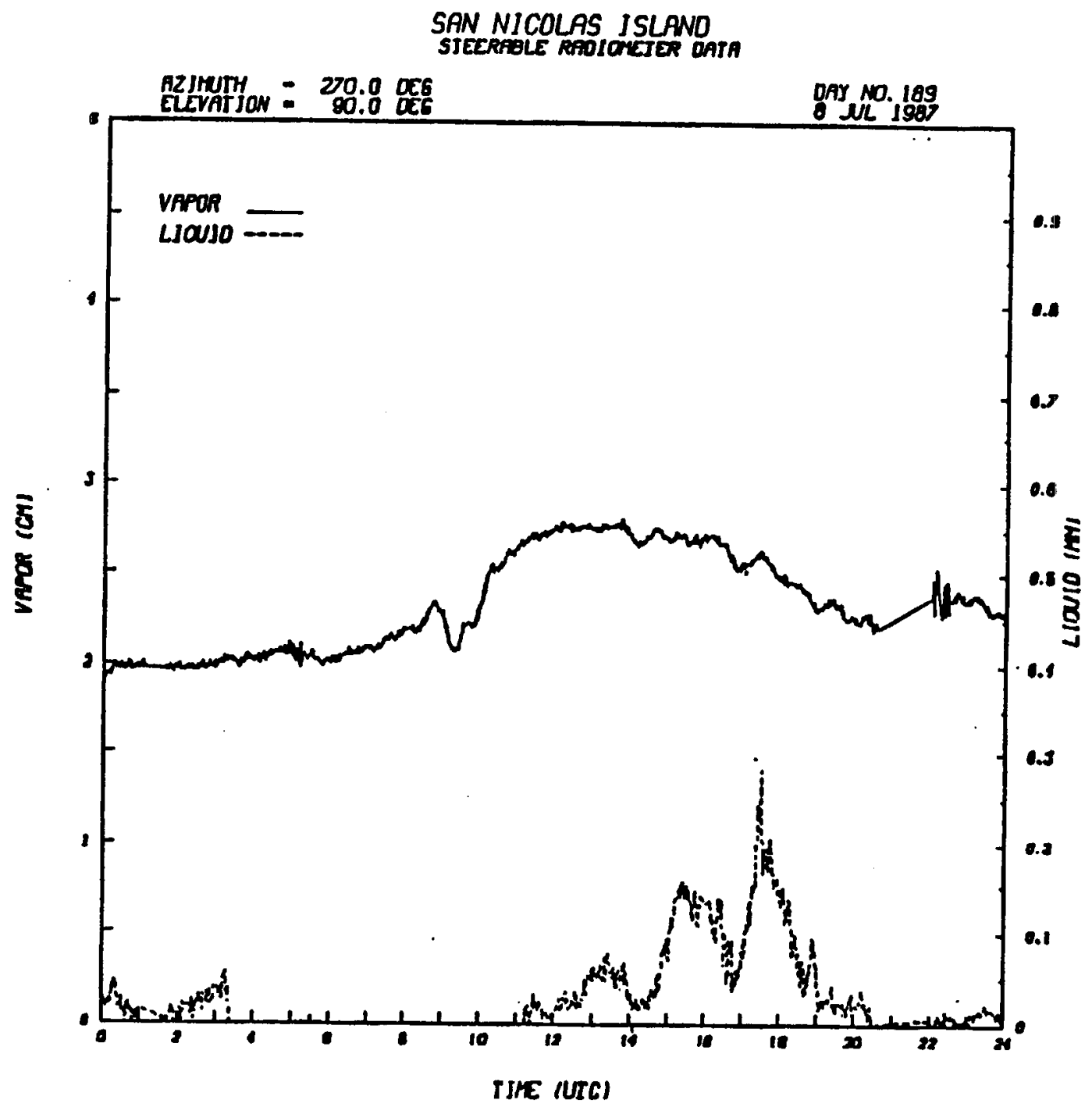

Figure 4.10: Water vapor path and liquid water path measured by the NOAA/WPL microwave radiometer for July 8, 1987. 


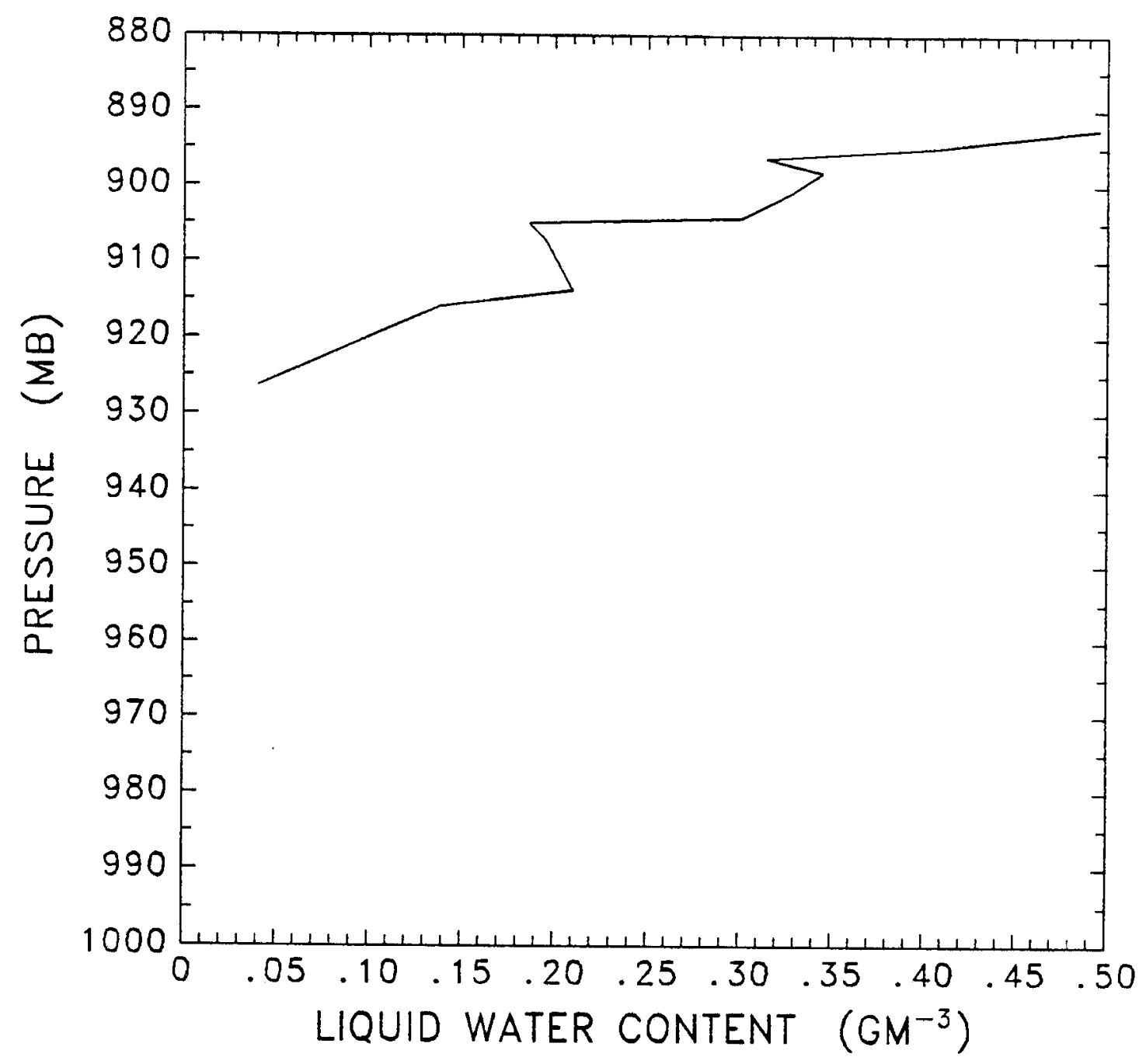

Figure 4.11: Profile of mean LWC computed for all legs of Flight 5. 


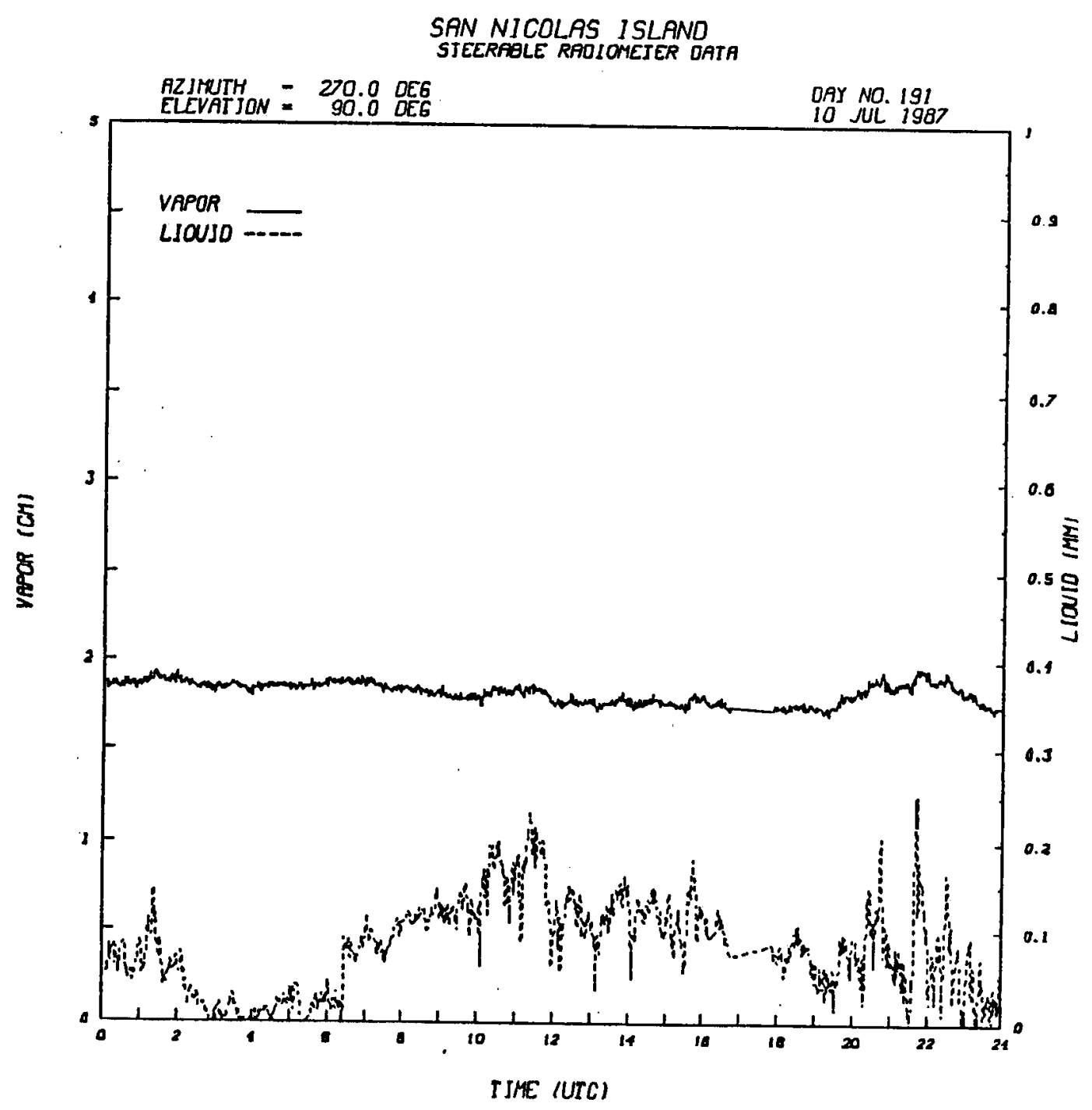

Figure 4.12: Water vapor path and liquid water path measured by the NOAA/WPL microwave radiometer for July 10, 1987. 


\subsubsection{Total number density}

Since the droplet size distributions did not vary much inside a cloud during each flight, the shape and the magnitude of the liquid water content profiles were greatly influenced by the shape and magnitude of the total number density profile. The total number density profile from Flight 2 (Figure 4.13) shows that most particles tend to be near the top of the cloud with mean values between $40 \mathrm{~cm}^{-3}$ and $50 \mathrm{~cm}^{-3}$.

The total number density profile from Flight 3 is shown in Figure 4.14. The mean total number density is variable through the cloud layer, with a peak value of $55 \mathrm{~cm}^{-3}$ at $947 \mathrm{mb}$. As with the LWC data, the standard deviation of the total number density data is extremely variable between each level and often is nearly as large as the mean values.

The total number density profile from Flight 5 (Figure 4.15) reflects the larger LWC observed by the FSSP as the mean particle concentrations inside the cloud ranged from 50 to $100 \mathrm{~cm}^{-3}$. The filtering of the data reduced the standard deviation of the data to under $50 \%$ of the mean value at each level.

\subsubsection{Effective and mean radius}

Profiles of the effective radius and mean radius from Flights 2, 3, and 5 are presented in Figures 4.16, 4.17 and 4.18 respectively. In each flight, both the effective and mean radii slowly increased from the cloud base to cloud top. Although the shape of the droplet size distribution curves from Flights 2 and 3 versus those from Flight 5 differ, the profiles of effective radius from those flights are nearly identical. The effective radius profile from Flight 2 ranges from approximately 10 microns at cloud base to over 14 microns at cloud top, while the profiles from Flights 3 and 5 increase from 10 microns to near 13 microns. During Flight 6 the effective radius is 10 microns.

The mean radii is a less ambiguous measure of the average droplet size in a cloud than effective radius, which is reflected in the profiles of the mean radius from each flight. The mean radii measured from Flights 2 and 3 are smaller than those measured from Flights 5 and 6 . The mean radii from the first two flights range from 5 microns to near 7 microns, while the mean radii from Flight 5 varies from 7.5 to 10 microns. The mean radius was 7.5 microns for Flight 6. 


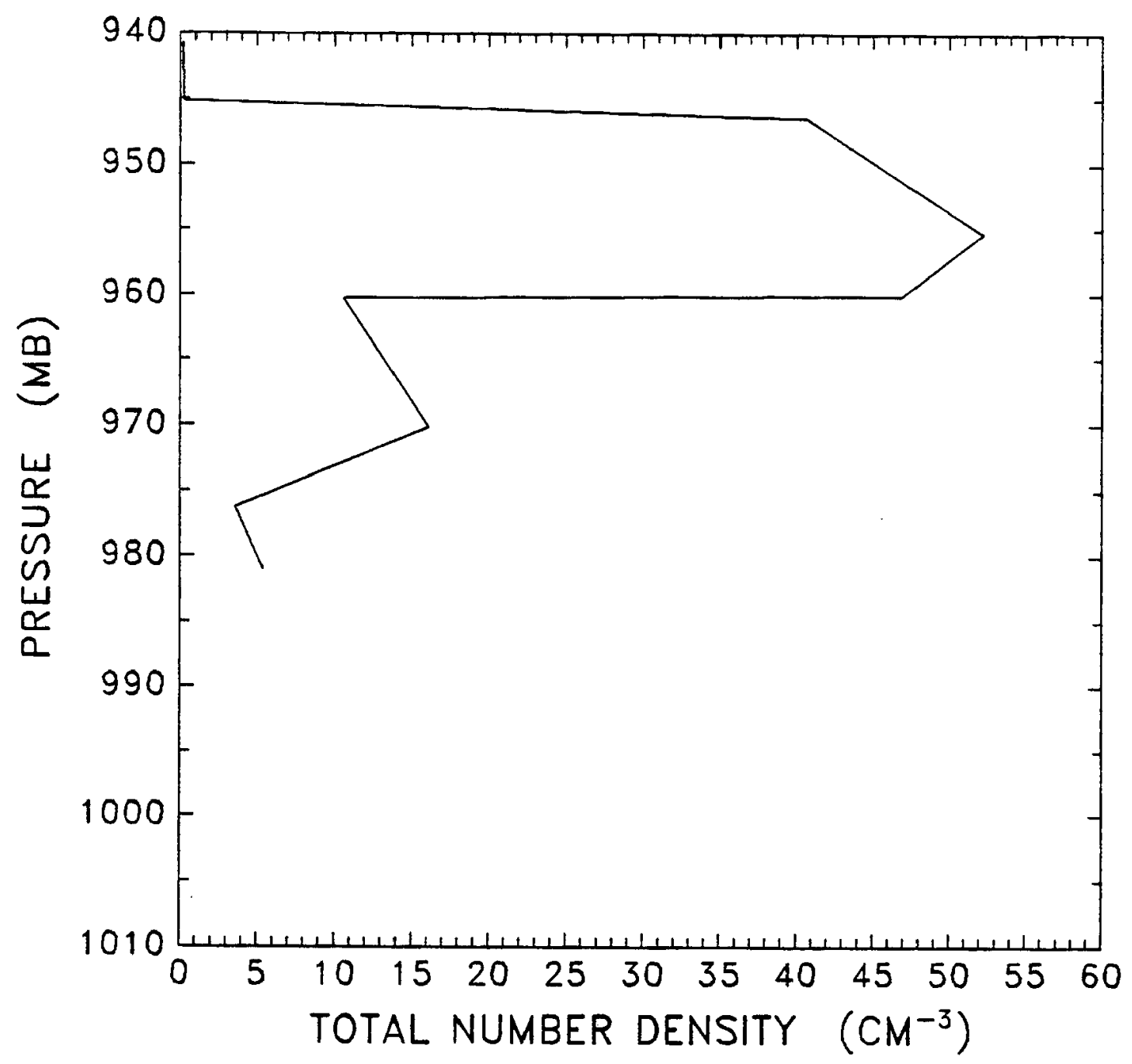

Figure 4.13: Profile of the average total number density taken from the constant level legs of Flight 2. 


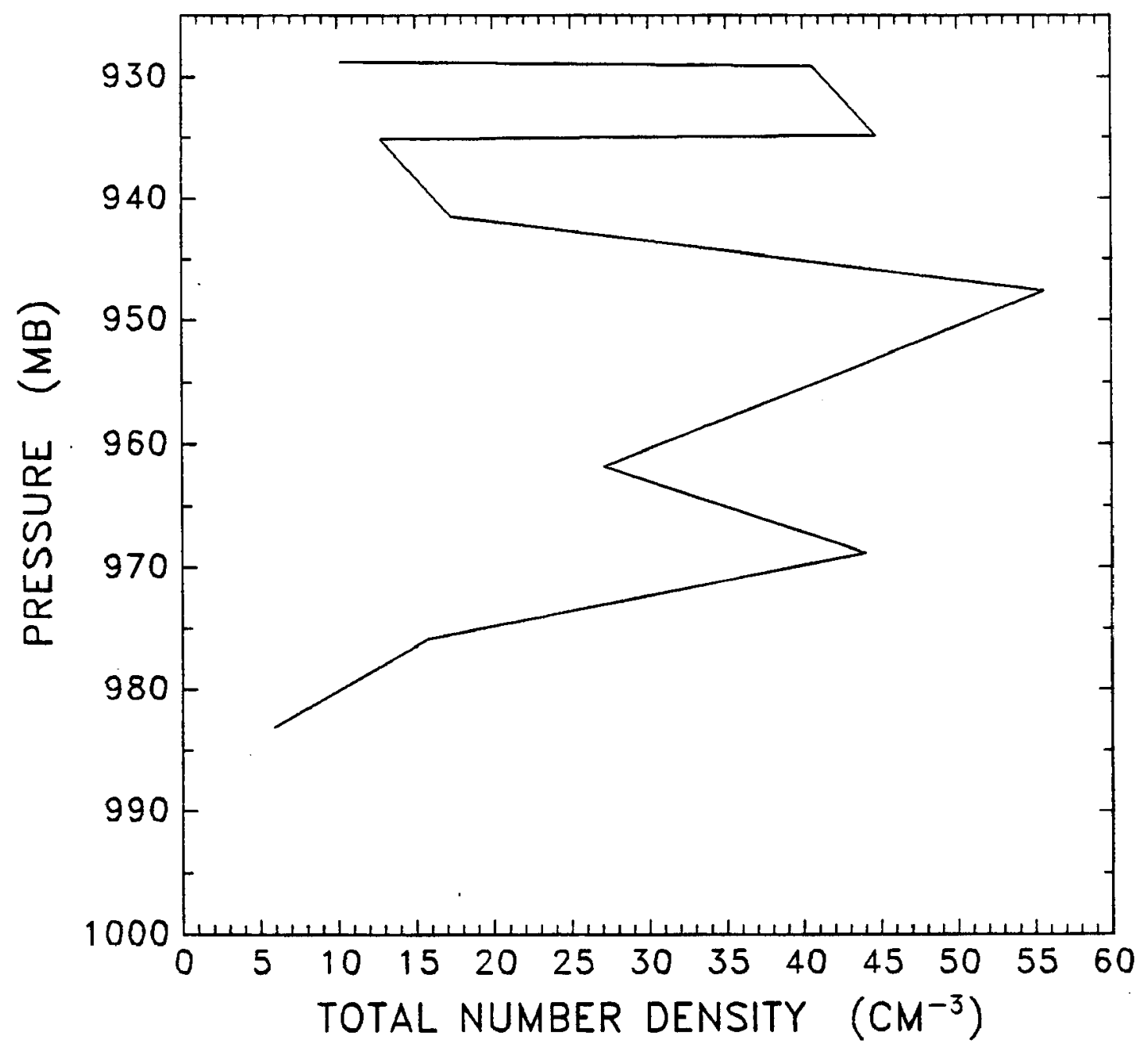

Figure 4.14: Profile of the average total number density taken from the constant level legs of Flight 3. 


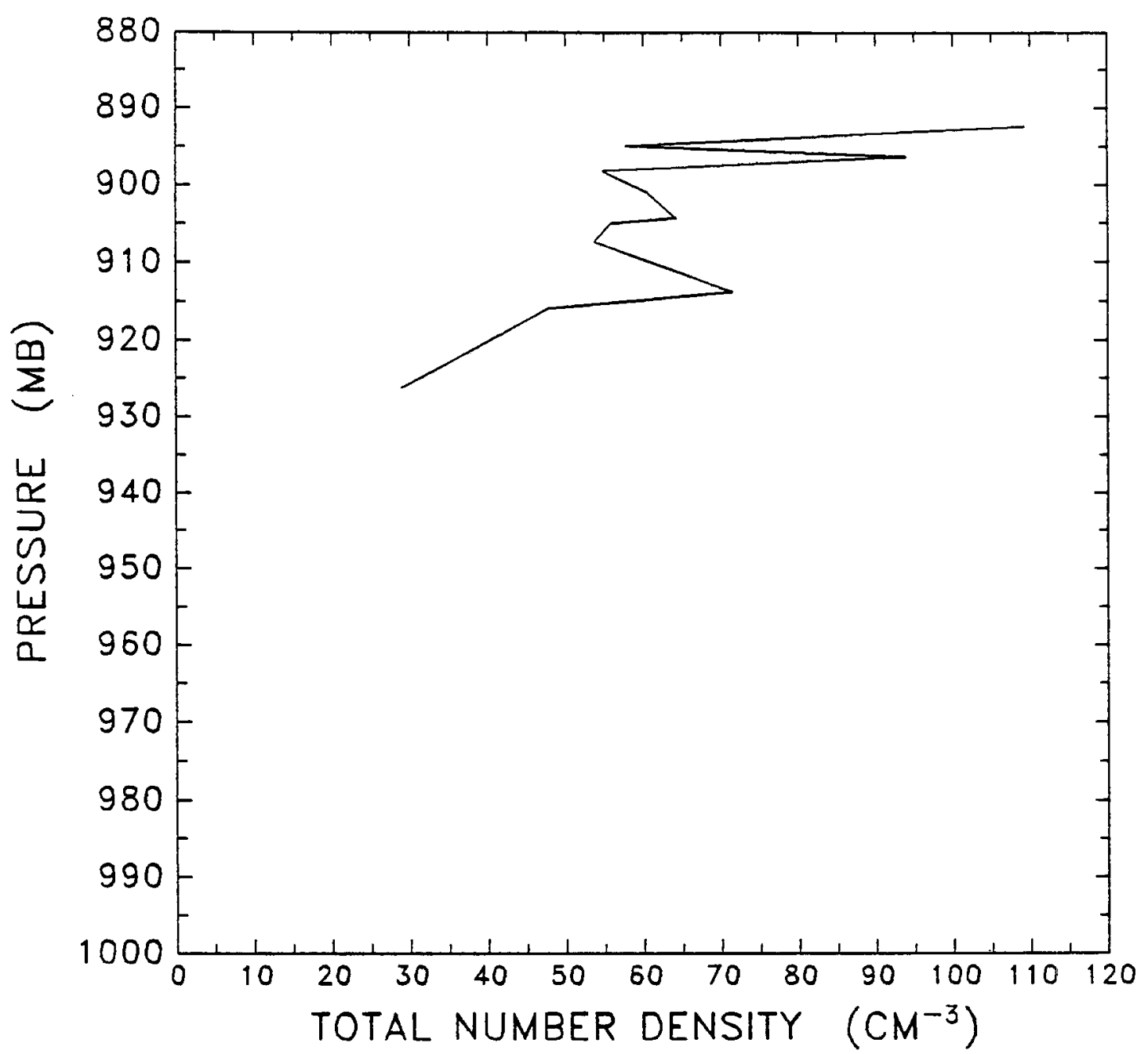

Figure 4.15: Profiles of the average total number density taken from the constant level legs of Flight 5. 


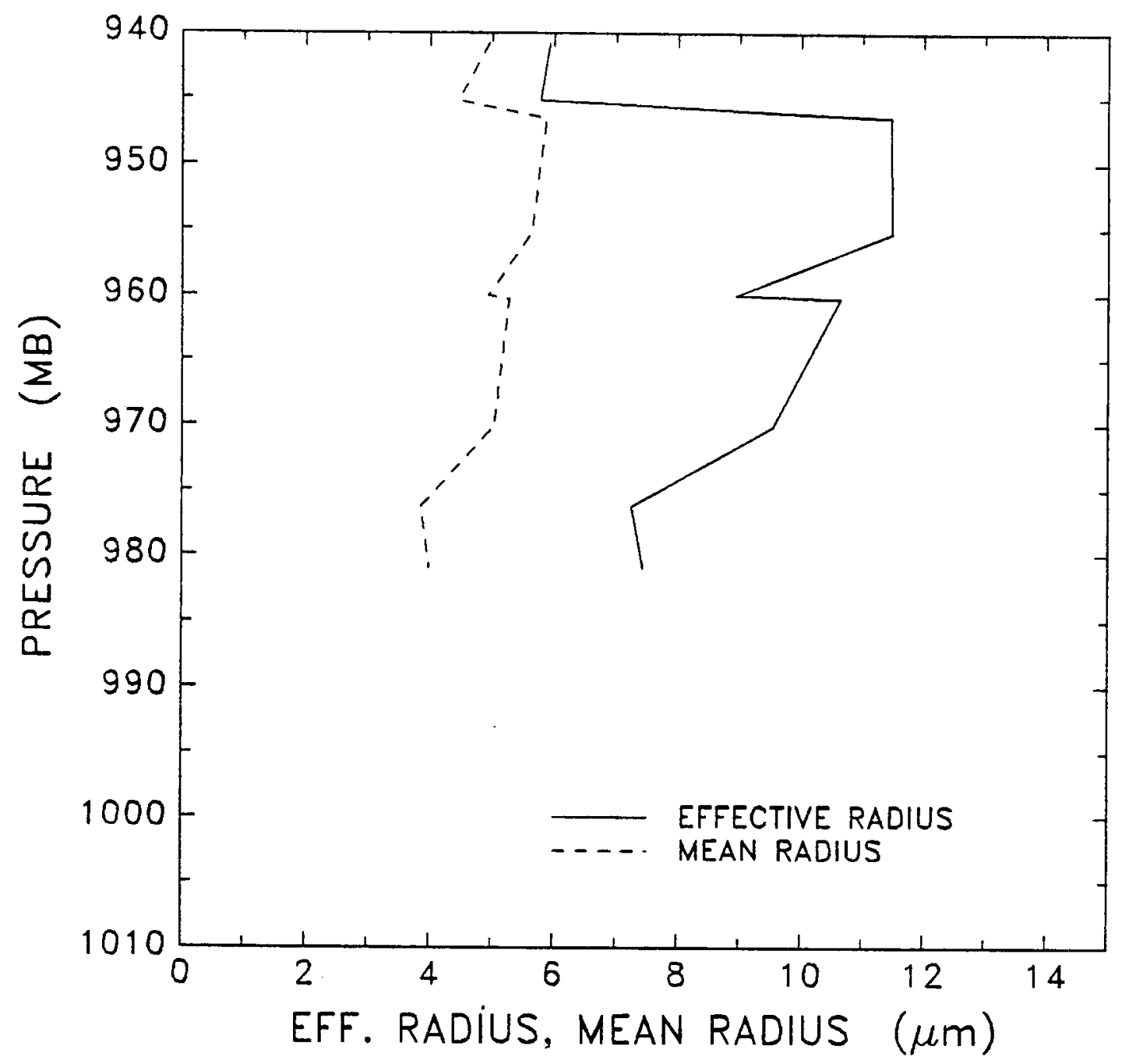

Figure 4.16: Profiles of the mean radius and the effective radius taken from the constant level legs of Flight 2. 


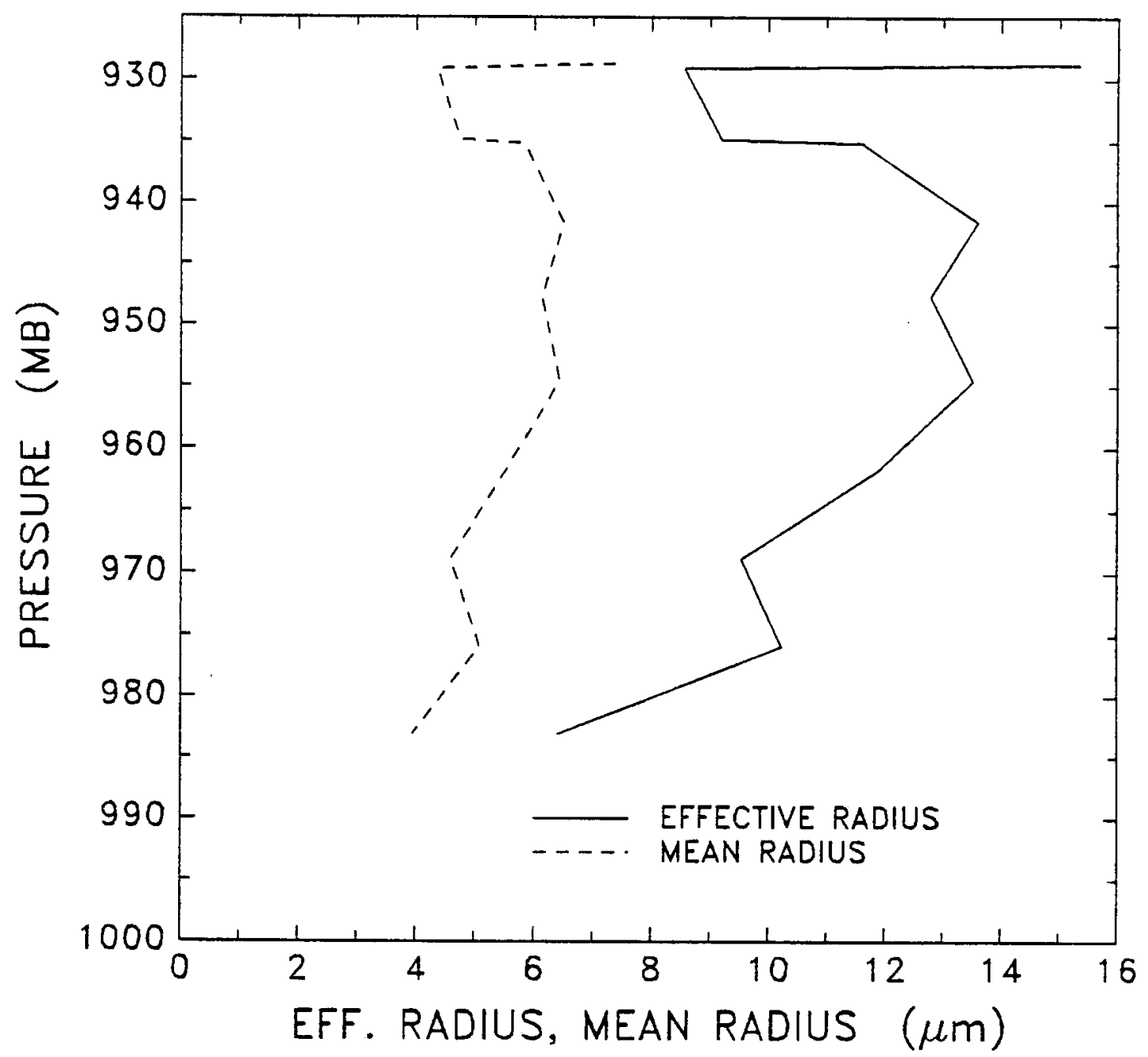

Figure 4.17: Profiles of the mean radius and the effective radius taken from the constant level legs of Flight 3. 


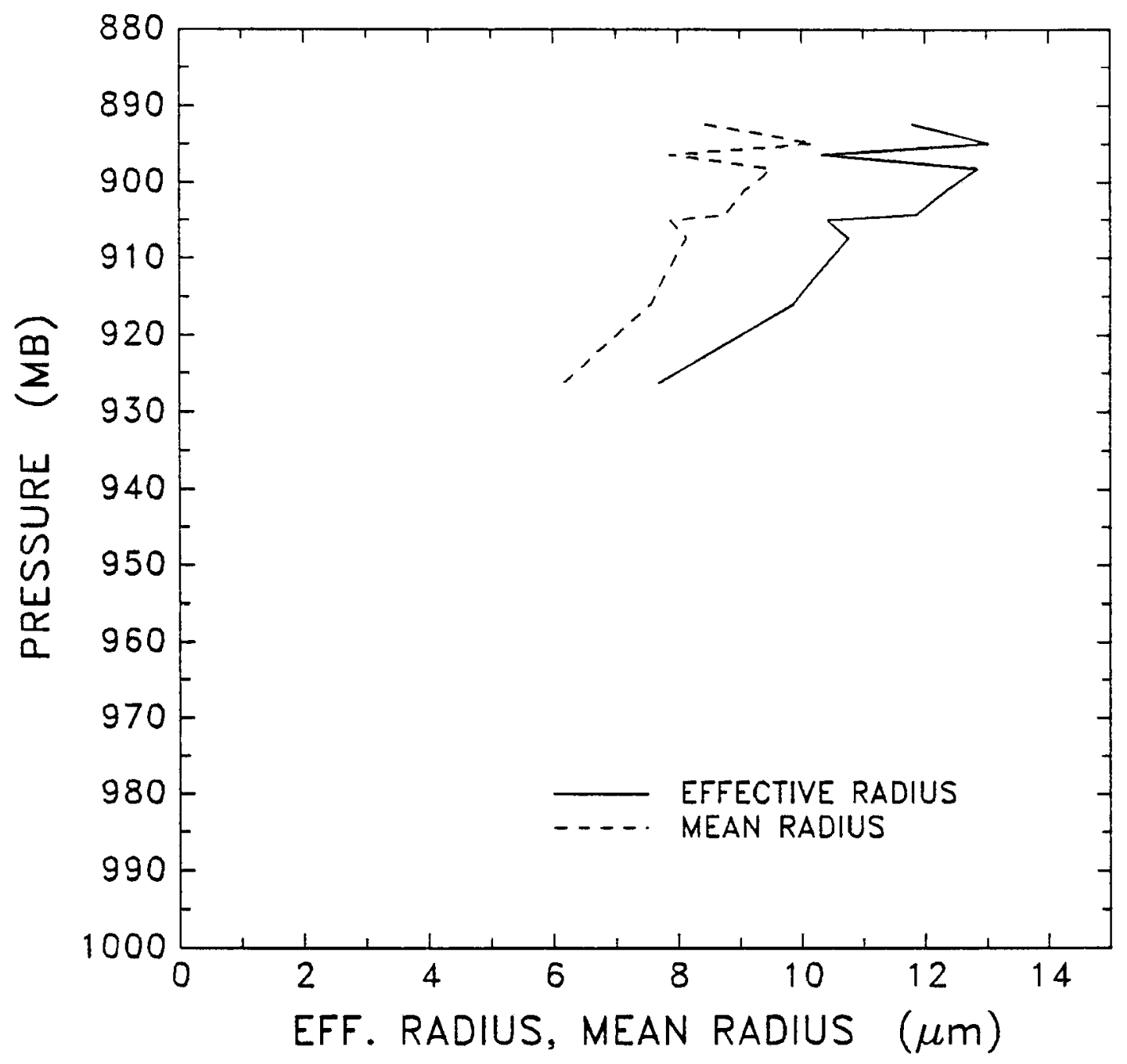

Figure 4.18: Profiles of the mean radius and the effective radius taken from the constant level legs of Flight 5. 


\subsubsection{Comparison with other measurements}

The cloud microphysical properties were measured by several other instrument systems during the FIRE marine stratocumulus IFO. Davies and Blaskovic (1988) eśtimated the average cloud LWC versus local time during the stratocumulus IFO by combining information on cloud thickness with the liquid water path data from the NOAA/WPL microwave radiometer. The mean LWC inside the cloud ranged from 0.4 to $0.125 \mathrm{~g} \cdot \mathrm{m}^{-3}$ from 1500 GMT to 0000 GMT, the time period when the instrument platform was usually inside the cloud. Measurements of LWC were also made by a forward scatter meter on a Naval Research Laboratory balloon stationed on SNI during the IFO (Gerber et al., 1988). The LWC measured inside a $150 \mathrm{~m}$ deep, dissipating cloud on July 23 was constant throughout the cloud layer with a mean of $0.22 \mathrm{~g} \cdot \mathrm{m}^{-3}$.

Cloud condensation nuclei were measured by the NCAR Electra aircraft several times during the observation program with the DRI instantaneous CCN spectrometer (Hudson, 1988). The particle concentrations below the cloud $\left(78 \mathrm{~cm}^{-3}\right)$ were lower than the concentrations above the cloud $\left(139 \mathrm{~cm}^{-3}\right)$ for all flights of the Electra. This supports the idea that continental air was advected over the SNI region above the boundary layer. Measurements of total droplet number density were also made by the University of Washington's C-131A research aircraft on July 10, 1987 in the vicinity of SNI (Radke et al., 1988). The total number density of droplets measured in the middle of a $500 \mathrm{~m}$ deep cloud at 1600 GMT was near $50 \mathrm{~cm}^{-3}$, which compares favorably to the total number density estimated by the FSSP during Flight 5.

A derivation of cloud optical parameters was made during the stratocumulus IFO from the Multispectral Cloud Radiometer on board the ER-2 aircraft (Nakajima and King, 1988). Mode radii between 12 and $15 \mu \mathrm{m}$ were retrieved over the stratocumulus on July 10,1987 , which is in the same range of particle sizes $(14-20 \mu \mathrm{m})$ measured by the FSSP. 


\subsection{Radiation Measurements}

\subsubsection{Longwave radiative heating rates}

After the upwelling and downwelling infrared fluxes were corrected for the differential heating of the instrument, the upwelling fluxes were subtracted from the downwelling fluxes to find the net longwave flux throughout the boundary layer. Figure 4.19 shows a smoothed profile of the net infrared fluxes measured in the morning (1442-1554 GMT) during Flight 2. The measurements show that the net flux increased to near zero as the platform entered the cloud, since the contribution from the upwelling flux decreased inside the cloud. The net flux stayed near zero throughout the middle of the cloud, and the upwelling and downwelling fluxes were within $5 \mathrm{~W} \cdot \mathrm{m}^{-2}$ of their blackbody values. Inside the cloud, the standard deviation of the measured fluxes for all flights was $2 \mathrm{~W} \cdot \mathrm{m}^{-2}$. The observed downwelling flux decreased sharply above the cloud top, and a layer of strong net flux divergence was measured in the top $50 \mathrm{~m}$ of the cloud. The radiative heating rates determined from the flux profile is presented on the right hand side of Figure 4.19. The heating rates were calculated from the flux gradients over $2 \mathrm{mb}$ intervals. A small amount of radiative warming was found near cloud base $\left(0.2^{\circ} \mathrm{C} \cdot \mathrm{hr}^{-1}\right)$, while large radiative cooling rates were found in the top $4 \mathrm{mb}$ (approximately $40 \mathrm{~m}$ ) of the cloud on the order of 3 to $4^{\circ} \mathrm{C} \cdot \mathrm{hr}^{-1}$. The depth and the magnitude of the cooling compares favorably to the rates found in the study of marine stratocumulus by Stephens et al. (1978) and by Slingo et al. (1982).

Three additional profiles of the longwave radiative heating rates measured at different times throughout Flight 2 are shown in Figures 4.20-4.22. The profiles are similar to the morning profile, with a region of radiative warming near cloud base, little warming or cooling in the middle of the cloud, and the largest flux divergence in the top 4 to 6 $\mathrm{mb}$ of the cloud layer. The maximum cooling rates in the profiles ranged from 3 to 5 ${ }^{\circ} \mathrm{C} \cdot \mathrm{hr}^{-1}$. However, the net flux profiles in Figures 4.20-4.22 show that the depth of the cooling at cloud top during the afternoon increased from the profile measured during the morning. The change in the net flux profiles from morning to afternoon suggests the optical thickness of the cloud diminished during the afternoon. This change is consistent 


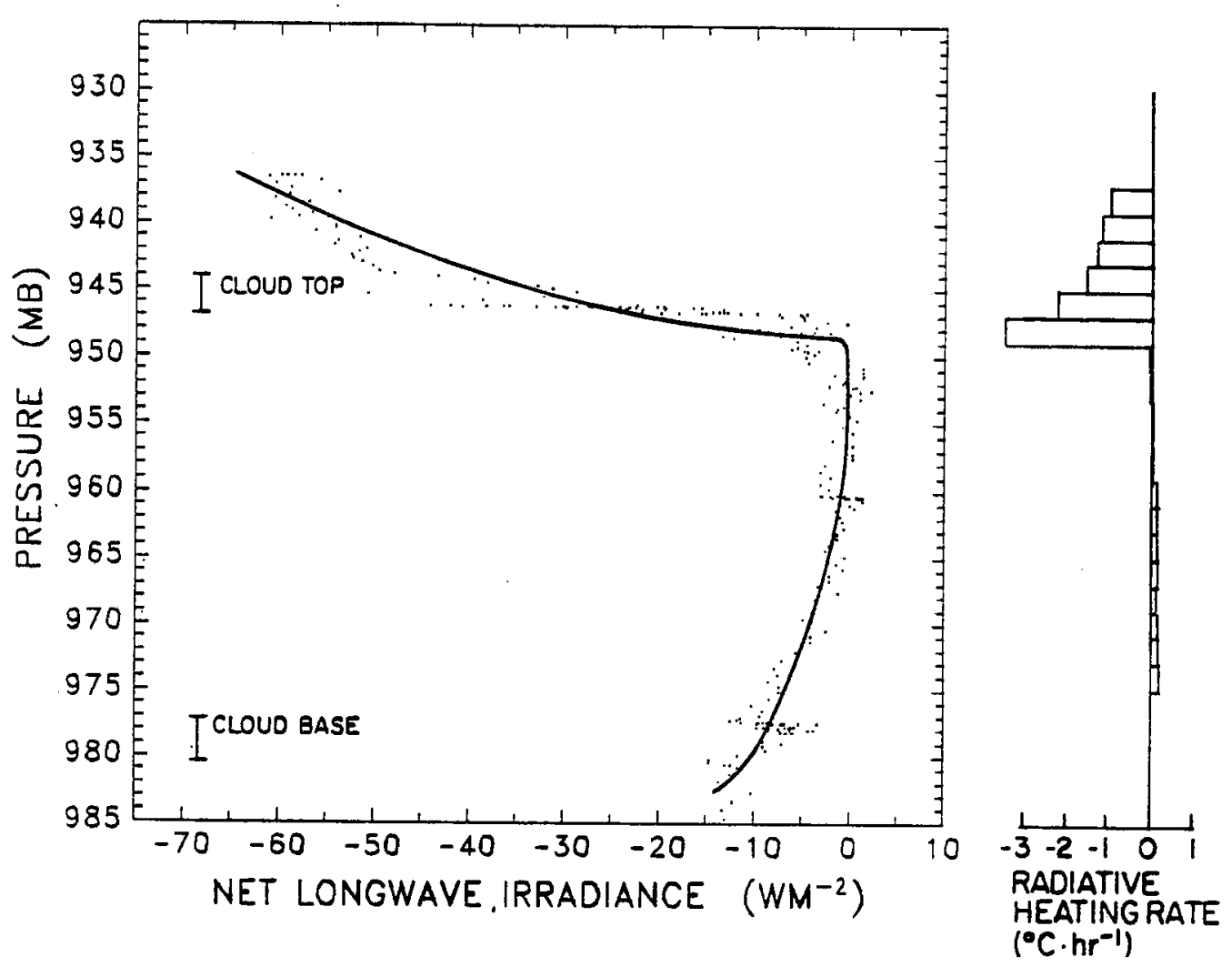

Figure 4.19: Longwave radiative fluxes and heating rates determined from the morning profile (1442-1554 GMT) taken during Flight 2 on July 7, 1987. 
with the radiometer estimated LWP from Flight 2 (Figure 4.7), which indicates a sharp decrease in the cloud LWP after 1900 GMT.

Figure 4.23 shows a smoothed profile of the net infrared fluxes measured between 1434 and 1534 GMT during Flight 3. The profile is similar in shape to the profiles from Flight 2. The net flux increased to near zero $\mathrm{W} \cdot \mathrm{m}^{-2}$ soon after the platform entered the cloud and the cloud was near its black body temperature throughout most of its depth. The strong flux divergence was confined to the top $4 \mathrm{mb}$ of the cloud in this case and the maximum cooling rate near cloud top was over $4{ }^{\circ} \mathrm{C} \cdot \mathrm{hr}{ }^{-1}$.

Since no rapid profile was made through the cloud layer on Flight 5, and the cloud appeared to be broken, no clear profile could be made of the net longwave radiative fluxes. While the instrument platform was near cloud top, it appeared to drift into and out of cloud. However, from the measurements made during the stepped levels toward the end of the flight the net flux above the cloud was consistently near $-70 \mathrm{~W} \cdot \mathrm{m}^{-2}$, and the net flux inside the cloud was approximately $-10 \mathrm{~W} \cdot \mathrm{m}^{-2}$. Assuming a profile similar to the other flights, the maximum longwave cooling rates at cloud top would be $5^{\circ} \mathrm{C} \cdot \mathrm{hr}^{-1}$.

\subsubsection{Cloud top solar fluxes}

The Eppley pyranometers measured the upwelling and downwelling total solar and near infrared fluxes throughout each of the flights. The downwelling solar fluxes in the clear sky above the boundary layer measured during the long constant level runs were normalized to local noon by

$$
F \downarrow_{\text {norm }}=F \downarrow_{\text {obs }} \times\left(\frac{\mu_{\text {noon }}}{\mu_{\text {obs }}}\right)
$$

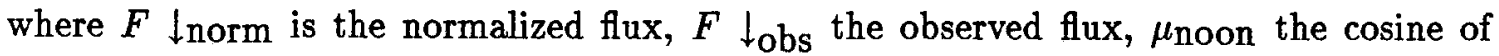
the zenith angle at local noon, and $\mu_{\mathrm{obs}}$ the cosine of the zenith angle at the time of the observation.

The average normalized downwelling flux measured at the top of the boundary layer during Flight 2 was $1135 \mathrm{~W} \cdot \mathrm{m}^{-2}$, and varied an average of $\pm 5 \mathrm{~W} \cdot \mathrm{m}^{-2}$ over each leg. However, the mean normalized downwelling flux measured above the cloud during Flight 3 was only $1105 \mathrm{~W} \cdot \mathrm{m}^{-2}$. The cloud-top irradiance observed during the flight was 30 

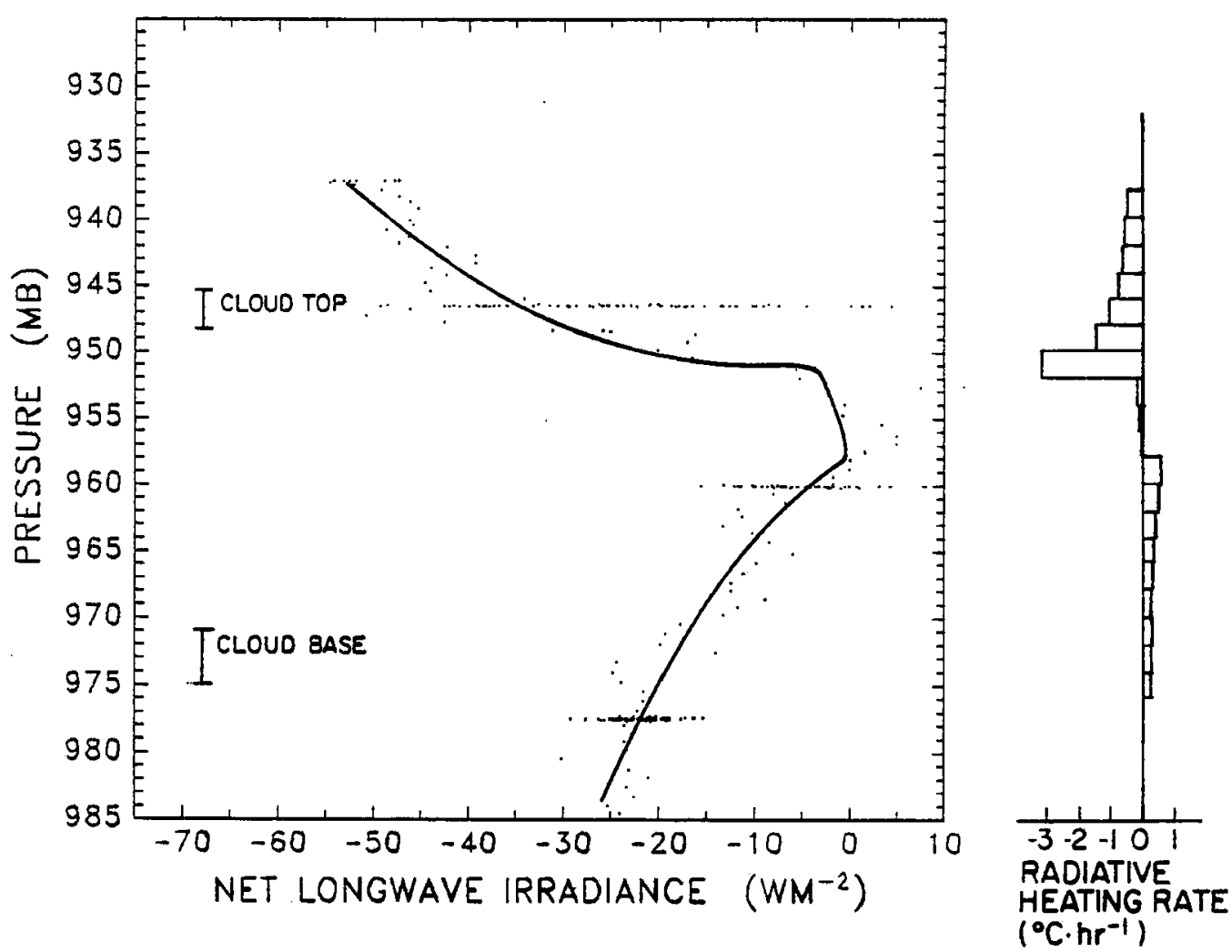

Figure 4.20: Same as Figure 4.19, except the profile was taken from 2038 to 2154 GMT. 

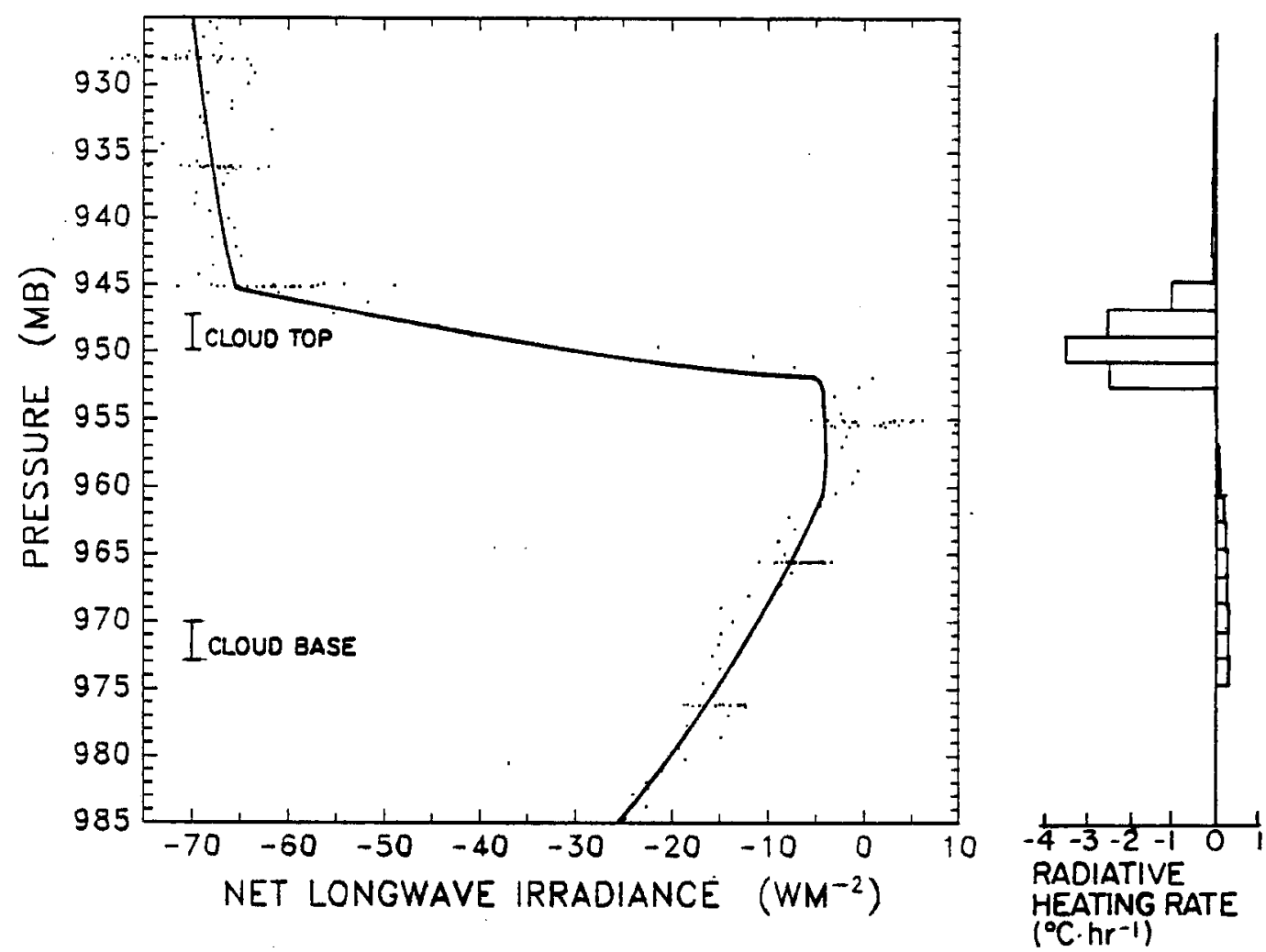

Figure 4.21: Same as Figure 4.19, except the profile was taken from 2203 to 2315 GMT. 

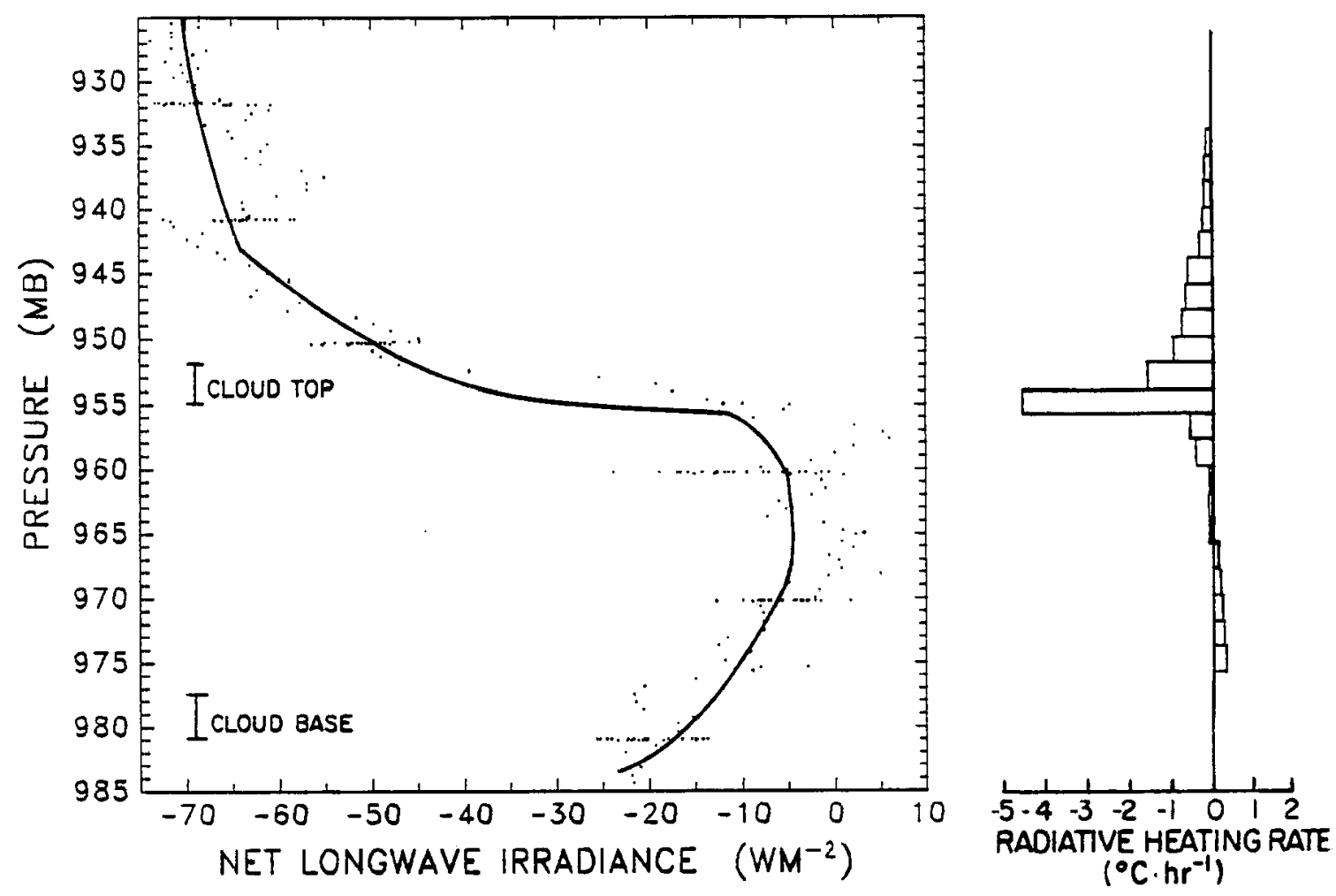

Figure 4.22: Same as Figure 4.19, except the profile was taken from 2320 to 0030 GMT. 

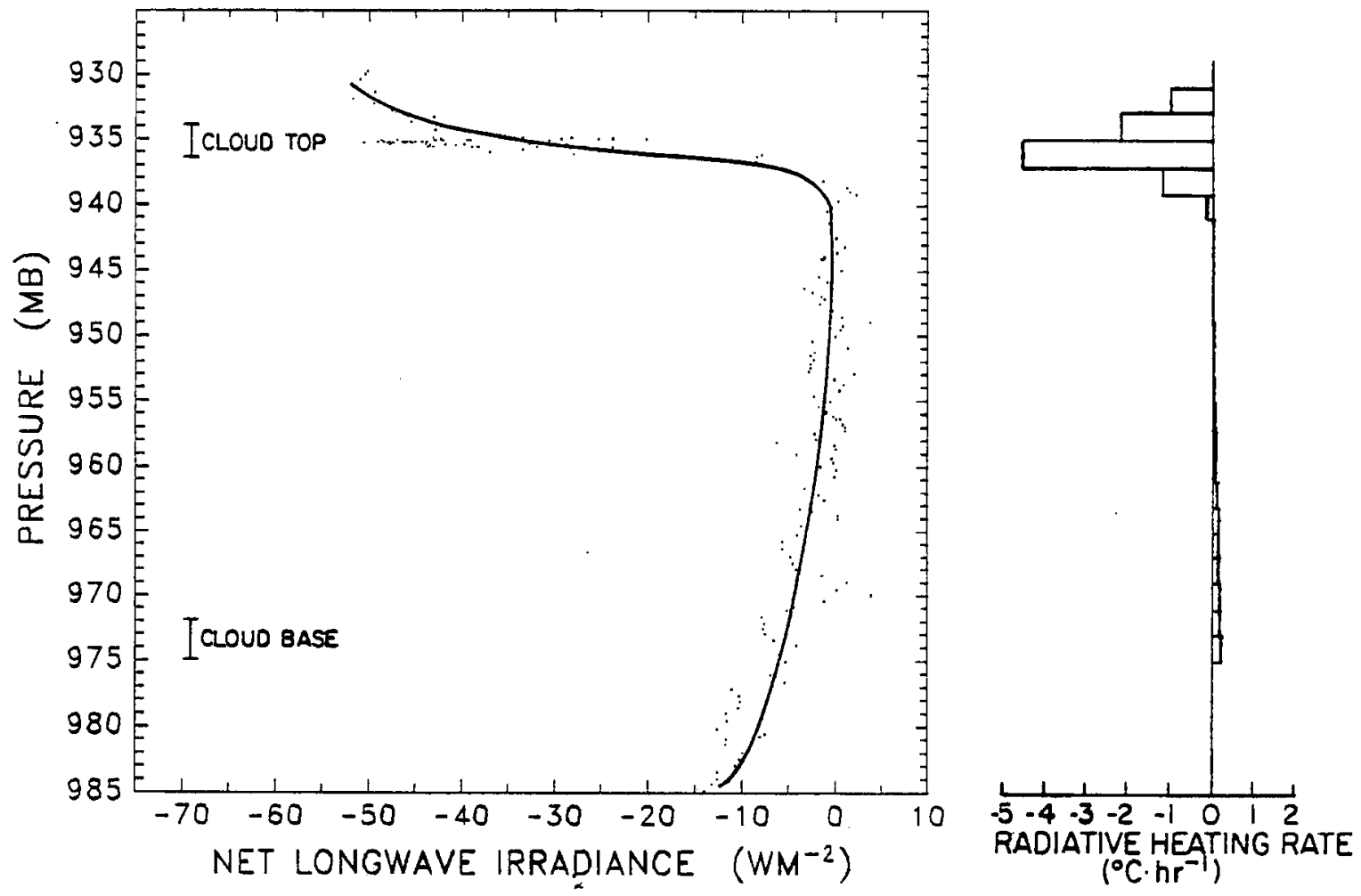

Figure 4.23: Longwave radiative fluxes and radiative heating rates determined from the profile taken between 1434 and 1534 GMT during Flight 3 on July 8, 1987. 
$\mathrm{W} \cdot \mathrm{m}^{-2}$ less than the flux measured on the other flights. (The normalized flux measured on July 10 was $1131 \mathrm{~W} \cdot \mathrm{m}^{-2}$.)

A computation of the downwelling solar flux at cloud top was made using the model described in Chapter 5. The downwelling flux through the atmosphere was simulated for Flights 3 and 5 using the temperature and moisture profiles from CLASS soundings launched during each flight and the radiative properties of the clouds derived from microphysics measurements and Mie scattering theory. A solar zenith angle of $20^{\circ}$ and a surface albedo of $25 \%$ were used in the calculations. The calculated normalized downwelling flux for Flight 3 was $1108 \mathrm{~W} \cdot \mathrm{m}^{-2}$, while the calculated flux for Flight 5 was $1152 \mathrm{~W} \cdot \mathrm{m}^{-2}$. The differences in the moisture profiles above the cloud produced most of the differences in the downwelling fluxes between Flights 3 and 5 .

\subsubsection{Shortwave radiative heating rates}

Figure 4.24 shows the smoothed net solar fluxes throughout the cloud during the profile run taken in the morning during Flight 2. The net solar flux increases exponentially upward through the cloud layer to the top of the cloud, and is nearly constant above the boundary layer. The right hand side of Figure 4.24 shows the radiative heating rates observed inside the cloud. The heating rates were found from the flux divergences over $5 \mathrm{mb}$ intervals. The strong flux convergence near cloud top shows the solar heating rate to be almost twice the infrared cooling rate. Figure 4.25 presents the net shortwave flux profile and radiative heating rates measured during a stepped descent through the boundary layer made in the from 2038 to 2154 GMT, when the zenith angle was near $20^{\circ}$. Although the net fluxes are generally larger throughout the cloud, they increase less rapidly through the cloud than in the morning profile. The radiative heating extends throughout the cloud layer during this profile, but the maximum heating rates are only 5.6 ${ }^{\circ} \mathrm{C} \cdot \mathrm{hr}^{-1}$. The solar heating rates inside of stratocumulus clouds have often been ignored in the study of stratocumulus clouds, but it appears that the solar forcing has as much or even greater effects on the cloud than the longwave cooling. Shortwave heating near the top of stratocumulus clouds has generally been considered to be unimportant compared to the longwave cooling at cloud top, and these observations are somewhat surprising. However, 
the possibility of large solar forcing in stratocumulus has previously been speculated by Twomey and Cocks (1982).

The heating rates from the morning profile are separated spectrally into contributions by the visible $(.3-.7 \mu \mathrm{m})$ and near IR (.7-2.8 $\mu \mathrm{m})$ regions and are shown in Figure 4.26. The visible fluxes were calculated by subtracting the measured near IR fluxes from the measured total solar fluxes. Figure 4.26 shows that both the visible and near IR parts of the spectrum contribute almost equally to the total solar heating rate. The large amounts of heating due to the visible light appear to be unreasonable since most absorption of solar radiation by water occurs in the near infrared region. The visible and near IR heating rates from the stepped profile presented in Figure 4.27 show that approximately $55 \%$ of the heating in the cloud is from the near IR part of the spectrum. It appears in this case the visible heating rates are also too large.

Figure 4.28 presents the smoothed net solar fluxes measured throughout the boundary layer during an ascending profile taken between 1434 and 1534 GMT during Flight 3 . The flux profile is similar to the morning profile taken during Flight 2. The maximum solar heating rate is contained in the top $5 \mathrm{mb}$ of the cloud with a value of $3.9^{\circ} \mathrm{C} \cdot \mathrm{hr} \mathrm{r}^{-1}$. The spectral components of the shortwave heating rate (Figure 4.29 ) show that $55 \%$ of the in-cloud heating is from the near IR wavelengths.

As with the longwave fluxes, the long sampling time and variability of the cloud structure made the determination of the net solar flux profile on Flight 5 difficult. The mean net normalized flux above the cloud was $475 \mathrm{~W} \cdot \mathrm{m}^{-2}$, while in-cloud measurements indicate the net flux was $350 \mathrm{~W} \cdot \mathrm{m}^{-2}$ near the base of the cloud (910-915 mb). Assuming a cloud thickness of $20 \mathrm{mb}$, the average normalized solar heating rate through the cloud would be $0.74{ }^{\circ} \mathrm{C} \cdot \mathrm{hr}^{-1}$. This heating rate is slightly less than the average heating rate $\left(0.92{ }^{\circ} \mathrm{C} \cdot \mathrm{hr}^{-1}\right)$ measured inside the cloud from the afternoon profile from Flight 2, which was taken at a similar time of the day but inside a deeper ( $35 \mathrm{mb})$ cloud.

\subsubsection{Transmissivity}

From the measurements of the downwelling solar fluxes taken above the cloud, estimates of the cloud top downwelling solar flux were made for each time interval during the 

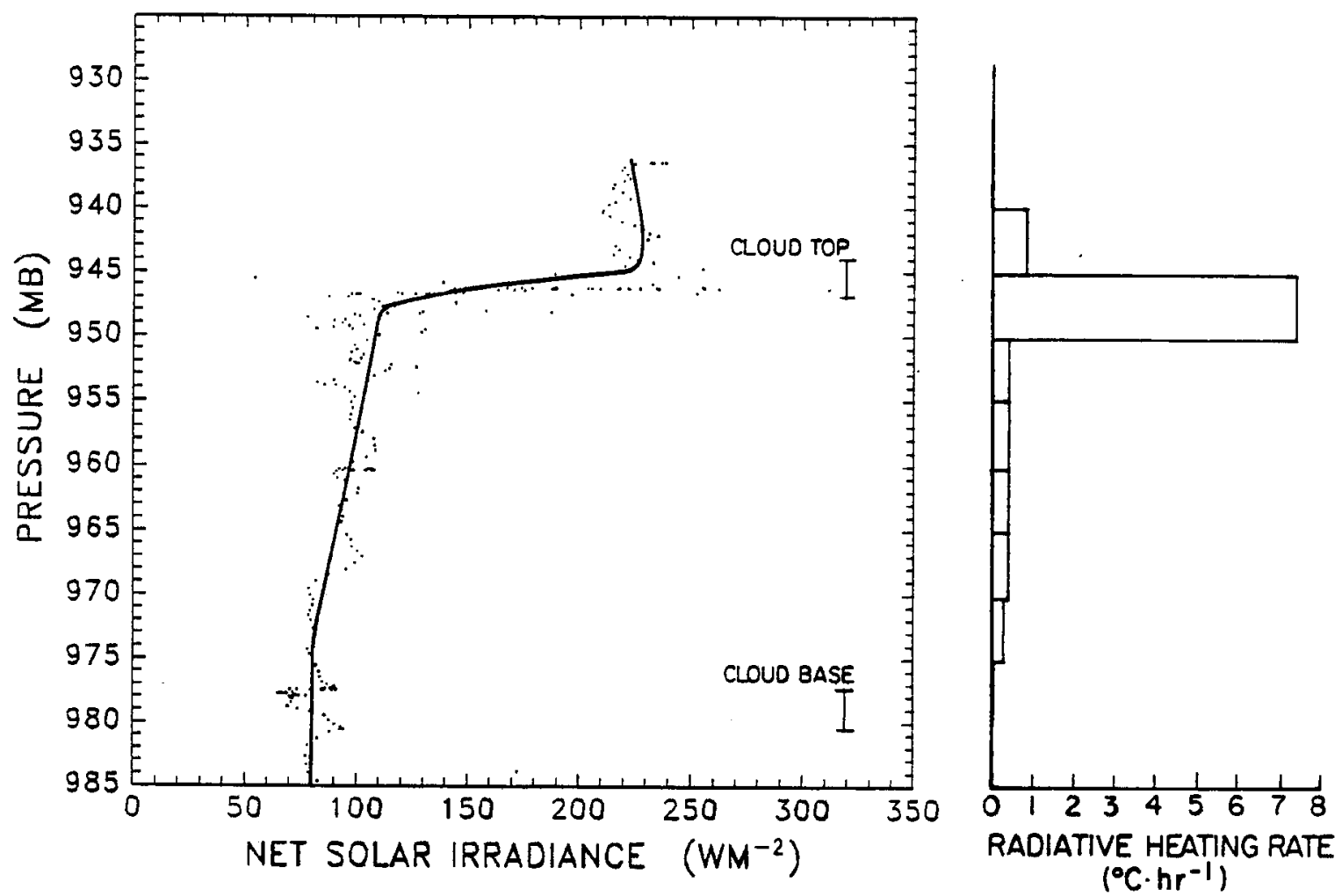

Figure 4.24: Shortwave radiative fluxes and radiative heating rates determined from the morning (1442-1554 GMT) profile taken during Flight 2 . The fluxes and the heating rates were normalized to the time midway through the profile (1518 GMT). 

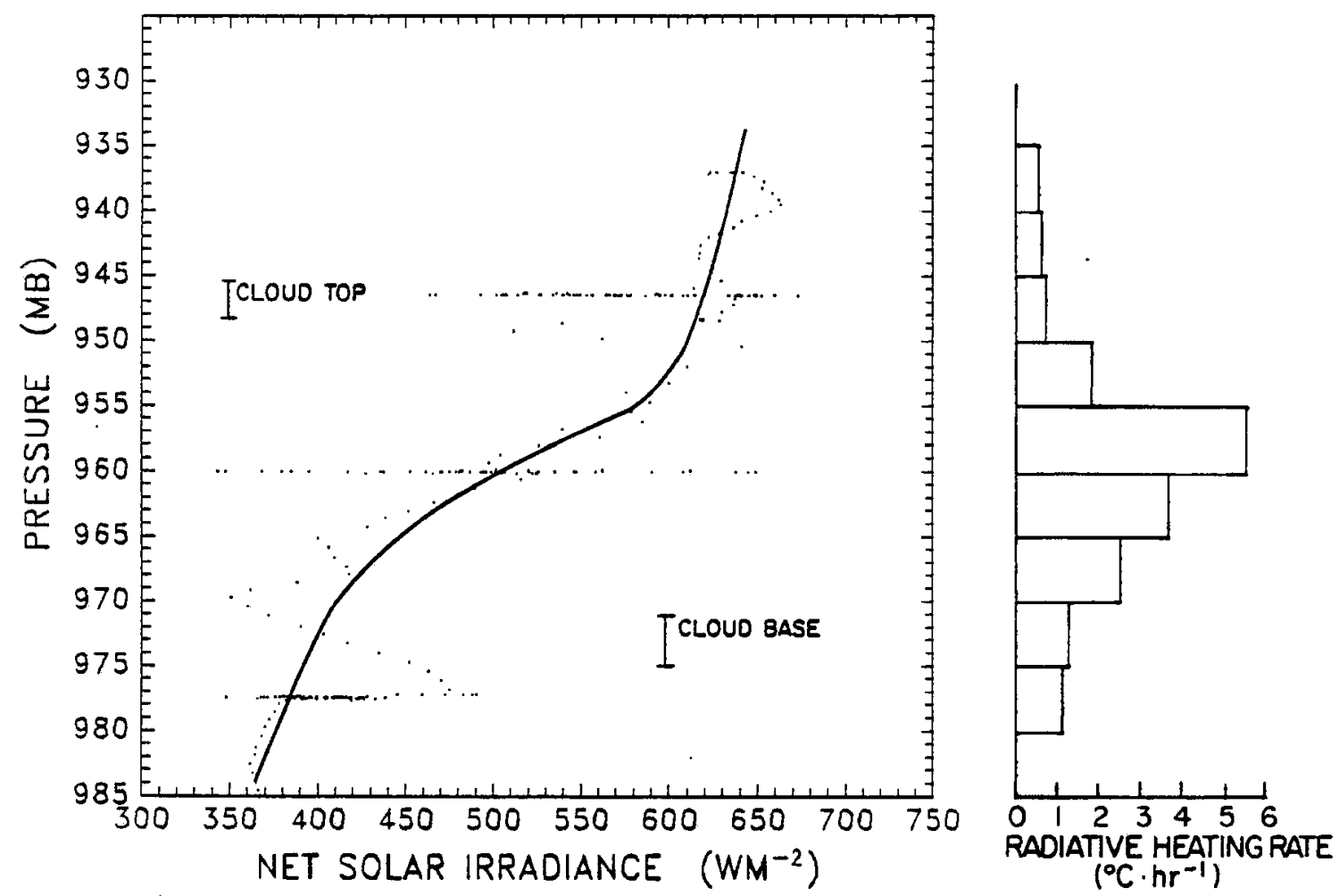

Figure 4.25: Shortwave radiative fluxes and radiative heating rates determined from the afternoon (2038-2154 GMT) profile taken during Flight 2. The fluxes and the heating rates were normalized to the time midway through the profile (2116 GMT). 

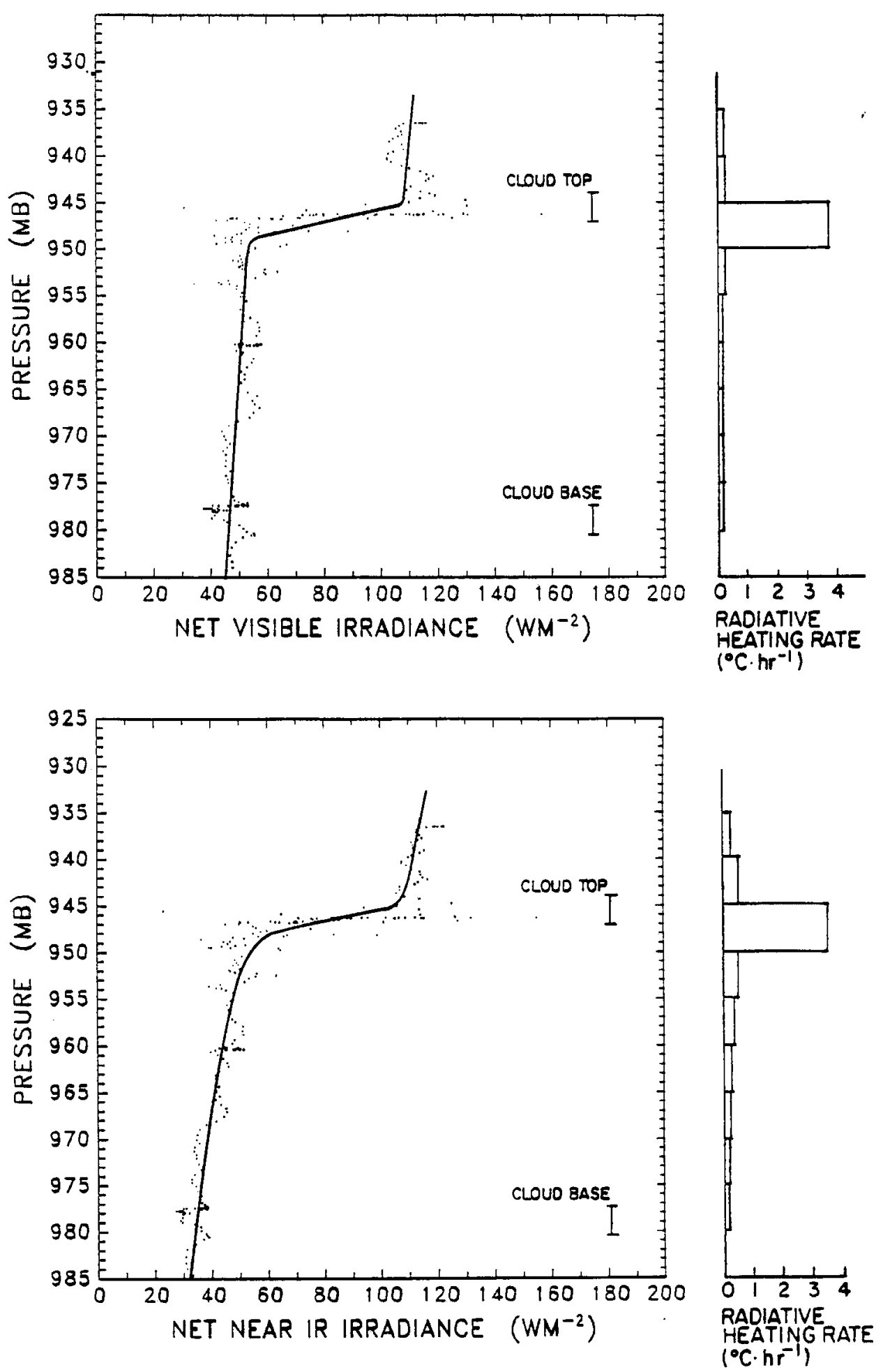

Figure 4.26: Visible and near IR radiative heating rates determined from the morning (1442-1554 GMT) profile taken during Flight 2. The fluxes and heating rates were normalized to $1518 \mathrm{GMT}$. 

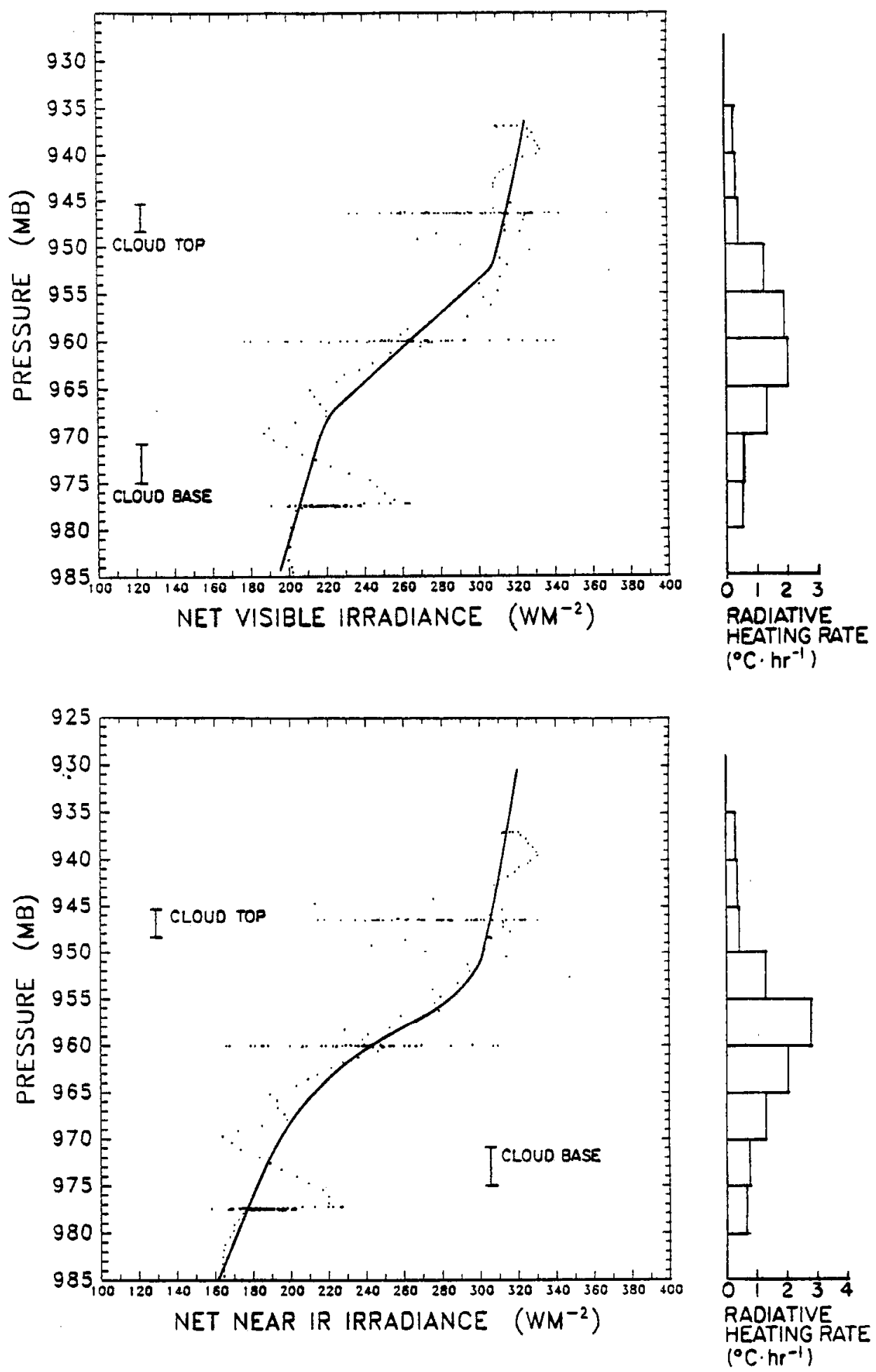

Figure 4.27: Visible and near IR radiative heating rates determined from the afternoon (2038-2154 GMT) profile taken during Flight 2. The fluxes and heating rates were normalized to 2116 GMT. 

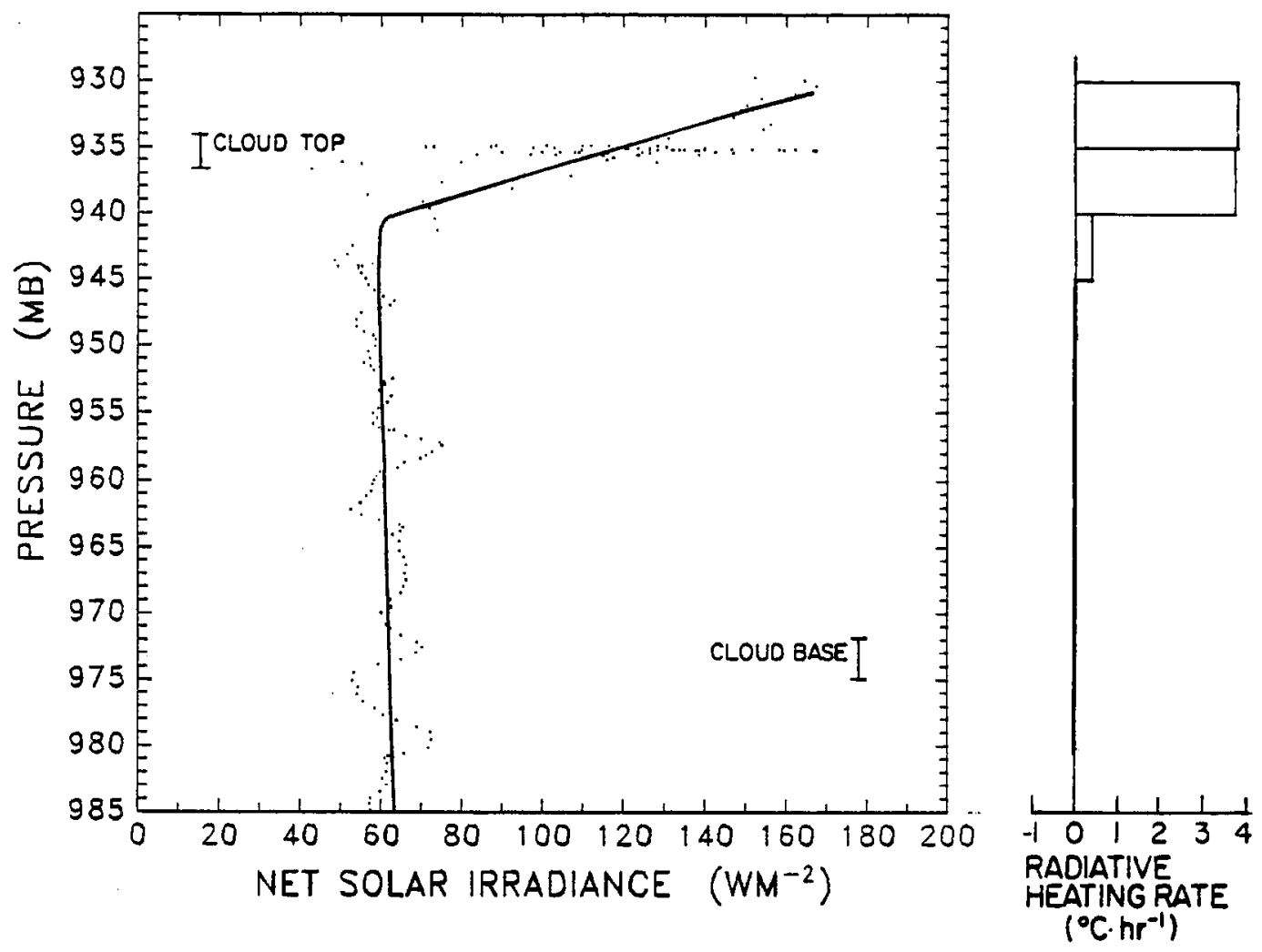

Figure 4.28: Shortwave radiative fluxes and radiative heating rates determined from the (1434-1534 GMT) profile taken during Flight 3. The fluxes and the heating rates were normalized to the time midway through the profile (1504 GMT). 

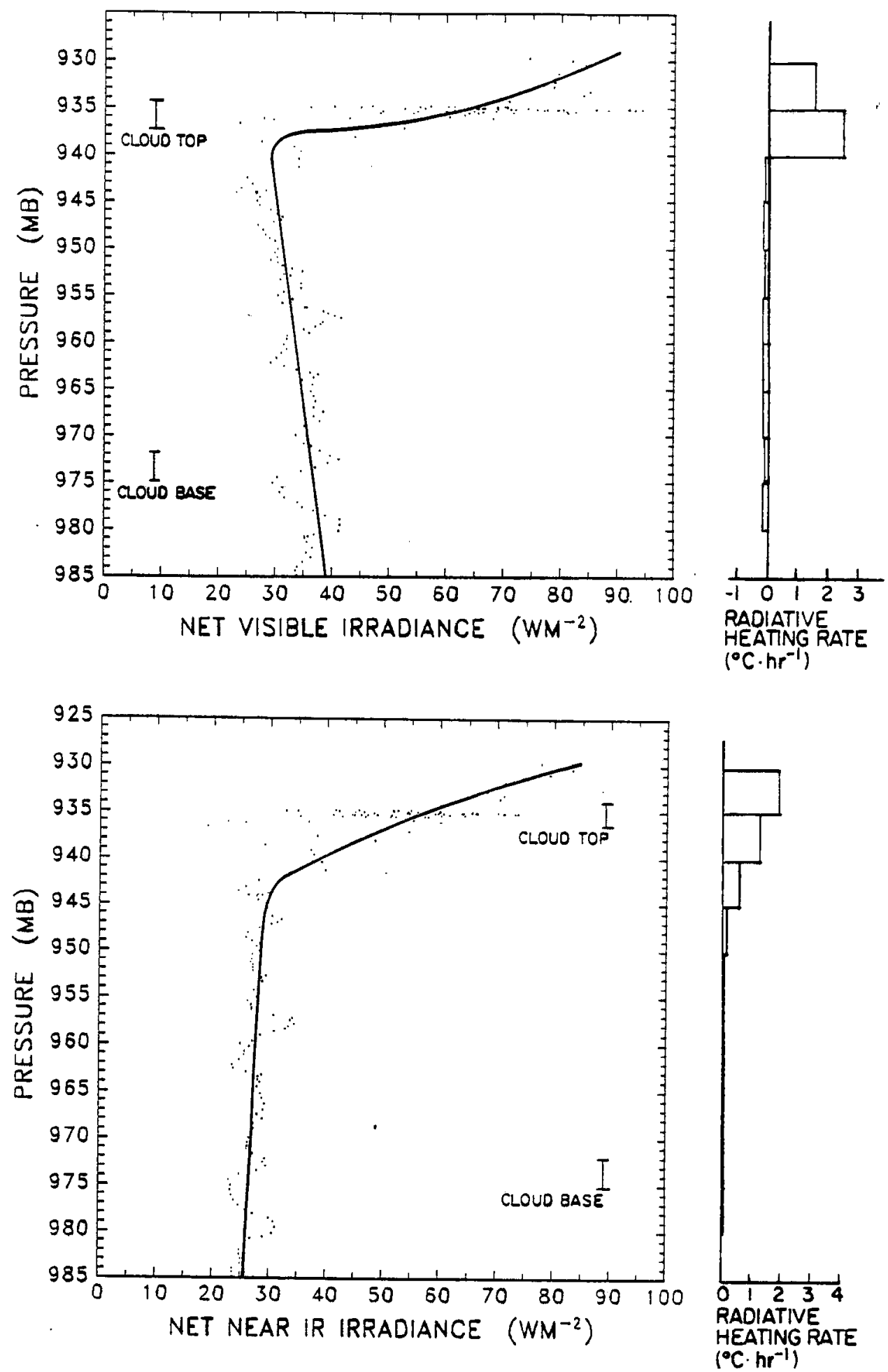

Figure 4.29: Visible and near IR radiative heating rates determined from the profile taken from 1434 to 1534 GMT during Flight 3 . The fluxes and heating rates were normalized to 1504 GMT. 
flight using equation (4.2),

$$
F \downarrow_{i}=F \downarrow_{\text {ref }} \times\left(\frac{\mu_{i}}{\mu_{\text {ref }}}\right)
$$

where $F \downarrow_{i}$ is flux at time interval $i, F \downarrow_{\text {ref }}$ the reference flux observed at a time when the platform was above the cloud, $\mu_{i}$ the cosine of the zenith angle at time interval $i$, and $\mu_{\text {ref }}$ the cosine of the zenith angle at the time of the observation. The transmissivity of solar radiation through the cloud at time interval $i$ was calculated throughout the boundary layer by dividing the measured downwelling flux by the estimated cloud top downwelling solar flux,

$$
T_{i}=\frac{F \downarrow_{\text {meas }}}{F \downarrow_{i}}
$$

Table 4.1 shows the average total solar and near IR transmissivity computed at each constant level leg during Flight 2. A comparison of the transmissivities shows the near IR transmissivity is a few percent lower than the total solar transmissivity below the cloud layer. The calculated total solar transmissivity at the surface was near $20 \%$ at the start of the flight, but during the descending profiles taken in the afternoon the surface transmissivity rose to $35 \%$. The increase in transmissivity from the morning to the afternoon may be due in part to the decrease in the thickness of the cloud through the day. Time series of the liquid water content made during the morning and the afternoon show that the cloud top had lowered approximately $60 \mathrm{~m}$ and the cloud base had risen $20 \mathrm{~m}$. Assuming the mean liquid water content in the cloud had not changed during the day, the decrease in cloud thickness would result in a greater than $20 \%$ decrease in cloud liquid water path.

During the morning when the balloon remained above the cloud, the calculated transmissivity remained near $100 \%$, which is consistent with the above definition of the solar transmissivity. However, the transmissivity above the cloud computed during the afternoon was only $90 \%$. The low value of the transmissivity suggests that either aerosol or higher clouds had drifted over San Nicholas Island later in the day and reduced the downwelling solar irradiance at cloud top. The transmissivities calculated at each constant level leg toward the end of the flight tended to slowly decrease in time, especially when the platform was inside or below the cloud layer. This slow decrease is probably due to 
Table 4.1: Mean and standard deviation of the solar transmissivity at each level from Flight 2 on July 7, 1987.

\begin{tabular}{|c|c|c|c|c|c|}
\hline \multirow{2}{*}{ LEG } & PRESS & TRATAL SOLAR & \multicolumn{2}{c|}{ NEAR IR } \\
& TRANS & STDEV & TRANS & STDEV \\
& $(\%)$ & $(\%)$ & $(\%)$ & $(\%)$ \\
\hline 1 & 946.4 & 82.4 & 12.5 & 81.7 & 12.1 \\
2 & 936.6 & 99.3 & 0.4 & 99.6 & 0.4 \\
3 & 930.4 & 97.9 & 1.4 & 99.1 & 0.9 \\
4 & 926.3 & 100.0 & 0.4 & 100.0 & 0.4 \\
5 & 934.3 & 80.1 & 33.2 & 78.4 & 35.6 \\
6 & 937.0 & 95.4 & 0.2 & 96.1 & 0.1 \\
7 & 946.5 & 94.0 & 3.6 & 94.1 & 6.1 \\
8 & 960.1 & 63.9 & 4.8 & 63.6 & 4.8 \\
9 & 977.5 & 45.7 & 1.9 & 44.3 & 1.8 \\
10 & 991.7 & 41.5 & 2.7 & 39.4 & 2.6 \\
11 & 1008.7 & 36.4 & 0.5 & 33.5 & 0.5 \\
12 & 997.9 & 38.1 & 1.4 & 35.4 & 1.4 \\
13 & 987.0 & 44.8 & 3.3 & 43.0 & 3.1 \\
14 & 976.3 & 41.7 & 0.5 & 40.3 & 0.5 \\
15 & 965.6 & 49.6 & 2.5 & 49.1 & 2.3 \\
16 & 955.3 & 67.8 & 2.8 & 67.8 & 2.7 \\
17 & 945.2 & 90.6 & 0.5 & 90.3 & 0.4 \\
18 & 936.3 & 87.8 & 0.3 & 87.1 & 0.4 \\
19 & 923.6 & 87.1 & 0.3 & 84.3 & 0.3 \\
20 & 931.7 & 84.8 & 0.5 & 81.6 & 0.4 \\
21 & 940.8 & 83.8 & 0.3 & 80.0 & 0.5 \\
22 & 950.3 & 81.3 & 0.5 & 78.0 & 0.3 \\
23 & 960.3 & 68.4 & 5.5 & 67.9 & 6.2 \\
24 & 970.2 & 48.2 & 2.6 & 47.6 & 2.7 \\
25 & 981.0 & 34.2 & 2.9 & 32.8 & 2.7 \\
26 & 991.7 & 29.6 & 3.8 & 27.5 & 3.8 \\
\hline
\end{tabular}


the increased extinction per unit length inside the cloud as the solar zenith angle increased during the legs.

Table 4.2 presents the mean calculated solar transmissivity at each leg during Flight 3. The mean cloud top transmissivity (based on a local noon maximum of $1105 \mathrm{~W} \cdot \mathrm{m}^{-2}$ ) was near $100 \%$, but more variable than the transmissivities computed for Flight 2 . Between 1800 and 1930 GMT, the transmissivities tended to increase in time at each constant level leg, but the range in the measurements at each leg were much larger (up to $10 \%$ change) than those observed during Flight 2. Although the high clouds may make the transmissivity measurements more sensitive to the changing zenith angle, it appears that the relatively large increases in transmissivity at a constant level are due to changes in the liquid water path of the cloud. Measurements by the NOAA/WPL microwave radiometer on SNI between 1800 and 1930 GMT show the liquid water path decreased from $200 \mathrm{~g} \cdot \mathrm{m}^{-2}$ to $30 \mathrm{~g} \cdot \mathrm{m}^{-2}$. The relatively high transmissivities near the surface also suggest the liquid water path through the cloud was less during the afternoon.

Table 4.2: Mean and standard deviation of the solar transmissivity at each level from Flight 3 on July 8, 1987.

\begin{tabular}{|c|c|c|c|c|c|}
\hline \multirow[b]{2}{*}{ LEG } & \multirow[b]{2}{*}{$\begin{array}{c}\text { PRESS } \\
(\mathrm{mb})\end{array}$} & \multicolumn{2}{|c|}{ TOTAL SOLAR } & \multicolumn{2}{|c|}{ NEAR IR } \\
\hline & & $\begin{array}{c}\text { TRANS } \\
(\%)\end{array}$ & $\begin{array}{c}\text { STDEV } \\
(\%)\end{array}$ & $\begin{array}{c}\text { TRANS } \\
(\%)\end{array}$ & $\begin{array}{c}\text { STDEV } \\
(\%)\end{array}$ \\
\hline 1 & 935.2 & 95.3 & 4.8 & 91.4 & 4.3 \\
\hline 2 & 929.2 & 99.8 & 0.6 & 99.1 & 0.7 \\
\hline 3 & 934.9 & 100.4 & 1.6 & 100.3 & 1.8 \\
\hline 4 & 941.6 & 77.4 & 11.3 & 76.3 & 11.5 \\
\hline 5 & 928.7 & 101.3 & 6.1 & 100.0 & 6.3 \\
\hline 6 & 947.7 & 63.0 & 6.0 & 61.0 & 6.4 \\
\hline 7 & 954.6 & 58.8 & 2.4 & 57.2 & 2.6 \\
\hline 8 & 961.8 & 58.7 & 5.3 & 58.1 & 5.8 \\
\hline 9 & 968.9 & 56.0 & 6.4 & 55.3 & 6.7 \\
\hline 10 & 975.9 & 55.4 & 5.0 & 54.1 & 5.1 \\
\hline 11 & 983.2 & 46.8 & 5.8 & 45.0 & 6.0 \\
\hline 12 & 990.3 & 45.4 & 4.7 & 42.9 & 4.7 \\
\hline 13 & 997.3 & 57.4 & 5.1 & 54.9 & 5.3 \\
\hline
\end{tabular}

Table 4.3 shows the solar transmissivities calculated for Flight 5. The transmissivities measured in the afternoon legs (legs 14-22) near cloud top vary by as much as $20 \%$ as 
the platform went into and out of cloud. The transmissivity at the surface during the morning is only $20 \%$, while below cloud base it is nearly $50 \%$. Similar to the results from the other flights, the measured near IR transmissivities tended to be slightly less than the total transmissivities below the cloud.

Table 4.3: Mean and standard deviation of the solar transmissivity at each level from Flight 5 on July 10, 1987.

\begin{tabular}{|c|c|c|c|c|c|}
\hline \multirow{2}{*}{ LEG } & & PRESS & TOTAL SOLAR & \multicolumn{2}{c|}{ NEAR IR } \\
& $\begin{array}{c}\text { TRANS } \\
(\mathrm{mb})\end{array}$ & $\begin{array}{c}\text { STDEV } \\
(\%)\end{array}$ & $\begin{array}{c}\text { TRANS } \\
(\%)\end{array}$ & $\begin{array}{c}\text { STDEV } \\
(\%)\end{array}$ \\
\hline 1 & 997.9 & 21.1 & 2.0 & 18.1 & 1.8 \\
2 & 998.0 & 25.6 & 1.1 & 22.4 & 1.0 \\
3 & 987.3 & 28.8 & 1.0 & 25.4 & 0.9 \\
4 & 976.8 & 37.3 & 1.9 & 33.6 & 1.7 \\
5 & 966.7 & 35.8 & 1.0 & 32.0 & 1.0 \\
6 & 956.7 & 39.2 & 2.3 & 35.3 & 2.2 \\
7 & 946.6 & 38.1 & 1.3 & 34.3 & 1.2 \\
8 & 936.4 & 44.9 & 3.5 & 41.2 & 3.4 \\
9 & 926.4 & 48.6 & 9.0 & 45.0 & 8.7 \\
10 & 916.0 & 51.7 & 7.9 & 48.3 & 7.8 \\
11 & 905.1 & 94.2 & 16.1 & 92.9 & 17.6 \\
12 & 896.3 & 101.5 & 8.4 & 100.8 & 8.6 \\
13 & 889.7 & 99.9 & 0.1 & 99.9 & 0.2 \\
14 & 891.6 & 100.7 & 3.2 & 100.4 & 3.3 \\
15 & 892.5 & 101.2 & 4.7 & 101.0 & 4.9 \\
16 & 893.7 & 100.5 & 1.1 & 100.7 & 1.2 \\
17 & 895.2 & 101.0 & 5.0 & 100.8 & 5.1 \\
18 & 898.3 & 96.2 & 10.6 & 95.7 & 10.9 \\
19 & 901.1 & 95.5 & 6.5 & 95.7 & 7.0 \\
20 & 904.5 & 93.1 & 10.3 & 92.9 & 10.9 \\
21 & 907.4 & 90.1 & 13.1 & 90.6 & 12.1 \\
22 & 913.9 & 77.5 & 11.9 & 77.3 & 12.2 \\
\hline
\end{tabular}

\subsubsection{Solar albedo measurements}

Figure 4.30 shows a plot of the total solar, visible and near infrared albedos measured while the instrument platform was above the cloud. The albedos were defined as the ratio of the flux measured by the downward facing pyranometer divided by the flux measured by the upward facing pyranometer. The time series of the albedos can be separated into 
several regimes. During the first two hours above the cloud, the instruments measured a total solar albedo which varied between 60 to $65 \%$. From approximately 1815 GMT to 1915 GMT the albedo rose above $70 \%$ and became less variable. The measured albedos then decreased to $60-65 \%$ again and dropped to near $47 \%$ for several minutes before the platform re-entered the cloud. Most of the variation in the magnitude of the albedo is probably a result of changes in cloud cover over the boundary layer since the microphysical properties did not tend to change much during the flight.

The visible component of the solar albedo was generally larger than the near infrared component while the platform was above the cloud. This is consistent with the optical properties of liquid water as more light is absorbed in the near infrared wavelengths by the cloud droplets. Figure 4.31 presents a time series of the near infrared to visible albedo ratio measured above the cloud. The albedo ratio remained near $90 \%$ throughout most of the time series, even when the magnitude of the albedos changed from 60 to $70 \%$. Before the instrument platform re-entered the cloud, however, the near IR to visible ratio approached 1.0.

Figure 4.32 shows a plot of the time series of the total, near IR and visible albedos above the cloud observed during Flight 3 . The total solar albedo measured during Flight 3 averaged near $70 \%$, although it fluctuated between 65 and $75 \%$. Figure 4.33 presents the near IR to visible albedo ratio for the same part of the flight. The ratio generally ranged from 90-92\%, although it became more variable after 1600 GMT.

Figure 4.34 shows the time series of the solar albedo measured while the instrument platform was above the cloud during Flight 5 . The albedos were much more variable during this flight than the other cases. The average albedo is $64 \%$, although it ranges between $30 \%$ to $75 \%$ before the platform re-enters the cloud. A plot of the near IR to visible albedo ratio (Figure 4.35) shows that it is more variable than the ratio measured from other flights, and averages over $96 \%$. The higher value of the ratio indicates that the visible portion of the spectrum tended to reflect less in this flight, rather than near IR part reflecting more. In order to illustrate this, Table 4.4 shows the mean downwelling and upwelling fluxes in $\mathrm{W} \cdot \mathrm{m}^{-2}$ measured during two legs taken above the cloud layer on 


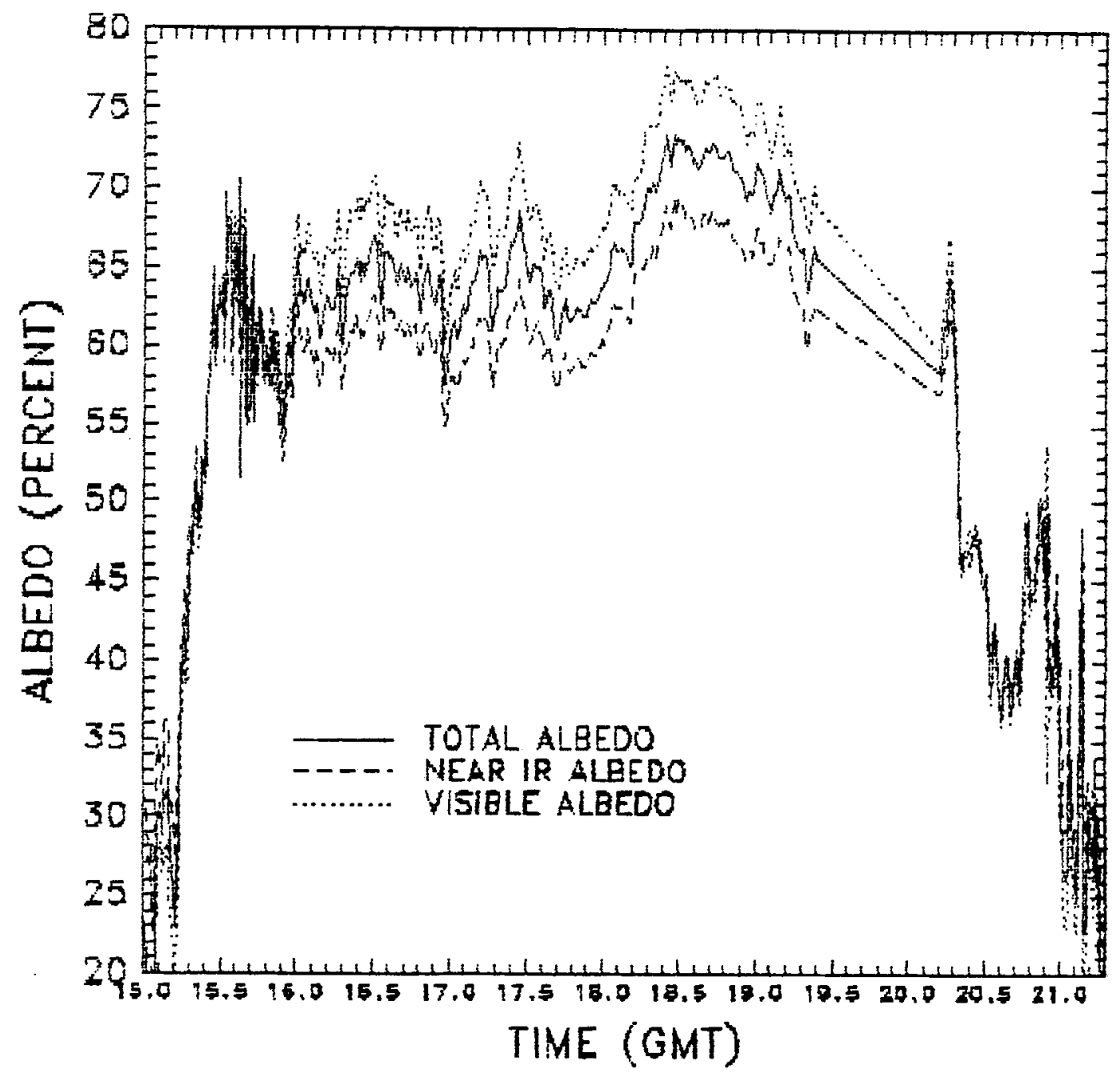

Figure 4.30: Time series of solar albedo measurements taken above the boundary layer during Flight 2. 


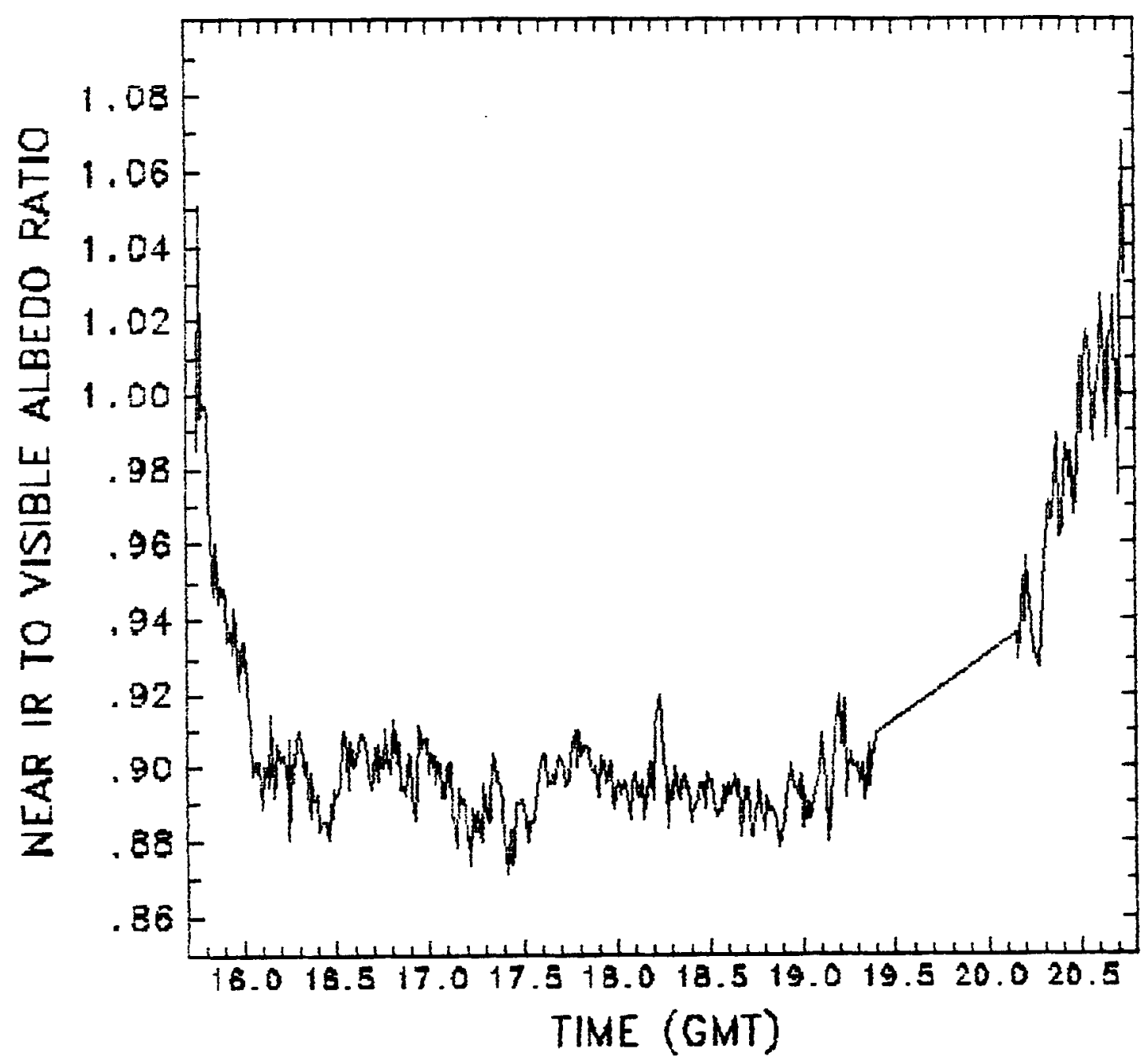

Figure 4.31: Time series of near IR albedo/visible albedo measurements taken above the boundary layer during Flight 2. 


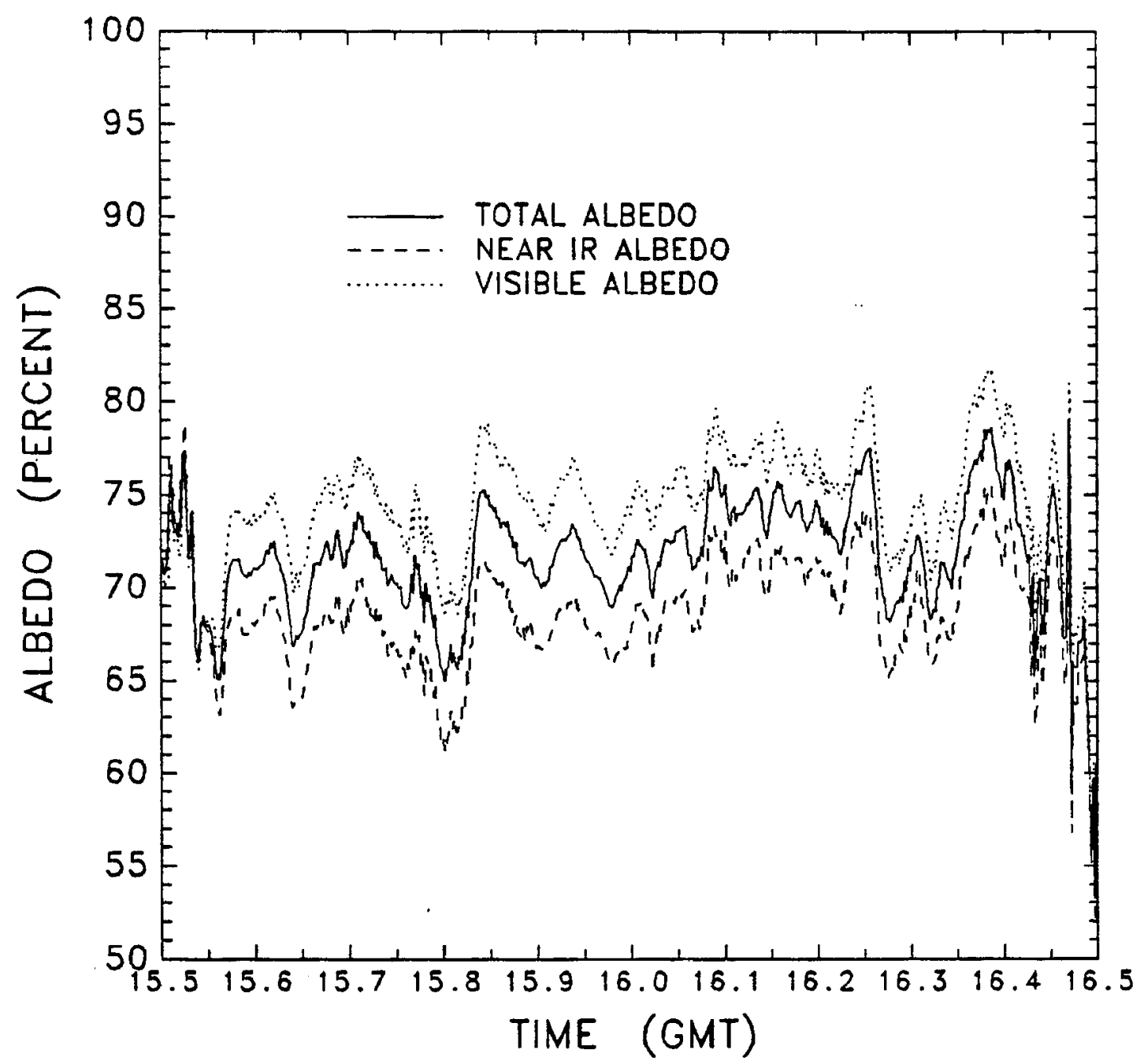

Figure 4.32: Time series of the total, near IR, and visible albedos above the cloud observed during Flight 3. 


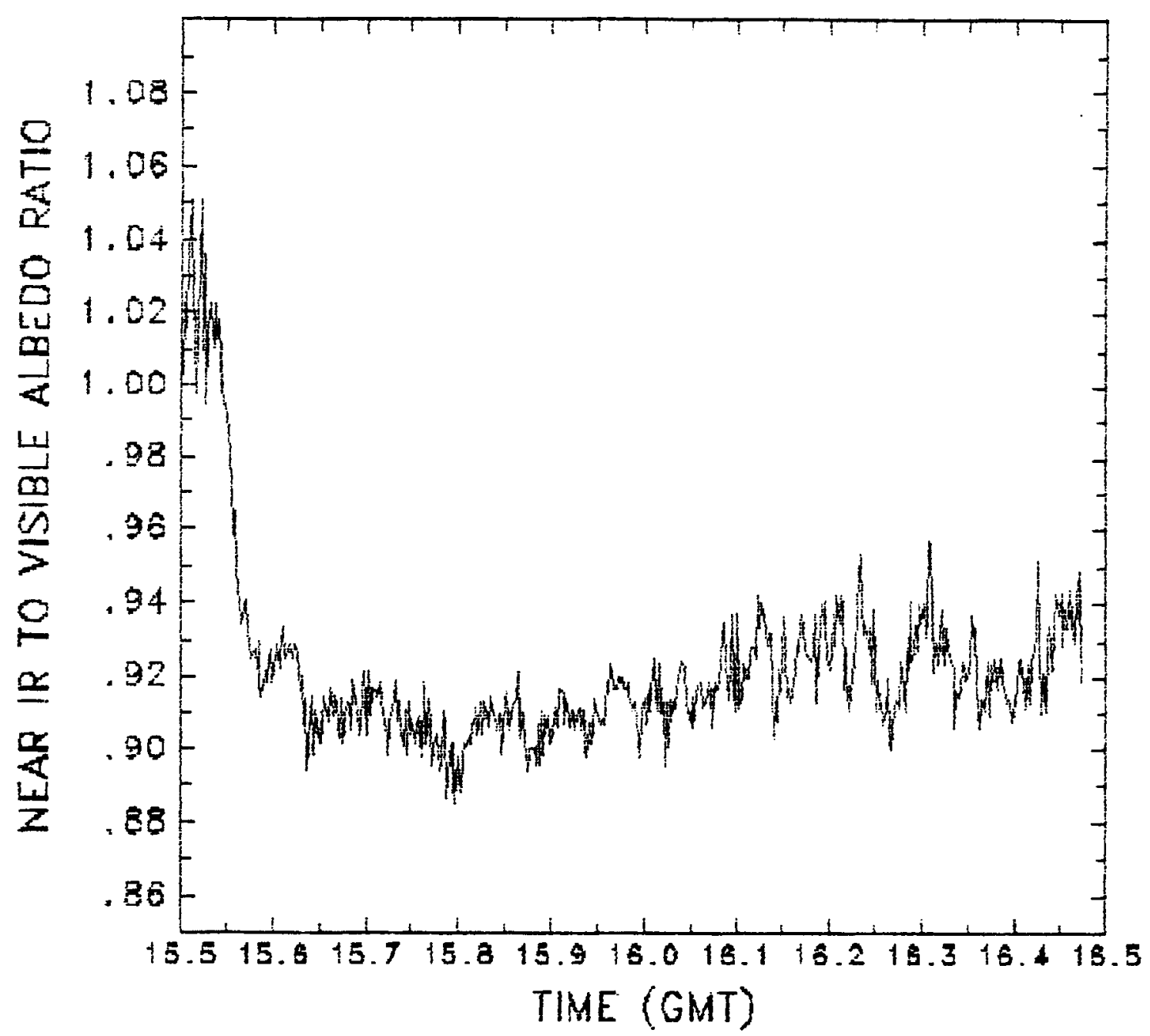

Figure 4.33: Time series of near IR albedo/visible albedo measurements taken above the boundary layer during Flight 3. 
July 7 and July 10. Although the albedos are lower on July 10, note that the difference in the upwelling visible fluxes between the flights is $46 \mathrm{~W} \cdot \mathrm{m}^{-2}$, while the difference in the upwelling near IR fluxes is only $8 \mathrm{~W} \cdot \mathrm{m}^{-2}$.

Table 4.4: Mean shortwave fluxes (in $\mathrm{W} \cdot \mathrm{m}^{-2}$ ) from constant level legs measured during flights on July 7 and July 10 .

\begin{tabular}{|c|c|c|c|c|}
\hline July 7 & & TOT & NIR & VIS \\
\hline Leg 3 & F $\downarrow$ & 1119.4 & 561.4 & 558.0 \\
& F $\uparrow$ & 711.4 & 337.4 & 374.0 \\
\hline & Albedo & .6355 & .6010 & .6703 \\
\hline NIR/VIS albedo & \multicolumn{3}{|c|}{.8966} \\
\hline
\end{tabular}

\begin{tabular}{|c|c|c|c|c|}
\hline July 10 & & TOT & NIR & VIS \\
\hline Leg 13 & $\mathrm{F} \downarrow$ & 1131.3 & 574.7 & 556.6 \\
& $\mathrm{~F} \uparrow$ & 657.2 & 329.3 & 327.9 \\
\hline & Albedo & .5809 & .5730 & .5891 \\
\hline NIR/VIS albedo & \multicolumn{3}{|c|}{.9727} \\
\hline
\end{tabular}

\subsection{Summary}

Microphysical and radiation data were analyzed for three flights during the marine stratocumulus IFO. Several results were found from the analysis which included:

1. The shape of the droplet size distributions remained constant throughout the flight and through all levels of the cloud.

2. Flights 2 and 3 revealed clouds predominated by small droplets ( $2-8 \mu \mathrm{m}$ in diameter). Flight 5 had a more typical marine stratocumulus droplet distribution.

3. The liquid water content profiles increased approximately linearly with height through the cloud layer. The observed values from Flights 2 and 3 were much less than the adiabatic LWC, although the measured LWC from Flight 5 was near the adiabatic value.

4. The total number densities varied with height inside the cloud for each flight. The peak number densities for Flights 2 and 3 were near $50 \mathrm{~cm}^{-3}$ and near $100 \mathrm{~cm}^{-3}$ for Flight 5.

5. The effective radius and mean radius slowly increased with height inside the cloud. Although the effective radius did not vary between flights, the mean radii measured 


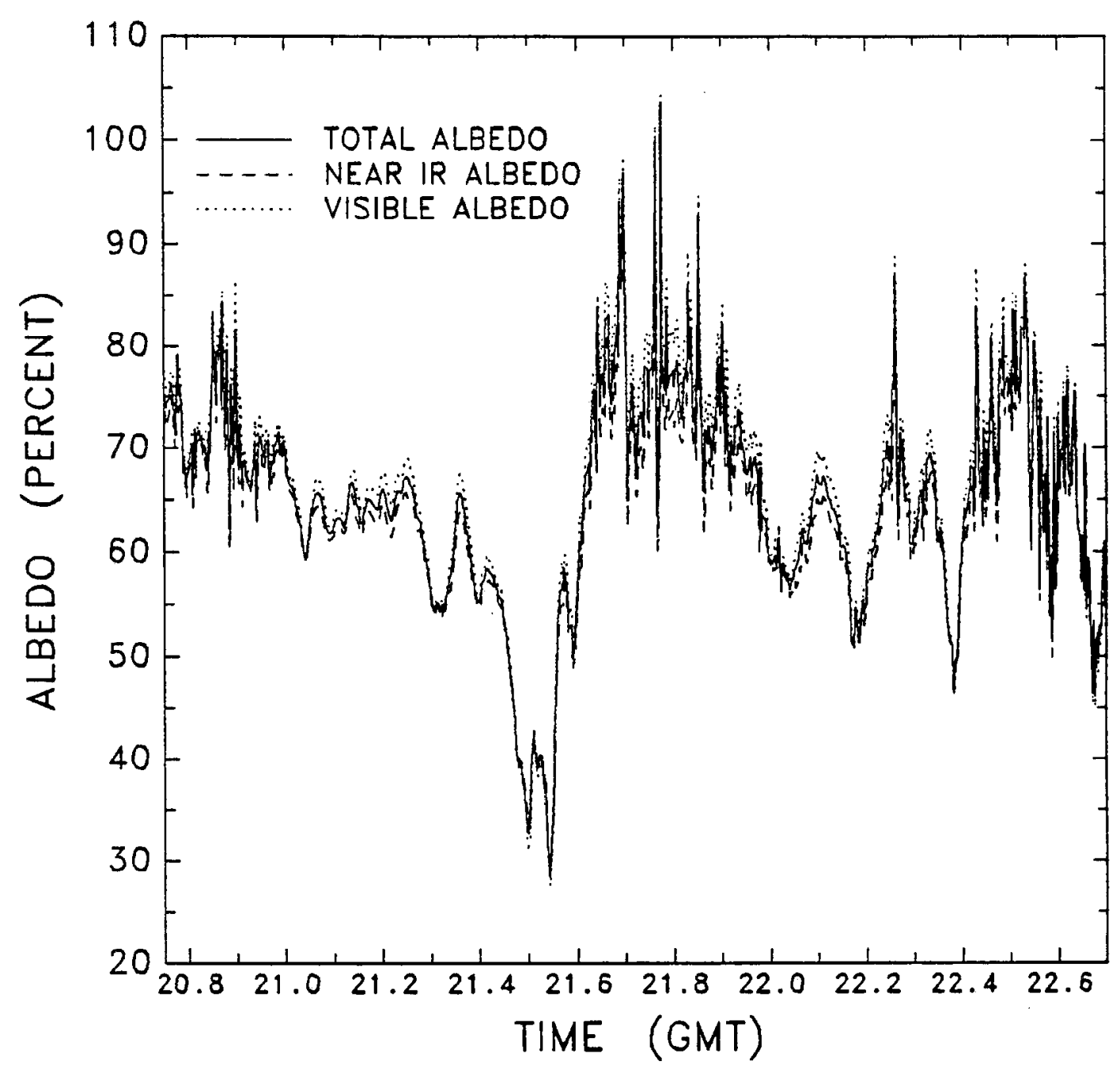

Figure 4.34: Time series of the total, near IR, and visible albedos above the cloud observed during Flight 5. 


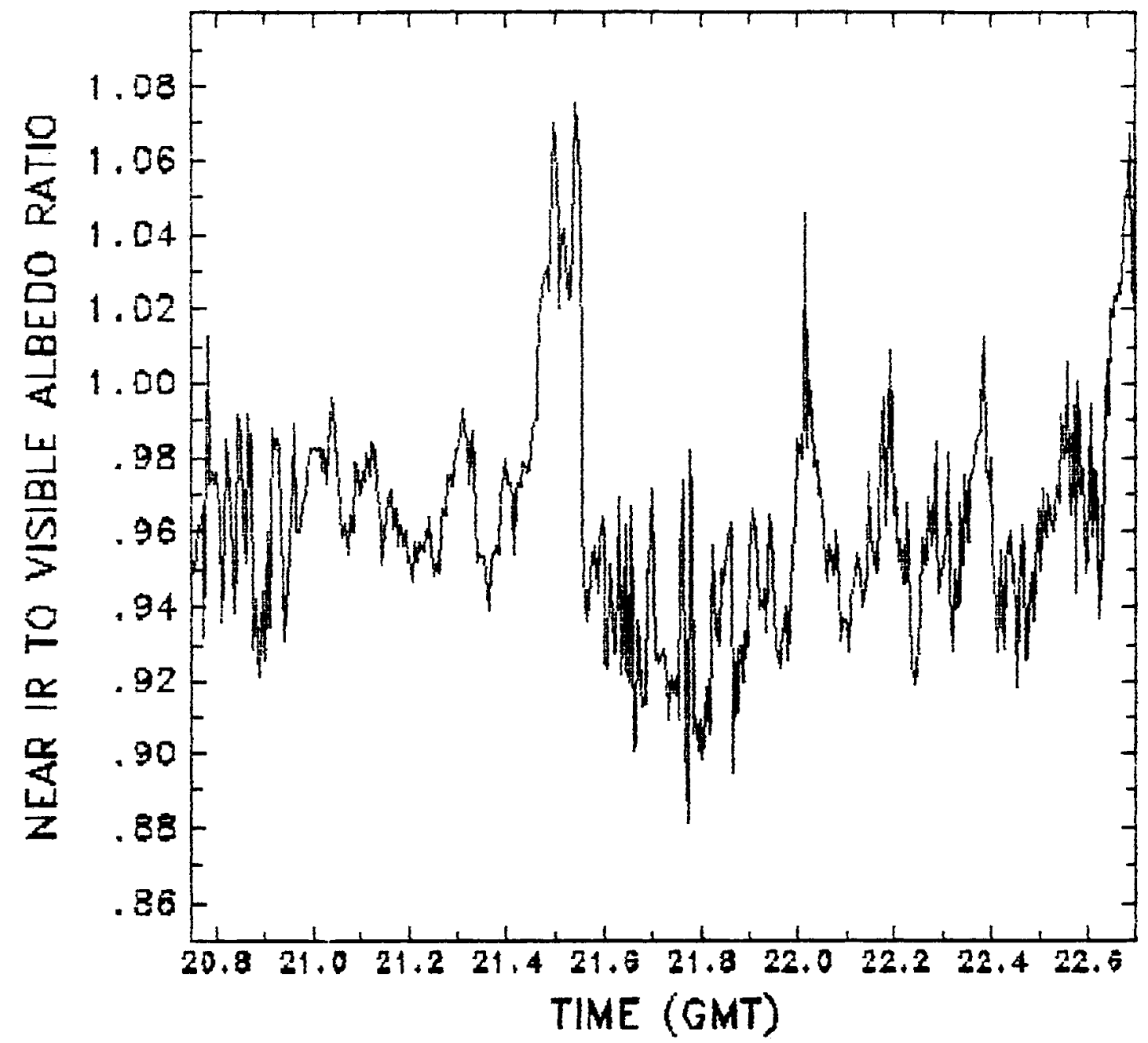

Figure 4.35: Time series of near IR albedo/visible albedo measurements taken above the boundary layer during Flight 5 . 
during Flight 5 were $45 \%$ larger than the mean radii observed during Flights 2 and 3.

6. The observed longwave cooling rates exhibited a sharp peak in the top $40 \mathrm{~m}$ of the cloud with maximum cooling rates up to $5^{\circ} \mathrm{C} \cdot \mathrm{hr}^{-1}$. The results compare favorably with other tethered balloon measurements and aircraft measurements of marine stratocumulus.

7. The solar heating rates increased with height inside the cloud. Although most of the heating in the early morning was only in the top $50 \mathrm{~m}$ of the cloud, the heating extended through the entire depth of the cloud by noon. Nearly equal contributions to the shortwave heating rates came from the visible and near IR portions of the spectrum. The shortwave heating rates were equal to or greater in magnitude than the longwave cooling rates.

8. The solar albedo measurements showed that the visible spectrum tended to be reflected by the clouds more than the near IR spectrum.

9. The ratio of reflected visible to reflected near IR remained fairly uniform except for the very nonhomogeneous case of Flight 5. For this case the visible albedo decreased relative to the near IR albedo. This suggests that the effects of heterogeneities on the radiative transfer through the cloud may be more important in the visible than in the near IR.

Chapter 6 will discuss the importance of the results given in this chapter in more detail. 


\section{Chapter 5}

\section{TWO STREAM RADIATIVE TRANSFER MODEL}

\subsection{Introduction}

One goal of FIRE mentioned above was the comparison of existing radiative transfer and dynamical models with the observations collected during the experiment. Such comparisons will allow investigators to evaluate the present understanding of the marine boundary layer and may lead to the improvement of models and parameterization schemes. In this chapter, a radiative transfer model is described which is used to simulate the radiation fields measured by the platform. The model cloud used in the radiative transfer calculations is based on the meteorological and microphysical measurements made during the flight.

Several criteria were used to select a proper radiative transfer model for the comparison study. The model was required to be complex enough to simulate the physical processes involved in the transfer of radiation inside a cloud, including particle absorption, multiple scattering and gaseous absorption. The model had to be flexible so that it could model the changing microphysical and thermodynamical conditions in the boundary layer. Finally, the model had to provide simple results which could easily be compared to the observations.

The two stream radiative transfer model satisfies these requirements. The two stream model contains the equations necessary to simulate the physical processes inside the cloud and has sufficient versatility to model a wide range of conditions. Since the model considers radiation travelling in only two general directions (upward and downward), it has the advantage over more complex models of calculating the same quantities measured by the radiation instruments without the expense of computing extra information on the 
directional variation of the fields. The two stream model also has the ability to compute fluxes in both the shortwave and longwave parts of the electromagnetic spectrum with high spectral resolution, which allows the model to be usable in future research when finer spectral measurements are made in the marine boundary layer.

The two stream radiative transfer model used in the comparisons is a modified version of the model developed by Stackhouse (1989), whose thesis contains a detailed account of the original model. A summary of the formulation of the model is given below.

\subsection{Formulation of the Two Stream Model}

The two stream radiative transfer model is a formal mathematical solution of the radiative transfer equation. Several assumptions are included in the radiative transfer equation in order to make the model more computationally efficient and to simplify the interpretation of the results of the simulations. The monochromatic radiative transfer equation is written below assuming a plane parallel, horizontally homogeneous atmosphere with azimuthal symmetry for the radiation field.

$$
\mu \frac{d I(\tau, \mu)}{d \tau}=-I(\tau, \mu)+\frac{\omega_{0}}{2} \int_{-1}^{1} P\left(\mu, \mu^{\prime}\right) I\left(\tau, \mu^{\prime}\right) d \mu^{\prime}+S_{s w, l w}(\tau) .
$$

$I(\tau, \mu)$ represents the diffuse intensity as a function of optical depth $(\tau)$ and cosine of the solar zenith angle $(\mu), \omega_{0}$ is the single scatter albedo, $S_{s w, l w}(\tau)$ are the diffuse intensity source terms and $P\left(\mu, \mu^{\prime}\right)$ is the normalized, azimuthally averaged angular distribution function (or phase function). Under this convention, $\tau$ and $z$ increase in the downward direction and it follows that $\mu>0(\mu<0)$ in the downward (upward) hemisphere.

Equation (5.1) is integrated over the upward and downward hemisphere and after some algebraic manipulation, transformed into two equations representing the upward and downward fluxes,

$$
\mp \frac{d F^{ \pm}(\tau)}{d \tau}=-\left(a^{ \pm}+b^{ \pm}\right) F^{ \pm}(\tau)+b^{\mp} F^{\mp}+U_{s w, l w}^{ \pm}
$$

where the fluxes are defined as (in units $\mathrm{W} \cdot \mathrm{m}^{-2}$ )

$$
\mp \int_{-1,0}^{0,1} \mu I(\tau, \mu) d \mu=\mp F^{ \pm}(\tau),
$$


and $U^{ \pm}$are upward and downward scalar irradiances in $\mathrm{W} \cdot \mathrm{m}^{-2}$

$$
\int_{-1,0}^{0,1} I(\tau, \mu) d \mu=U^{ \pm}(\tau)
$$

$a^{ \pm}=\frac{k_{\text {sca }}}{k_{\text {ext }}} D^{ \pm}$is the fraction of the total extinction due to particle absorption and $D^{ \pm}$is the layer diffusivity and is defined as

$$
D^{ \pm}=\frac{U^{ \pm}(\tau)}{F^{ \pm}(\tau)}
$$

The layer diffusivity represents the increase in the optical path of a photon due to scattering and absorption-emission processes as it passes through a horizontal layer.

From (5.2), $b^{ \pm}$is the backward scattered fraction of diffuse radiation from the layer. This fraction results from the integration of the multiple scattering term in (5.1). However, due to the lack of information on the directional variation in the radiation fields, an exact solution for the backscattering fraction cannot be formulated. Since the diffusivity factor is considered to be constant and equal in both directions in the model, the diffuse backscatter coefficient is approximated as $b=\omega_{0}(1-g)$. This expression corresponds to the mean hemispheric approximation proposed by Sagan and Pollack (1967), where $g$ is the asymmetry factor. This definition of the backward scattering fraction results in an isotropic intensity and a layer diffusivity of 2 in both hemispheres, and is expressed in terms of $\omega_{0}$ and $g$, which can be determined from Mie scattering theory.

Equation (5.2) can be reformulated into second order differential equations in $F^{+}$and $F^{-}$. Assuming the optical depth is zero at the top of a layer and $\tau_{1}$ at the bottom, the equations are solved with suitable boundary conditions $F^{+}\left(\tau_{1}\right)$ and $F^{-}(0)$. The solutions are arranged to separate the boundary conditions and the sources and are presented below in matrix notation.

$$
\left[\begin{array}{l}
F^{+}(\tau) \\
F^{-}(\tau)
\end{array}\right]=\mathcal{M}\left[\begin{array}{l}
F^{+}\left(\tau_{1}\right) \\
F^{-}(0)
\end{array}\right]+\left[\begin{array}{l}
\mathcal{S}_{s w, l w}^{+}(\tau) \\
\mathcal{S}_{s w, l w}^{-}(\tau)
\end{array}\right]
$$

where the total source contribution is given by,

$$
\left[\begin{array}{l}
\mathcal{S}_{s w, l w}^{+}(\tau) \\
\mathcal{S}_{s w, l w}^{-}(\tau)
\end{array}\right]=\left[\begin{array}{l}
F s^{+}(\tau) \\
F s^{-}(\tau)
\end{array}\right]-\mathcal{M}\left[\begin{array}{l}
F s^{+}\left(\tau_{1}\right) \\
F s^{-}(0)
\end{array}\right]
$$


where,

$$
\mathcal{M}=\left[\begin{array}{ll}
\mathcal{T}\left(\tau_{1}, \tau, 0\right) & \mathcal{R}\left(0, \tau, \tau_{1}\right) \\
\mathcal{R}\left(\tau_{1}, \tau, 0\right) & \mathcal{T}\left(0, \tau, \tau_{1}\right)
\end{array}\right]
$$

and where $\mathcal{T}$ and $\mathcal{R}$ correspond to the transmittance and reflectance of the layer, respectively. The transmittances and reflectances shown below were reformulated by Stackhouse (1989) in order to avoid a numerical instability problem in the exponential terms when the optical depth became large $\left(>10^{2}\right)$.

$$
\begin{aligned}
& \mathcal{T}\left(0, \tau, \tau_{1}\right)=\frac{1}{\Delta\left(\tau_{1}\right)}\left[\eta_{+}^{+} \eta_{-}^{-} e^{k_{-} \tau}-\eta_{+}^{-} \eta_{-}^{+} e^{\left(k_{+}\left(\tau-\tau_{1}\right)+k_{-} \tau_{1}\right)}\right] \\
& \mathcal{R}\left(0, \tau, \tau_{1}\right)=\frac{\eta_{+}^{+} \eta_{-}^{+}}{\Delta\left(\tau_{1}\right.}\left[e^{k_{-} \tau}-e^{\left(k_{+}\left(\tau-\tau_{1}\right)+k_{-} \tau_{1}\right)}\right] \\
& \mathcal{T}\left(\tau_{1}, \tau, 0\right)=\frac{1}{\Delta\left(\tau_{1}\right)}\left[\eta_{+}^{+} \eta_{-}^{-} e^{k_{+}\left(\tau-\tau_{1}\right)}-\eta_{+}^{-} \eta_{-}^{+} e^{\left(k_{-} \tau-k_{+} \tau_{1}\right)}\right] \\
& \mathcal{R}\left(\tau_{1}, \tau, 0\right)=\frac{\eta_{+}^{+} \eta_{-}^{+}}{\Delta\left(\tau_{1}\right)}\left[e^{k_{+}\left(\tau-\tau_{1}\right)}-e^{\left(k_{-} \tau-k_{+} \tau_{1}\right)}\right]
\end{aligned}
$$

where,

$$
\Delta\left(\tau_{1}\right)=\eta_{+}^{+} \eta_{-}^{-}-\overline{\eta_{+}} \eta_{-}^{+} e^{\tau_{1}\left(k_{-}-k_{+}\right)}
$$

The constants $\eta_{ \pm}^{ \pm}$are defined as

$$
\begin{aligned}
& \eta_{+}^{ \pm}=1 \pm \frac{a^{\mp}}{k_{+}} \\
& \eta_{-}^{ \pm}=1 \pm \frac{a^{\mp}}{k_{-}}
\end{aligned}
$$

where

$$
k_{ \pm}=\frac{1}{2}\left\{\left(t^{-}-t^{+}\right) \pm\left[\left(t^{+}+t^{-}\right)^{2}-4 b^{+} b^{-}\right]^{\frac{1}{2}}\right\}
$$

and

$$
t^{ \pm}=-\left(a^{ \pm}+b^{ \pm}\right)
$$

The solution (5.4) gives the monochromatic diffuse irradiances at any level inside a homogeneous layer given the parameters $\tau, \omega_{0}, g$ and the sources of radiative flux within the layer. This solution is added to the direct downward solar component, $e^{-\tau / \mu_{0}}$ in order to calculate the total downwelling solar flux.

\subsection{Development of the Source Terms}

Although (5.4) provides a general solution of the radiative transfer equation, particular solutions are derived for the longwave and shortwave source terms due to the nature of these terms. A derivation of the terms is given below. 


\subsubsection{Lóngwave source terms}

A linear relation of the Planck function is used in the model for the longwave source term. The emission at one level inside the layer is a function of the emission at the top and bottom of the layer and is expressed as

$$
S_{l w}=2 \pi\left(1-\omega_{0}\right) \mathcal{B}_{\nu}(\tau)
$$

where,

$$
\mathcal{B}_{\nu}(\tau)=B_{\nu}\left(T_{0}\right)+B_{\nu}^{1}\left(T_{0}, T_{1}\right) \tau
$$

and,

$$
B_{\nu}^{1}\left(T_{0}, T_{1}\right) \tau=\frac{B_{\nu}\left(T_{1}\right)-B_{\nu}\left(T_{0}\right)}{\tau_{1}} .
$$

$B_{\nu}\left(T_{0}\right)$ and $B_{\nu}\left(T_{1}\right)$ represent the Planck function at a particular wavenumber for temperatures at the top $\left(T_{0}\right)$ and bottom $\left(T_{1}\right)$ of the layer respectively. The particular solution of $(5,12)$ can be found following a procedure similar to those in steps in the derivation from (5.2) to (5.4) and is

$$
F_{3} 3_{l w}^{ \pm}(\tau)=\frac{2 \pi\left(1-\omega_{0}\right)}{v}\left\{x^{\mp} B_{\nu}\left(T_{0}\right)+B_{\nu}^{1}\left(T_{0}, T_{1}\right)\left[x^{\mp}\left(\tau-\frac{u}{v}\right) \mp 1\right]\right\}
$$

where,

$$
\begin{aligned}
& u=t^{+}-t^{-} \\
& v=b^{+} b^{-}-t^{+} t^{-} \\
& x^{ \pm}=t^{ \pm}-b^{ \pm} .
\end{aligned}
$$

A numerical instability problem was noted for the small optical depths encountered in the wings of the absorption bands. At small optical depths $\left(<10^{-8}\right)$, the solution of equation (5.12) becomes extremely large and results in the loss of precision when added to much smaller terms. Stackhouse (1989) avoided the problem by combining the two terms in (5.5) to obtain an alternative form of the solution, which is given below:

$$
\begin{aligned}
\mathcal{S}_{l w}^{+}(0) & =\frac{2 \pi\left(1-\omega_{0}\right) x^{-}}{v}\left\{B_{\nu}\left(T_{0}\right)\left(1-\frac{x^{+}}{x^{-}} \mathcal{R}^{-}\right)-\mathcal{T}^{+} B_{\nu}\left(T_{1}\right)\right. \\
& \left.-\left[B_{\nu}\left(T_{1}\right)-B_{\nu}\left(T_{0}\right)\right]\left[\frac{1-\mathcal{T}^{+}+\mathcal{R}^{-}}{x^{-} \tau_{1}}+\frac{u\left(1-\mathcal{T}^{+}-\frac{x^{+}}{x^{-}} \mathcal{R}^{-}\right)}{v \tau_{1}}\right]\right\} \\
\mathcal{S}_{l w}^{-}\left(\tau_{1}\right) & =\frac{2 \pi\left(1-\omega_{0}\right) x^{+}}{v}\left\{B_{\nu}\left(T_{1}\right)\left(1-\frac{x^{+}}{x^{-}} \mathcal{R}^{+}\right)-\mathcal{T}^{-} B_{\nu}\left(T_{0}\right)\right. \\
& \left.+\left[B_{\nu}\left(T_{1}\right)-B_{\nu}\left(T_{0}\right)\right]\left[\frac{1-\mathcal{T}^{-}+\mathcal{R}^{+}}{x^{+} \tau_{1}}+\frac{u\left(1-\mathcal{T}^{-}+\frac{x^{-}}{\tau^{+}} \mathcal{R}^{+}\right)}{v \tau_{1}}\right]\right\}
\end{aligned}
$$

where for the reflectance and transmittance coefficients + corresponds to $\left(\tau_{1}, \tau, 0\right)$ and corresponds to $\left(0, \tau, \tau_{1}\right)$ and the remaining variables are defined above. 


\subsubsection{Shortwave source terms}

The shortwave source term is represented as

$$
S_{s w}(\tau)=\frac{\omega_{0} F_{0}}{2} P\left(\mu, \mu_{0}\right) e^{-\frac{\tau}{\mu_{0}}}
$$

where $\mu_{0}$ is the cosine of the solar zenith angle and $F_{0}$ is the downwelling solar irradiance at the top of the atmosphere. Integrating $S_{s w}^{ \pm}$yields:

$$
U s_{s w}^{ \pm}=\frac{\omega_{0} F_{0}}{2} e^{-\frac{\tau}{\mu_{0}}} \int_{-1,0}^{0,1} P\left(\mu, \mu_{0}\right) d \mu
$$

Since the phase function can be expanded in terms of Legendre polynomials, the backscattered fraction is defined after Meador and Weaver (1980) as

$$
\beta_{0}\left(\mu_{0}\right)=\frac{1}{2} \int_{-1}^{0} P\left(\mu, \mu_{0}\right) d \mu
$$

and the forward scattered fraction is $1-\beta_{0}$. Thus, (5.20) can be written as

$$
\begin{aligned}
& U s_{s w}^{+}=\omega_{0} F_{0} \beta_{0} e^{-\frac{\tau}{\mu_{0}}} \\
& U s_{s w}^{-}=\omega_{0} F_{0}\left(1-\beta_{0}\right) e^{-\frac{\tau}{\mu_{0}}}
\end{aligned}
$$

This form of the backscattered fraction increases the versatility of the model by allowing the incorporation of both cloud particle and molecular scattering in one function.

Equation (5.22) is converted into second order differential equations and solved to become:

$$
\begin{aligned}
& F s_{s w}^{+}(\tau)=\omega_{0} F_{0} \frac{\left(t-+\frac{1}{\mu_{0}}\right) \beta_{0}-b^{-}\left(1-\beta_{0}\right)}{\left(k_{+}+\frac{1}{\mu_{0}}\right)\left(k_{-}+\frac{1}{\mu_{0}}\right)} e^{-\frac{\tau}{\mu_{0}}} \\
& F s_{s w}^{-}(\tau)=\omega_{0} F_{0} \frac{\left(t^{+}-\frac{1}{\mu_{0}}\right)\left(1-\beta_{0}\right)-b^{+} \beta_{0}}{\left(k_{+}+\frac{1}{\mu_{0}}\right)\left(k-+\frac{1}{\mu_{0}}\right)} e^{-\frac{\tau}{\mu_{0}}}
\end{aligned}
$$

A problem was also found in the shortwave source term as a singularity occurred when $k_{-}=-\frac{1}{\mu_{0}}$. The problem was overcome by using an alternative expression for the particular solutions outlined by King and Harshvardhan (1986). If $D^{+}=D^{-}$and $b^{+}=b^{-}$, the particular solutions reduce to

$$
\begin{aligned}
& F s_{s w}^{+}(\tau)=\frac{1}{2} \omega_{0} \mu_{0} \tau F_{0}\left[b^{-}\left(1-\beta_{0}\right)-\left(t^{-}+\frac{1}{\mu_{0}}\right) \beta_{0}\right] \exp -\left(\frac{\tau}{\mu_{0}}\right) \\
& F s_{s w}^{-}(\tau)=\frac{1}{2} \omega_{0} \mu_{0} \tau F_{0}\left[b^{+} \beta_{0}-\left(t^{+}-\frac{1}{\mu_{0}}\right)\left(1-\beta_{0}\right)\right] \exp -\left(\frac{\tau}{\mu_{0}}\right)
\end{aligned}
$$




\subsection{The Incorporation of Absorption and Scattering Processes of Both Gases and Cloud Particles}

The physical processes are accounted for in the model by the use of three parameters, optical depth $(\tau)$, single scatter albedo $\left(\omega_{0}\right)$, and the asymmetry parameter $(g)$. The optical depths inputted into the model are derived from the various physical processes simulated in the radiative transfer model. Gaseous absorption and scattering and the absorption by cloud particles is accounted for in both the shortwave and longwave regions, while Rayleigh scattering is modeled in the shortwave region.

\subsubsection{Calculation of optical depth}

The scattering and absorption processes in the atmosphere and in a cloud increase the optical depth of a particular wavelength of light through a layer. The total optical depth can be considered to be the sum of the optical depths resulting from each atmospheric process and thus:

$$
\begin{aligned}
& \tau_{l w}=\tau_{\text {cloud }}+\tau_{\text {gas }}+\tau_{e-t y p e} \\
& \tau_{s w}=\tau_{\text {cloud }}+\tau_{\text {gas }}+\tau_{\text {Rayleigh }} .
\end{aligned}
$$

The optical depths due to the scattering and absorption of radiation by cloud particles is written as:

$$
\tau_{\text {cloud }}=\sigma_{\text {ext }} \Delta z
$$

where $\Delta z$ is the thickness of the layer in $\mathrm{km}$ and $\sigma_{\text {ext }}$ is the total extinction in the layer in $\mathrm{km}^{-1}$. The total extinction is determined by Mie scattering theory given the microphysical parameters about the cloud layer.

The optical depth due to gaseous absorption can be expressed as:

$$
\tau_{g a s}=k u
$$

where $u$ is the optical path of a particular absorbing gas in the layer in units of $\mathrm{g} \cdot \mathrm{cm}^{-2}$ and $k$ represents the absorption of radiation by that gas in units $\mathrm{of}^{2} \cdot \mathrm{g}^{-1}$. The optical path for each layer is determined from:

$$
u=\left(\frac{\bar{p}}{p_{r e f}}\right)^{n}\left(\frac{T_{r e f}}{\bar{T}}\right)^{m} \frac{\bar{w} \Delta p}{g_{r}}
$$


where $\bar{p}$ and $\bar{T}$ represent the mean pressure and temperature in the layer, $p_{r e f}$ and $T_{r e f}$ the reference temperature and pressure and $n$ and $m$ are empirical factors chosen depending on how $k$ is computed. $\bar{w}$ is the mean mixing ratio of the particular gas in the layer of $\Delta p$ thickness and $g_{r}$ is the acceleration due to gravity. The values of $k$ are determined by the K-distribution method for most spectral regions of the model and by the sum of exponentials method for ozone absorption. More details on the implementation of the K-distribution method are given below.

E-type absorption in the longwave region is computed via an empirical fit of water vapor continuum absorption (8-12 $\mu \mathrm{m})$ by Roberts et al. (1976). The empirical formula is:

$$
k_{e-t y p e}=\frac{\phi(\bar{T})}{\phi\left(T_{0}\right)} \Psi\left(\nu, T_{0}\right) e_{c}
$$

where

$$
\begin{aligned}
& \phi(T)=\exp (1800 / T), \\
& \Psi\left(\nu, T_{0}\right)=c_{1}+c_{2} e^{-c_{3} \nu},
\end{aligned}
$$

and

$$
e_{c}=e_{\mathrm{H}_{2} \mathrm{O}}+\gamma\left(\bar{P}-e_{\mathrm{H}_{2} \mathrm{O}}\right) \text {. }
$$

$T_{p}=1800 \mathrm{~K}, T_{0}=296 \mathrm{~K}, c_{1}=4.18 \mathrm{~cm}^{2} \cdot \mathrm{g}^{-1} \cdot \mathrm{atm}^{-1}, c_{2}=5578 \mathrm{~cm}^{2} \cdot \mathrm{g}^{-1} \cdot \mathrm{atm}^{-1}, c_{3}=$ $.00787 \mathrm{~cm}, \bar{P}$ and $e_{\mathrm{H}_{2} \mathrm{O}}$ are the mean ambient pressure and partial pressure of water vapor in atm and $\gamma=0.002$. This optical depth is calculated as the optical path due to water vapor in the layer, $\tau_{\text {gas }}$.

The contribution to optical depth due to Rayleigh scattering is computed using an empirical formula presented by Paltridge and Platt (1976). Their equation calculates the Rayleigh scattering optical depth from the top of the atmosphere to a height above the surface, and is given as,

$$
\tau_{\text {Rayleigh }}=.0088 \lambda^{(-4.15+0.2 \lambda)} e^{\left(-0.1188 H-0.00116 H^{2}\right)}
$$

where $\lambda$ is the wavelength and $H$ is the height in $\mathrm{km}$ above the surface. 


\subsubsection{Scaling of the Single Scatter Albedo, Asymmetry Parameter and Direct Backscattered Fraction}

After the optical depths due to the various processes are calculated, a scaling correction is applied to the single scatter albedo $\omega_{0}$ and the asymmetry factor $g$ in order to account for the effect of molecular scattering and absorption on those parameters. The scaling used in the model is from Slingo and Schrecker (1982), and is given as:

$$
\begin{aligned}
\omega_{0_{l w}} & =\frac{\omega_{\text {cloud }} \tau_{\text {cloud }}}{\tau_{l w}} \\
\omega_{\text {osw }} & =\frac{\tau_{\text {Rayleigh }}+\omega_{\text {cloud }} \tau_{\text {cloud }}}{\tau_{s w}} \\
g_{s w, l w} & =g_{\text {cloud }}\left(\frac{\omega_{\text {cloud }} \tau_{\text {cloud }}}{\omega_{s w, l w} \tau_{s w, l w}}\right)
\end{aligned}
$$

In the shortwave region, Rayleigh scattering also affects the phase function and therefore the backscattered fraction. The phase functions for Rayleigh scattering and the cloud particles are weighted according to their relative scattering importance in order to account for this effect.

$$
P\left(\mu, \mu_{0}\right)=\frac{\tau_{\text {Rayleigh }} P_{\text {Rayleigh }}+\omega_{\text {cloud }} \tau_{\text {cloud }} P_{\text {cloud }}}{\tau_{\text {Rayleigh }}+\omega_{\text {cloud }} \tau_{\text {cloud }}}
$$

\subsection{The Integration of Spectral Fluxes and the K-Distribution Method}

The upward and downward fluxes at one wavelength are solved from the radiative transfer equation described above. In order to provide information on broadband fluxes, the spectrum is divided into bands over which $\tau, \omega_{0}$, and $g$ are assumed to vary smoothly. For gaseous absorption, these properties vary greatly depending on the location and intensity of absorption lines, pressure and temperature. Although the line by line calculation of gaseous absorption is the most accurate method, it is computationally impractical for this study. Instead, the K-distribution method is used to treat gaseous absorption in the model and is discussed below.

Equation (5.26) defines the optical depth associated with a single wavelength. Averages of $k$ over some spectral regions are difficult to calculate since $k$ is a highly variable function of wavelength. The K-distribution solves this problem by transforming the highly 
irregular transmittance function in frequency space into a smooth probability distribution function in $k$ space.

$$
\mathcal{T}_{\nu}(u)=\frac{1}{\Delta \nu} \int_{\Delta \nu} e^{-k_{\nu} u} d \nu=\int_{0}^{\infty} f(k) e^{-k u} d k
$$

Equation (5.35) can be discretized to the following form:

$$
\mathcal{T}_{\nu}(u) \approx \sum_{i=1}^{n} w_{i} e^{-k_{i} u}
$$

where $n$ is the total number of extinction values $k_{i}$ in the band and $w_{i}$ is the weight representing the fraction of the wavenumber band with $k_{i}$ as the extinction. Stephens (1984) summarized the results from Hansen et al. (1983) showing that the K-distribution method can treat vertical inhomogeneity accurately and noting that the strongest and weakest absorption occurs at the same frequency at all altitudes. This allows the pressure effects to be included explicitly in the choice of $k$.

With the expression in (5.36), a set of $n$ optical thicknesses is used to approximate the total optical depth in band $\Delta \nu$. These thicknesses are defined as:

$$
\tau_{g a s_{i}}=k_{i} u \text {. }
$$

where $i=1, \ldots, n$. The optical depth due to all processes in the spectral interval is

$$
\begin{aligned}
& \tau_{l w_{i}}=\tau_{\text {cloud }}+\tau_{\text {gas }_{i}}+\tau_{e-\text { type }} \\
& \tau_{s w_{i}}=\tau_{\text {cloud }}+\tau_{\text {gas }}+\tau_{\text {Rayleigh }} .
\end{aligned}
$$

The flux solutions for the two-stream model solved for each $\tau_{i}$ can be represented as $F_{i}^{ \pm}\left(\tau_{i}\right)$ and the broadband flux at some level in a layer for a particular interval $\Delta \nu$ is found from:

$$
F_{\Delta \nu}^{ \pm}=\sum_{i=1}^{n} w_{i} F_{i}^{ \pm}\left(\tau_{i}\right)
$$

Absorption in bands where two gases (gas 1 and gas 2) overlap is accounted for by assuming

$$
T_{12} \approx\left(\sum_{i=1}^{n_{1}} w_{1 i} e^{-k_{1 i} u}\right)\left(\sum_{j=1}^{n_{2}} w_{2 j} e^{-k_{2 j} u}\right)=\sum_{i=1}^{n_{1}} \sum_{j=1}^{n_{2}} w_{1 i} w_{2 j} e^{-u\left(k_{1 i}+k_{2 j}\right)}
$$

and thus the optical depth in the overlap region is defined as:

$$
\tau_{i j}=u\left(k_{1 i}+k_{2 j}\right)
$$


and the fluxes become:

$$
F_{\Delta \nu}^{ \pm}=\sum_{i=1}^{n_{1}} \sum_{j=1}^{n_{2}} w_{1 i} w_{2 j} F_{i j}^{ \pm}\left(\tau_{i j}\right)
$$

One advantage of the $\mathrm{K}$-distribution method is that the distribution function can be scaled to any reference temperature and pressure. The accuracy of the K-distribution can be favorable compared to line-by-line calculations with the proper choice of reference temperature and pressure. The scaling methods introduced by Chou (Chou and Arking, 1980; Chou and Arking, 1981; Chou and Peng, 1983; Chou, 1984) are used to help optimize the choice of pressure and temperature in the model.

Water vapor, carbon dioxide, oxygen and ozone absorption are included in the $\mathrm{K}$ distribution data. Table 5.1 lists each gas and the wavenumber limits of these bands. Only two gases are overlapped in any spectral interval. The resolution of the K-distribution bands is $20 \mathrm{~cm}^{-1}$ in the longwave and $50 \mathrm{~cm}^{-1}$ in the shortwave. Although this resolution is not necessary for the broadband comparisons in this study, it may be useful for future comparisons with spectral measurements of the fluxes.

The K-distribution method could not be used in the spectral region from $0.69 \mu \mathrm{m}$ to $0.28 \mu \mathrm{m}$ due to the lack of $k$ data. In this region the sum of exponentials approach is adopted for ozone absorption.

The number of bands used in the longwave region is 130 , while 249 intervals, including 11 bands of exponential sum fitting of ozone absorption are used to resolve the solar spectrum.

Table 5.1: Bandwidths of Absorbing Gases

\begin{tabular}{|c|c|c|l|c|}
\hline \multirow{2}{*}{ Gas } & \multicolumn{2}{|c|}{ Longwave } & \multicolumn{1}{c|}{ Shortwave } \\
\cline { 2 - 5 } & Bandwidth $\left(\mathrm{cm}^{-1}\right)$ & Bands & Bandwidth $\left(\mathrm{cm}^{-1}\right)$ & Bands \\
\hline \hline $\mathrm{H}_{2} \mathrm{O}$ & $20-2620$ & 130 & $2600-14450$ & 237 \\
$\mathrm{CO}_{2}$ & $540-800$ & 13 & $3300-4000,4600-5300$, & 48 \\
& & & $6000-7000$ & \\
$\mathrm{O}_{3}$ & $980-1100$ & 6 & $14550-35710$ & 11 \\
& & & $($ Sum of Exp. Fit $)$ & 11 \\
$\mathrm{O}_{2}$ & - & 0 & $12850-13150,14300-14550$ & 11 \\
\hline
\end{tabular}




\subsection{Multi-layer Solution}

Since the atmosphere and clouds are vertically inhomogeneous, the model atmosphere is divided into several layers in order to simulate the conditions measured by the instrument platform. The method used to join these layers together into a multi-layer solution is the adding method, which is presented by Stephens and Webster (1979).

The adding method requires that the boundary conditions be specified for the top and bottom of the atmosphere before the fluxes at each level of the atmosphere can be computed. The direct, downwelling solar fluxes at the top of the atmosphere (level 0 ) for each wavenumber interval were derived from the solar data of Iqbal (1983). The upper boundary conditions shown below apply for the diffuse longwave and shortwave fluxes in each waveband.

$$
\begin{aligned}
& \operatorname{Re}(1,1)=0 \\
& F^{-}(1)=F_{d i f}^{-}(1) \\
& V^{-}\left(\frac{1}{2}\right)=F^{-}(1)
\end{aligned}
$$

$F_{d i f}^{-}$is the diffuse flux down at the top of the model atmosphere and generally $F_{\text {dif }}^{-}(l)=0$. for both long- and shortwave fluxes. $\operatorname{Re}(1, n)$ represents the reflection of a composite of layers from 1 to $n$, and $V^{-}\left(n+\frac{1}{2}\right)$ is the cumulative flux through layer $n$, resulting from the flux transmitted downward from the top boundary to level $n+1$ plus the flux emitted from sources above and inside layer $n$ which flow downward through the layer. The boundary condition at the bottom of a layer is generally independent of wavelength and equals $F^{+}\left(l_{m+1}\right)=F_{d i f}^{+}$for both the longwave and shortwave regions, where $m$ is the total number of specified layers. If the bottom of the layers corresponds to the surface of the earth, then the boundary conditions for the longwave and shortwave depend upon wavelength and are based on the blackbody emission from the surface of the earth and the surface albedo respectively. The surface boundary conditions are:

$$
\begin{aligned}
& F_{l w}^{+}\left(l_{m+1}\right)=\pi B_{\nu}(T s) \\
& F_{s w}^{+}\left(l_{m+1}\right)=\frac{A_{\nu} V-\left(l_{n+1}+\frac{1}{2}\right)+\mu_{0} F_{0} e^{\left(-\frac{\tau_{t_{t}}(n)}{\mu_{0}}\right)}}{1-A_{\nu} \operatorname{Re}\left(1, l_{n+1}\right)} .
\end{aligned}
$$

where $B_{\nu}(T s)$ is the flux from blackbody emission at the surface for a particular temperature $T s$ and wavenumber $\nu$ and $A_{\nu}$ is the spectral albedo of the surface of the earth. $\tau_{t_{i}}$ 
is the total optical depth from the top of the atmosphere to the surface for a particular $k$ value and represents the amount of direct beam radiation incident on the surface of the earth. With these boundary conditions specified the diffuse fluxes up and down at each level of the atmosphere can be completely determined using the adding method for a particular wavenumber band.

\subsection{Computation of Heating Rates}

Once the total upward and downward fluxes at any particular wavenumber band are computed, the heating rate through a layer of the atmosphere can be determined as follows:

$$
\frac{d T}{d t}=-\frac{g_{\tau}}{C_{p}} \frac{d F_{n e t}}{d p}
$$

where $F_{n e t}=F^{-}(l)-F^{+}(l)$ is the net radiation at a specific level, $g_{r}$ is the acceleration due to gravity and $C_{p}$ is the specific heat of air. The heating rates are computed for each layer from the top down and thus $\Delta p<0$ and $\Delta F_{\text {net }}=F_{\text {net }}(l-1)-F_{\text {net }}(l)$.

\subsection{Comparison Between Simulated and Observed Radiation Fields}

The radiative transfer model was used to simulate the radiation fields measured inside the clouds during the balloon flights. The following sections describe the model simulations in more detail and presents the results of the model calculations. These results are compared to the measurements and the significance of the comparisons is discussed.

\subsection{Implementation of the Two Stream Model}

As discussed above, several cloud optical properties were required in order to calculate the scattering and absorption of cloud particles in the radiative transfer model. Via Mie scattering theory, the composite droplet size distributions obtained from each flight leg were used to compute the total extinction coefficient $\left(\sigma_{\text {ext }}\right)$, single scatter albedo $\left(\omega_{0}\right)$, and asymmetry parameter $(g)$ for each waveband at several levels inside of the cloud. Figure 5.1 presents the droplet size distributions used in each model case. Three different model cases were used to illustrate the effects of differing microphysics. The first case was derived 
from the microphysics obtained during Flight 5, which contained pure maritime clouds with a moderate LWP $\left(77 \mathrm{~g} \cdot \mathrm{m}^{-2}\right)$. The second case was a modified version of the Flight 5 microphysics, which was produced by shifting the size distribution intervals from Range 0 ( 2 to $47 \mu \mathrm{m}$ in diameter) to Range 1 ( 2 to $32 \mu \mathrm{m}$ in diameter). The shift resulted in the same general LWC structure throughout the cloud as in Case 1, but with only one-third the liquid water path $\left(26 \mathrm{~g} \cdot \mathrm{m}^{-2}\right)$. The final case included the microphysics from Flight 3 , which contained clouds influenced by continental air. The droplet size distribution was predominantly composed of small droplets and the LWP was nearly the same as Case 2 $\left(34 \mathrm{~g} \cdot \mathrm{m}^{-2}\right)$.

The atmosphere used in Cases 1 and 2 was derived from a CLASS sounding launched from SNI at 2006 GMT on July 10, 1987, while the instrument platform was inside the cloud. Above $16 \mathrm{~km}(\approx 100 \mathrm{mb})$ for the temperature profile and above $14 \mathrm{~km}(\approx 150$ $\mathrm{mb}$ ) for the moisture profile, the sounding was modified to merge with the midlatitude summer sounding of McClatchey et al. (1972). In Case 3, the data from a CLASS sounding launched at 1211 GMT on July 8, 1987 was also merged with the midlatitude summer sounding data for the temperature (above $16 \mathrm{~km}$ ) and moisture (above $10 \mathrm{~km}$ ) profiles. The ozone concentrations in all three cases were taken from the McClatchey sounding. Tables 5.2-5.3 show the location of the cloud in the model atmosphere, and the LWC profile for each case. The flight legs used to compute the optical properties inside the cloud are presented in Tables 5.4-5.5. The atmosphere was divided into 60 layers in Cases 1 and 2 and 64 layers in Case 3, and a solar zenith angle of $20^{\circ}$ was used in the calculations. The surface albedo used in the shortwave section of the model was $25 \%$, which was the mean albedo measured below the cloud layer during the flights.

\subsection{Longwave Flux Results}

Figures 5.2-5.4 show the net longwave irradiances computed for each of the model cases. The upwelling and downwelling longwave fiuxes were calculated for the wavenumber bands in the model which corresponded to the spectral range of the Eppley pyrgeometers. For all of the cases, the greatest flux divergence occurs in the $5 \mathrm{mb}$ layer below cloud 


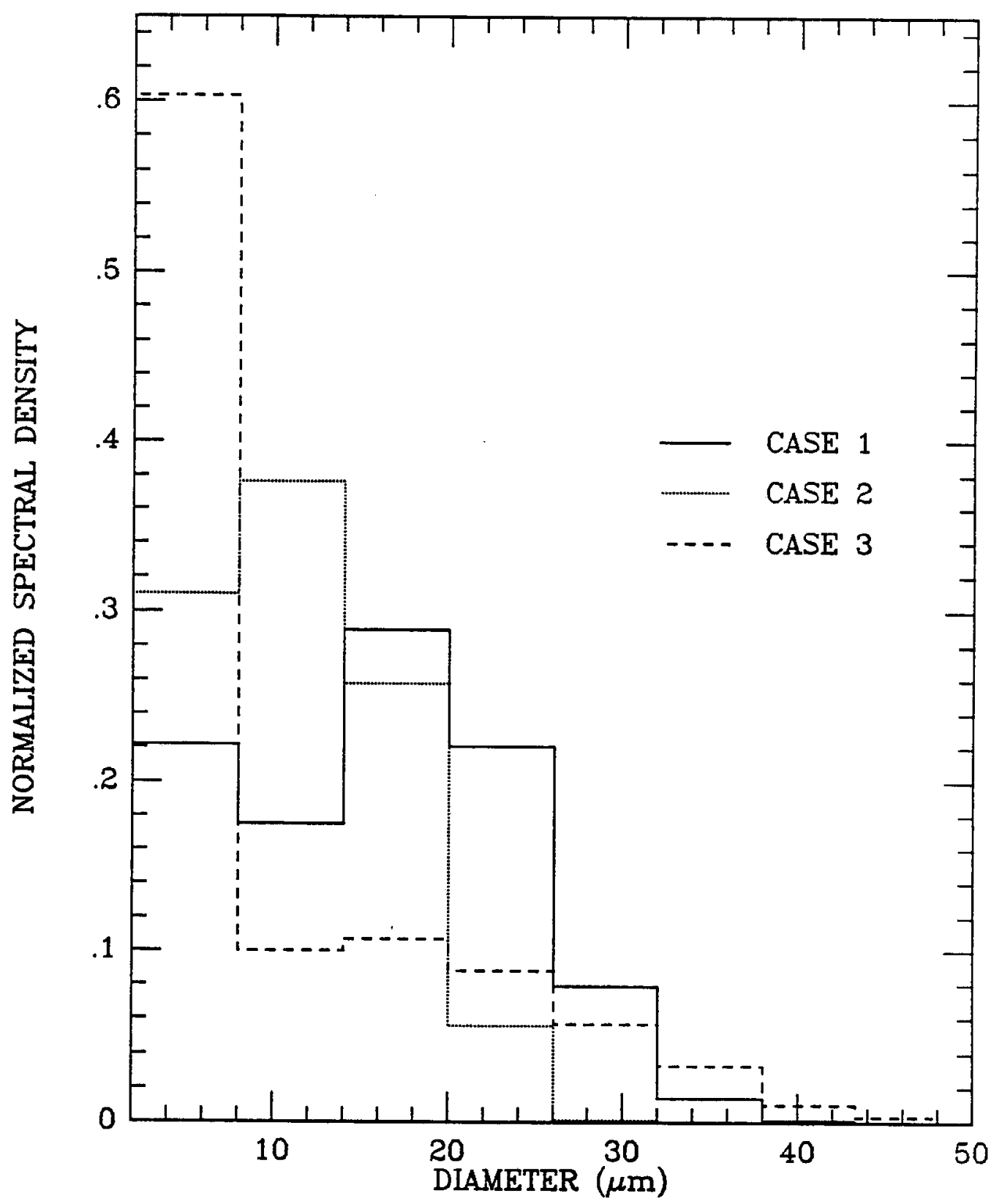

Figure 5.1: Droplet size distributions used in the radiative transfer model cases. 
Table 5.2: Location of cloud in model atmosphere and the LWC profile for Cases 1 and 2.

\begin{tabular}{|c|c|c|c|}
\hline Pressure & Height & \multicolumn{2}{|c|}{ LWC $\left(\mathrm{g} \cdot \mathrm{m}^{-3}\right)$} \\
$(\mathrm{mb})$ & $(\mathrm{m})$ & Case 1 & Case 2 \\
\hline $891.0-894.8$ & $1050-1010$ & 0.495 & 0.166 \\
$894.8-900.2$ & $1010-965$ & 0.364 & 0.124 \\
$900.2-905.1$ & $965-920$ & 0.315 & 0.107 \\
$905.1-910.0$ & $920-875$ & 0.220 & 0.078 \\
$910.0-915.0$ & $875-830$ & 0.213 & 0.074 \\
$915.0-919.9$ & $830-785$ & 0.154 & 0.054 \\
\hline
\end{tabular}

Table 5.3: Location of cloud in model atmosphere and the LWC profile for Case 3.

\begin{tabular}{|c|c|c|}
\hline $\begin{array}{c}\text { Pressure } \\
(\mathrm{mb})\end{array}$ & $\begin{array}{c}\text { Height } \\
(\mathrm{m})\end{array}$ & $\begin{array}{c}\text { LWC }\left(\mathrm{g} \cdot \mathrm{m}^{-3}\right) \\
\text { Case 3 }\end{array}$ \\
\hline $930.0-935.0$ & $650-604$ & 0.068 \\
$935.0-940.0$ & $604-559$ & 0.070 \\
$940.0-945.0$ & $559-514$ & 0.068 \\
$945.0-950.0$ & $514-470$ & 0.190 \\
$950.0-955.0$ & $470-426$ & 0.166 \\
$955.0-960.0$ & $426-382$ & 0.070 \\
$960.0-965.0$ & $382-339$ & 0.121 \\
$965.0-970.0$ & $339-296$ & 0.027 \\
\hline
\end{tabular}

Table 5.4: Flight legs used to calculate the optical properties of the simulated clouds in Cases 1 and 2.

\begin{tabular}{|c|c|c|}
\hline \multicolumn{3}{|c|}{ Cases 1 and 2 } \\
\hline $\begin{array}{c}\text { Pressure } \\
(\mathrm{mb})\end{array}$ & $\begin{array}{c}\text { Height } \\
(\mathrm{m})\end{array}$ & Flight Leg \\
\hline $891.0-894.8$ & $1050-1010$ & Flt. 5, Leg 2 \\
$894.8-900.2$ & $1010-965$ & Flt. 5, Leg 6 \\
$900.2-905.1$ & $965-920$ & Flt. 5, Leg 8 \\
$905.1-910.0$ & $920-875$ & Flt. 5, Leg 10 \\
$910.0-915.0$ & $875-830$ & Flt. 5, Leg 11 \\
$915.0-919.9$ & $830-785$ & Flt. 5, Leg 12 \\
\hline
\end{tabular}


top. The flux divergence is greatest in Case 1, with a difference in net flux of nearly 120 $\mathrm{W} \cdot \mathrm{m}^{-2}$ in the top layer, and the least in Case 3 with a value of $75 \mathrm{~W} \cdot \mathrm{m}^{-2}$. The calculated flux divergence tends to be larger than the divergence observed during the flights, which varied from $40 \mathrm{~W} \cdot \mathrm{m}^{-2}$ to $70 \mathrm{~W} \cdot \mathrm{m}^{-2}$ in the top $4 \mathrm{mb}$ of the cloud. As in the observations, the calculated net flux approached zero $\mathrm{W} \cdot \mathrm{m}^{-2}$ in the middle of the cloud and a layer of weak flux convergence was produced near cloud base by the contribution to the upwelling flux by the relatively warmer ocean surface.

The calculated longwave heating rates for Case 1 are presented in Figure 5.5. The peak cooling occurred in the top $5 \mathrm{mb}$ of the cloud, with a value near $-10^{\circ} \mathrm{C} \cdot \mathrm{hr}^{-1}$. The maximum cooling rate in Case 2 (Figure 5.6) was also located near cloud top, and was $-6.7^{\circ} \mathrm{C} \cdot \mathrm{hr}^{-1}$. The calculated rates in Case 3 (Figure 5.7) show strong cooling extending through the top $20 \mathrm{mb}$ of the cloud, with a peak value of $-1.5^{\circ} \mathrm{C} \cdot \mathrm{hr} \mathrm{r}^{-1}$. The calculated cooling rates compare favorably with the peak cooling rates measured inside the clouds, which varied from -3 to $-5{ }^{\circ} \mathrm{C} \cdot \mathrm{hr}^{-1}$.

A comparison of the heating rates in each case shows that the depth of the cooling inside the cloud appears to be influenced mainly by the LWC structure inside of the cloud, rather than by the droplet size distribution. The heating rates from Cases 1 and 2 have similar shapes, even though the total liquid water path and droplet size distribution is different in each case. The heating rate in Case 3 is much different in depth and intensity from Case 2 although both clouds have nearly the same LWP. Stephens (1978) noted this dependence in the heating rates on the LWC structure in low level clouds. Although the observed profiles of longwave heating showed some differences in the depth of the cooling throughout the cloud during the day, microphysical measurements could not be made quickly enough to determine the changes in the LWC structure necessary to confirm this relationship in the observations.

\subsection{Shortwave Flux Results}

Profiles of the net shortwave irradiances through the model cloud for each case are shown in Figures 5.8-5.10. The upwelling and downwelling fluxes are calculated by matching the wavenumber bands with the spectral ranges of the filtered and unfiltered Eppley 


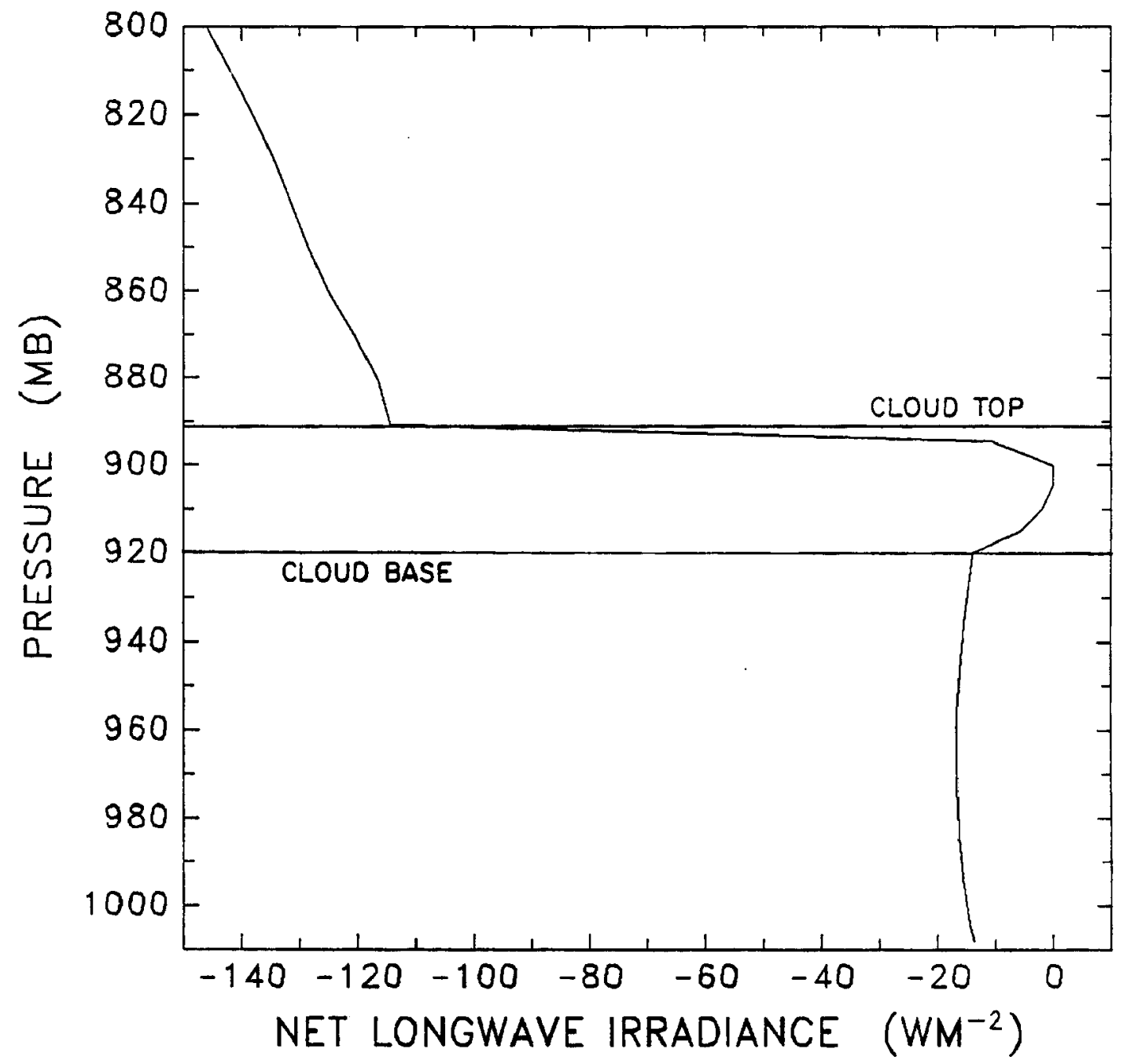

Figure 5.2: Calculated net longwave irradiances for Case 1. 


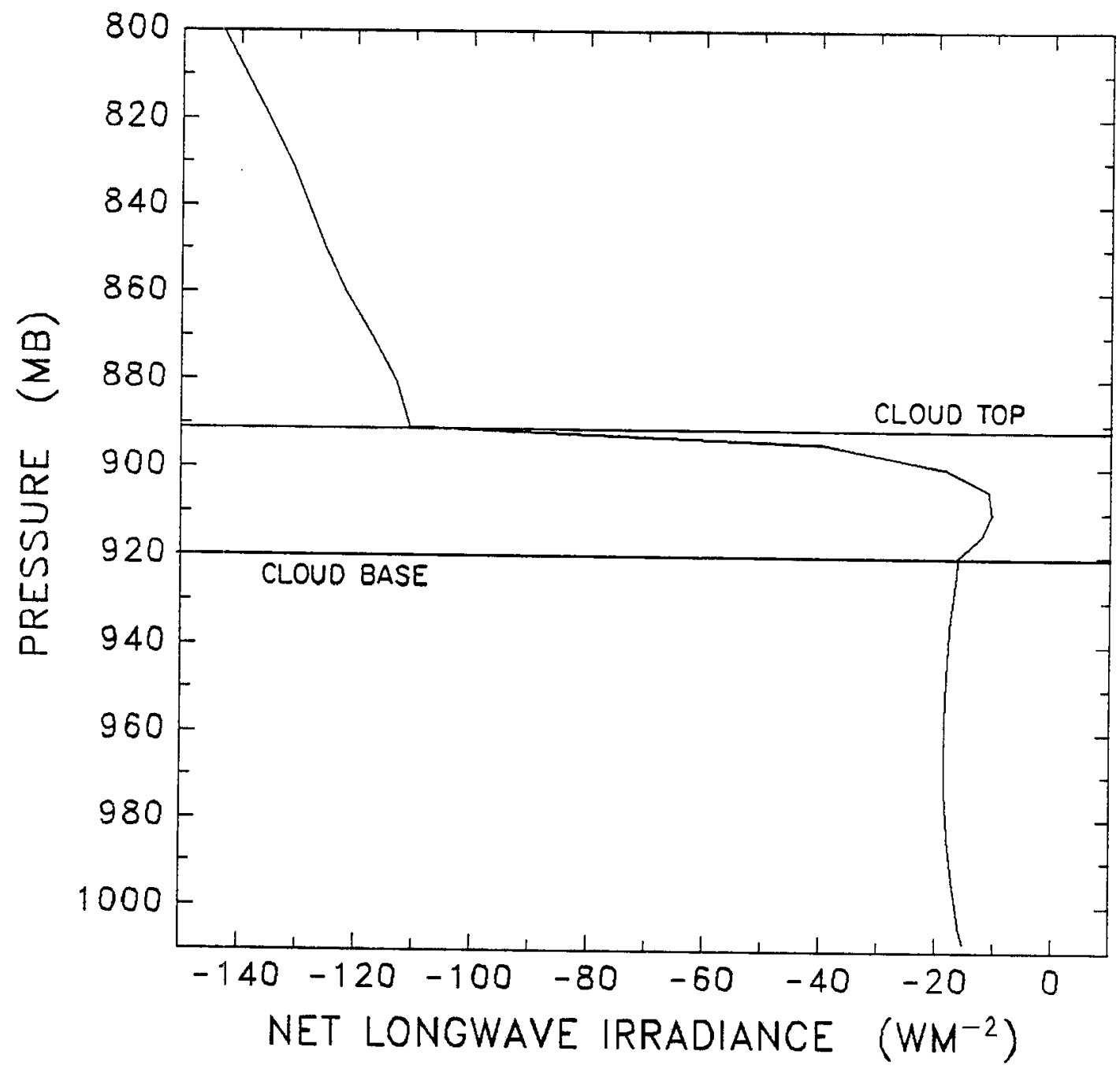

Figure 5.3: Calculated net longwave irradiances for Case 2. 


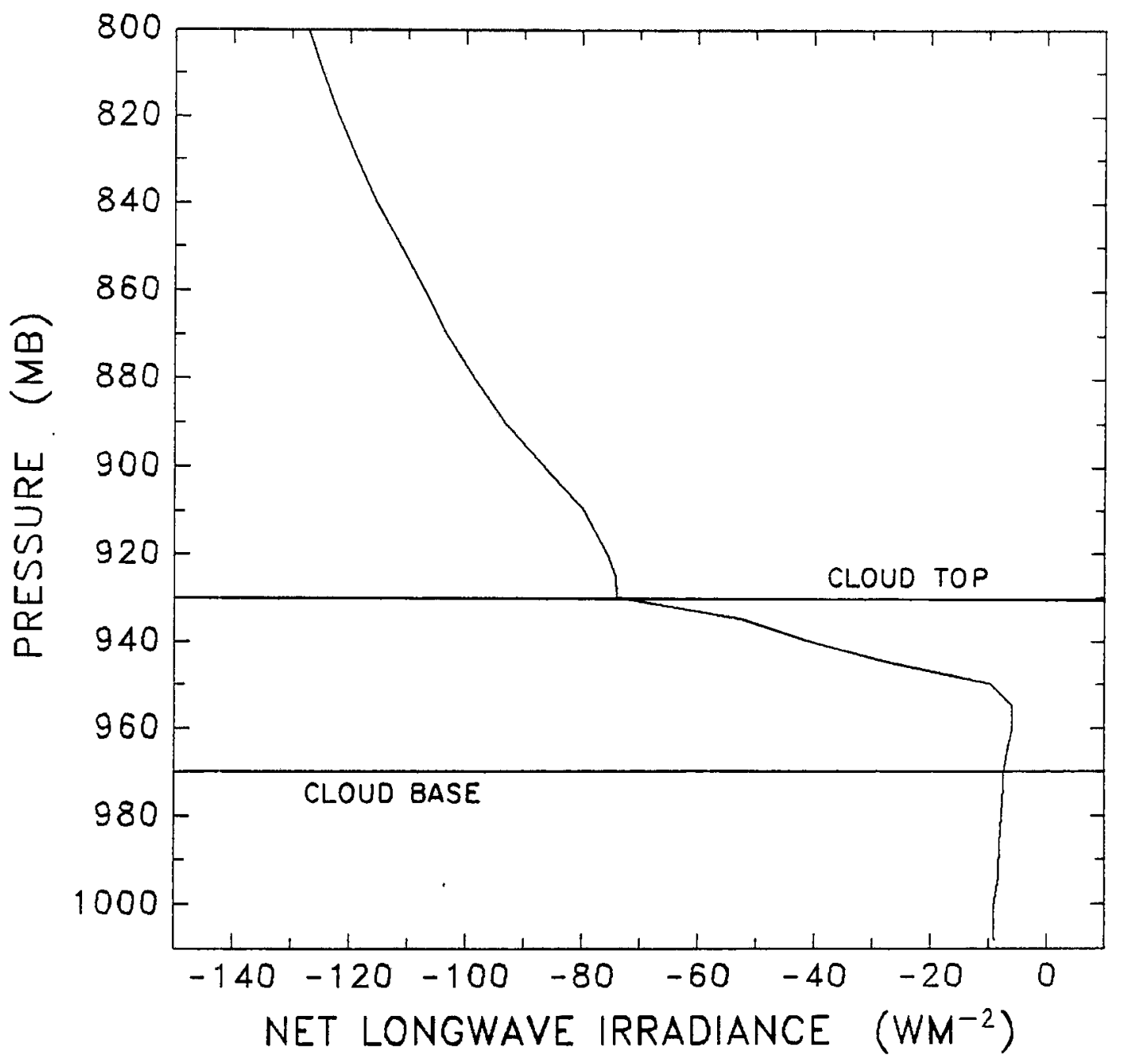

Figure 5.4: Calculated net longwave irradiances for Case 3. 


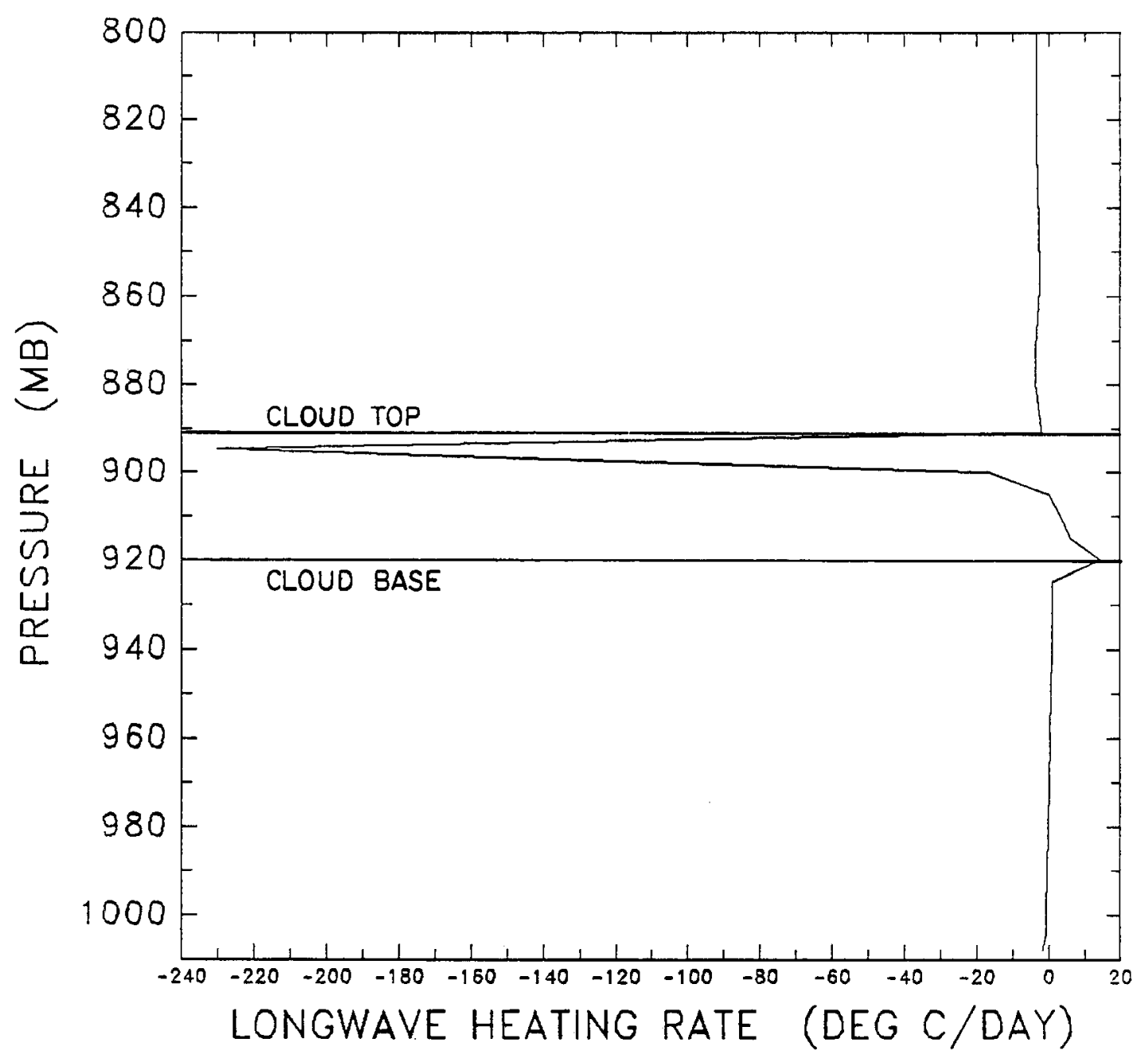

Figure 5.5: Calculated longwave heating rates for Case 1. 


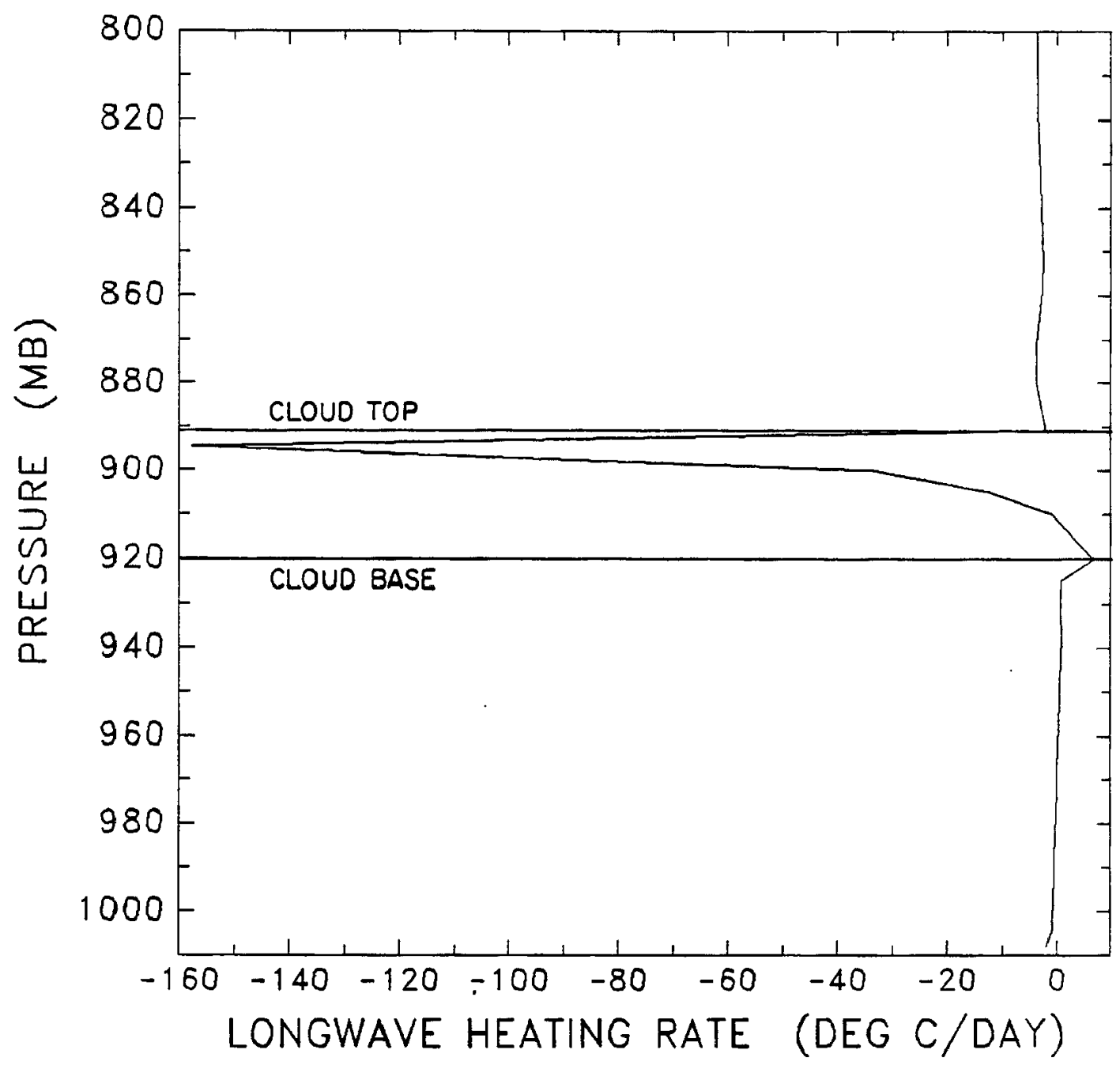

Figure 5.6: Calculated longwave heating rates for Case 2. 


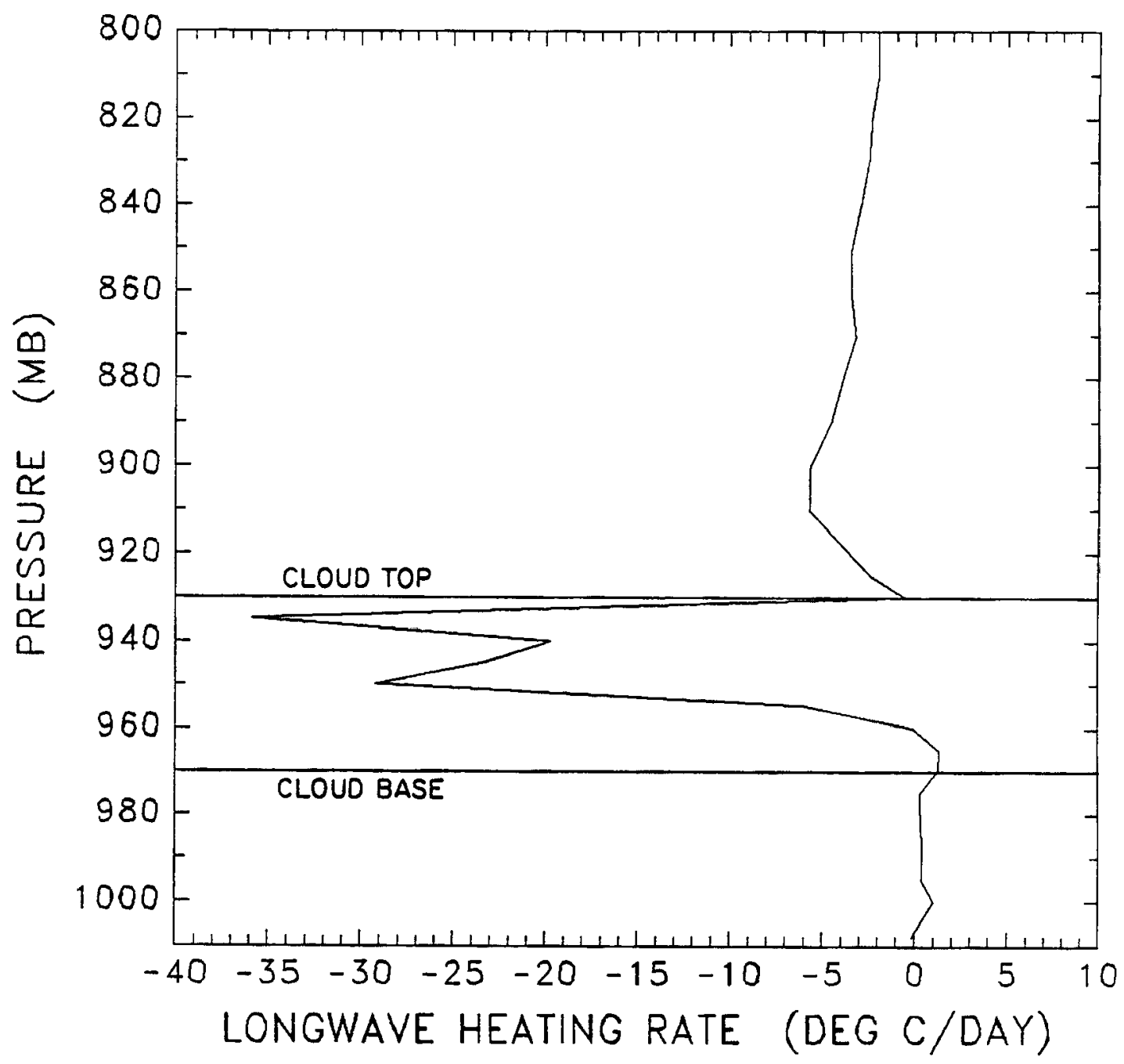

Figure 5.7: Calculated longwave heating rates for Case 3 . 
pyranometers. In each case, and unlike the observations the flux convergence through the cloud is produced almost entirely in the near-infrared wavelengths. The net visible flux is nearly constant through the cloud, as expected from the theory of conservative scattering. This result differs greatly from the observed flux profiles, which showed an approximately equal contribution to the flux convergence by both the visible and near IR spectral regions. The calculated change in net flux through the cloud in Case 1 is $44 \mathrm{~W} \cdot \mathrm{m}^{-2}$, while it is approximately $28 \mathrm{~W} \cdot \mathrm{m}^{-2}$ in Cases 2 and 3 . These changes are much smaller than the flux convergence measured during the early afternoon, which decreased over $200 \mathrm{~W} \cdot \mathrm{m}^{-2}$ through the cloud.

Figures 5.11-5.13 present the shortwave heating rates for each case. The maximum heating in Case 1 occurs in the top of the cloud and decreases roughly linearly through the cloud. The peak heating rate of $1^{\circ} \mathrm{C} \cdot \mathrm{hr}{ }^{-1}$ is much less than the 4 to $7^{\circ} \mathrm{C} \cdot \mathrm{hr}^{-1}$ rates observed by the tethered balloon instruments. The large discrepancy between the observed and calculated solar heating rates indicates either that the model cannot compute the solar heating inside of the cloud accurately or the measurements are suspect. One major problem in reconciling the model calculations with the measurements is the apparent flux convergence observed in the visible wavelengths. More spectral measurements of the fluxes through the cloud are necessary to determine whether the flux convergence is real or the result of erroneous measurements (eg. Stephens and Tsay, 1989.)

The heating rate profile calculated for Case 2 shows the heating deeper inside the cloud than Case 1, while the maximum heating in Case 3 occurs in the middle of the cloud. A comparison between the theoretical heating rates in each case reveals that the distribution of LWC inside the cloud is important in determining the depth of the solar heating as well as the longwave cooling. The differences in the heating profiles from Case 1 and Case 2 also suggests that the shape of the droplet size distribution may be somewhat important in the distribution of shortwave heating inside the cloud.

\subsection{Radiative Energy Budget}

The measured (Flight 3 ) and calculated (Case 3) radiative heating balances inside of the cloud observed on July 8, 1987 are shown in Figure 5.14. The net radiative heating 


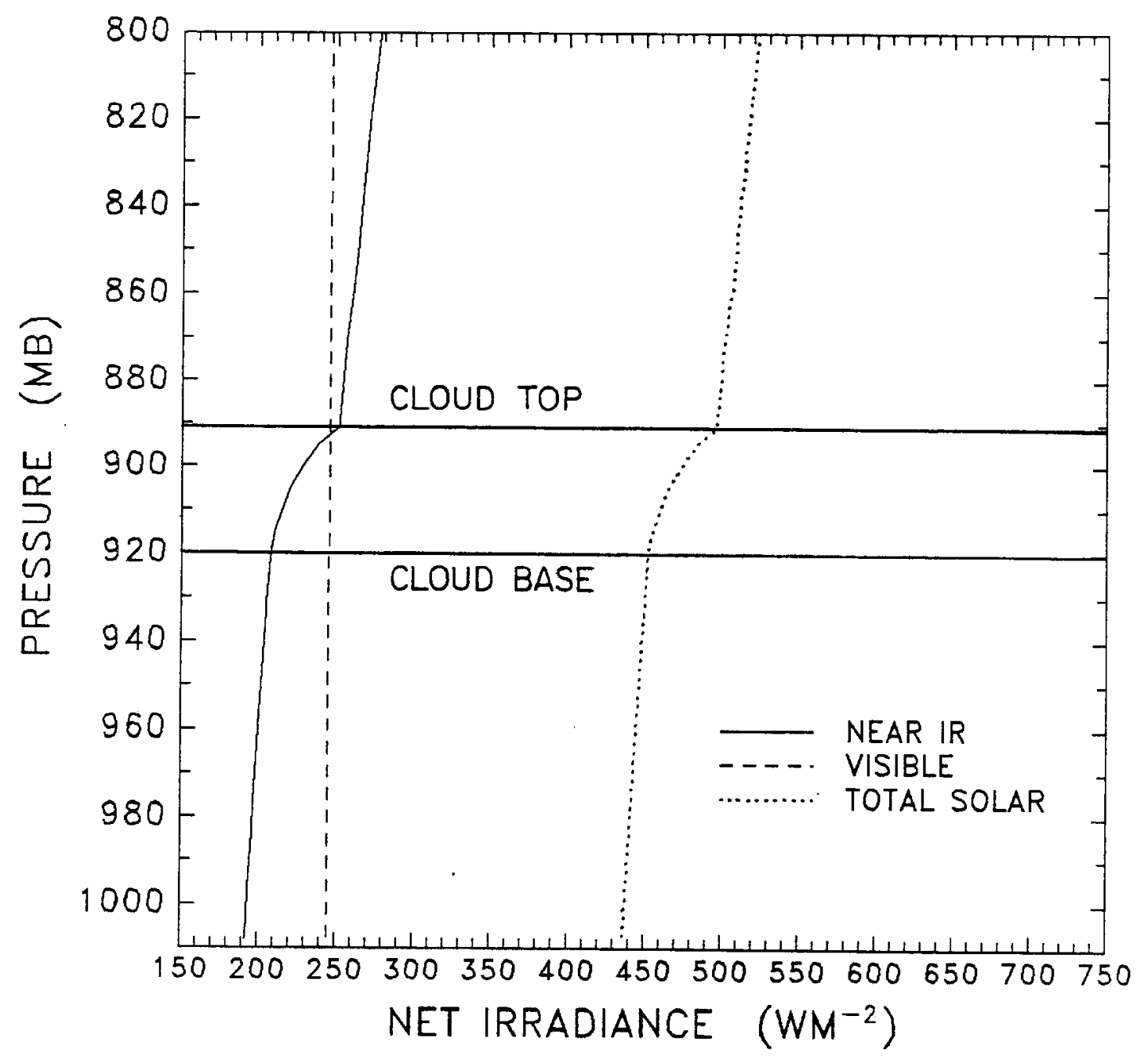

Figure 5.8: Calculated net shortwave irradiances for Case 1. 


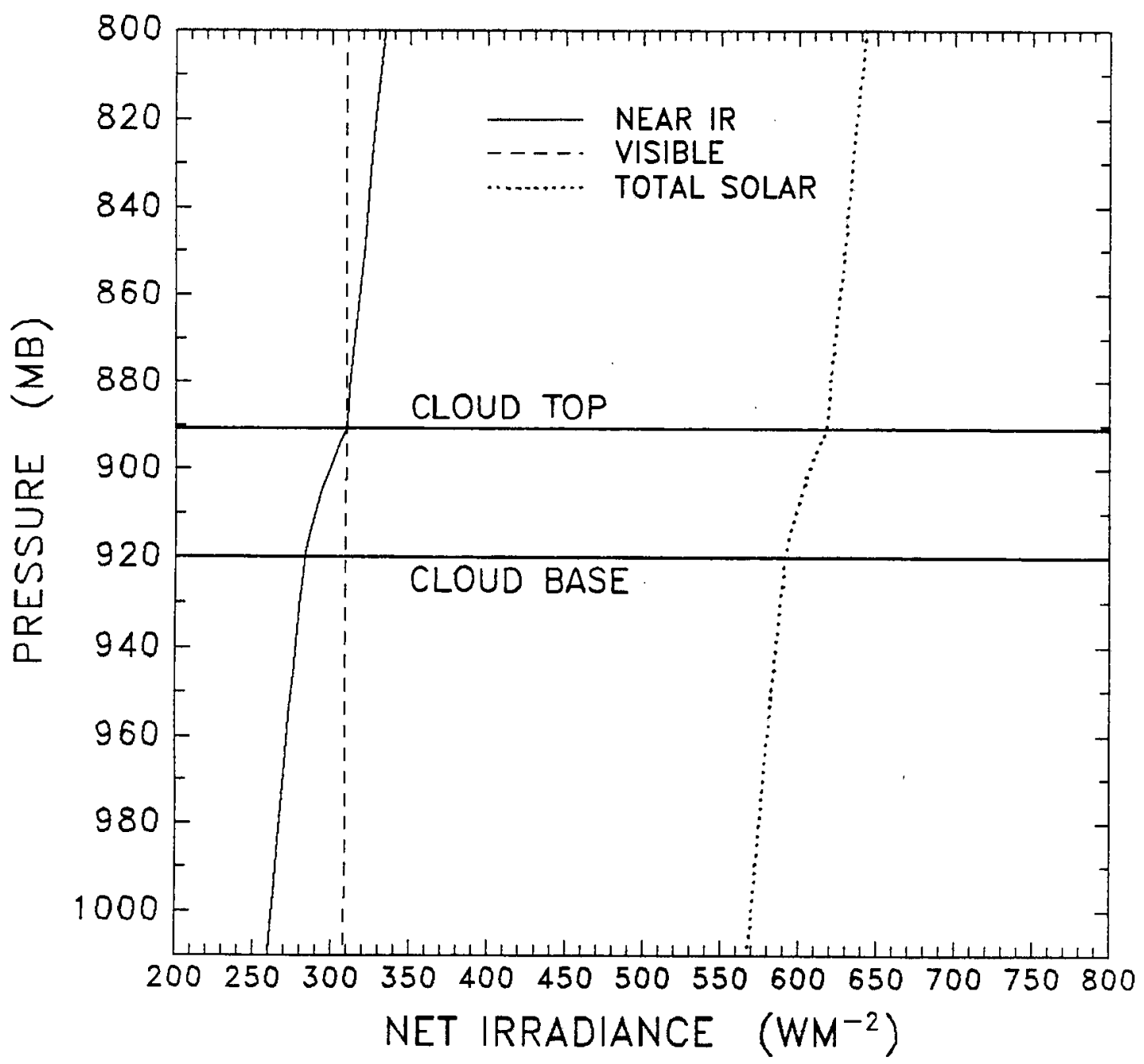

Figure 5.9: Calculated net shortwave irradiances for Case 2. 


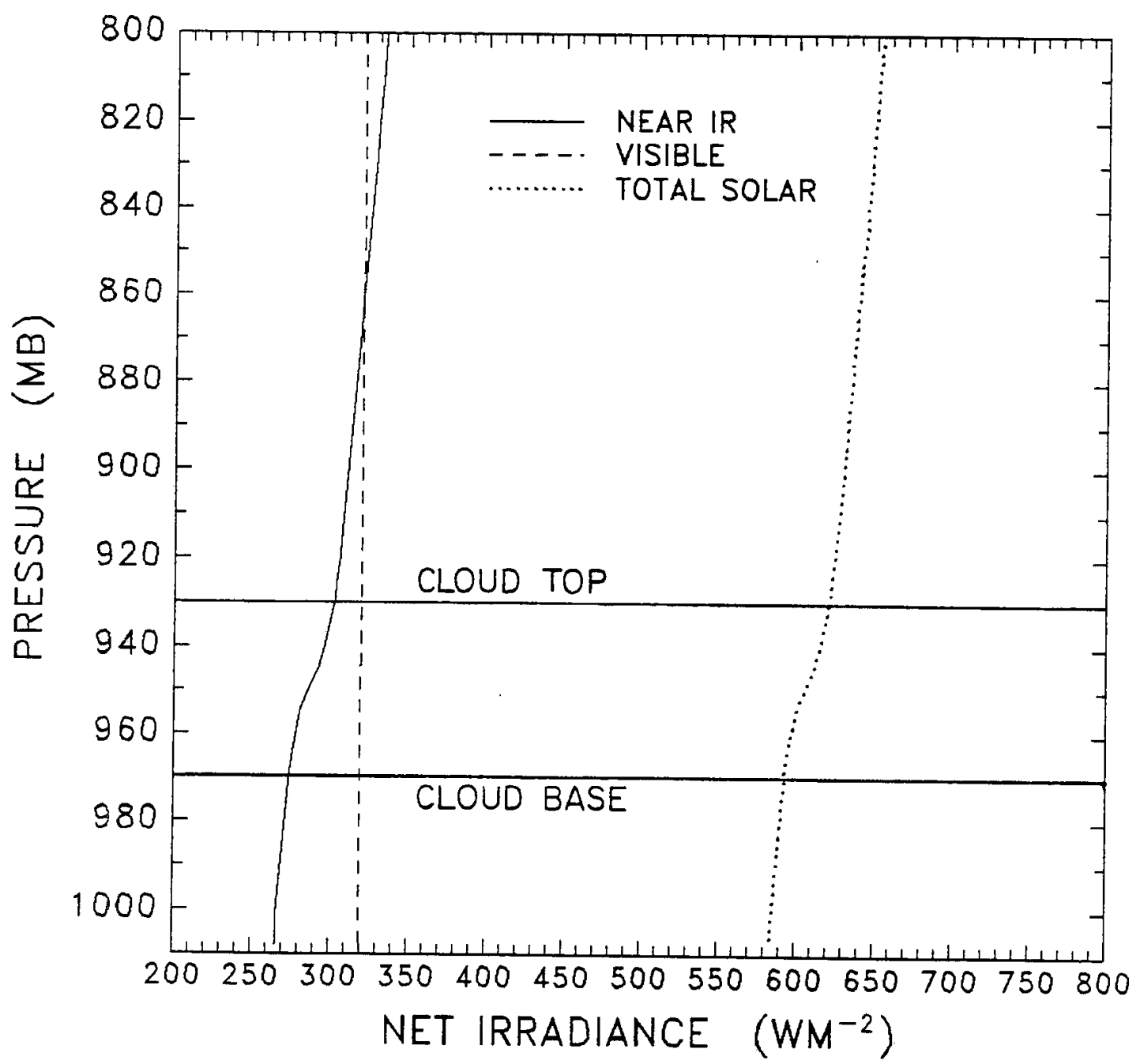

Figure 5.10: Calculated net shortwave irradiances for Case 3. 


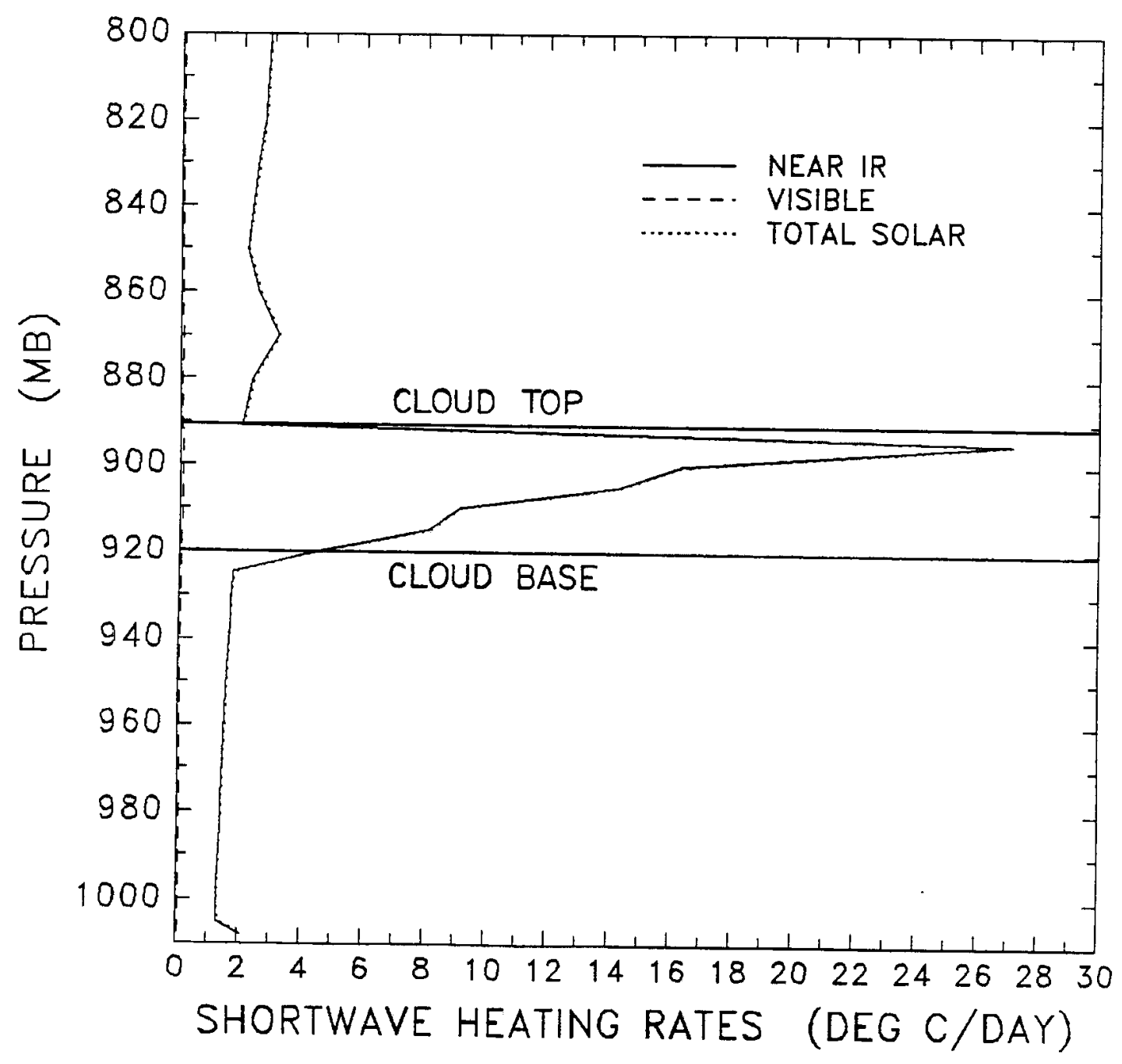

Figure 5.11: Calculated shortwave heating rates for Case 1. 


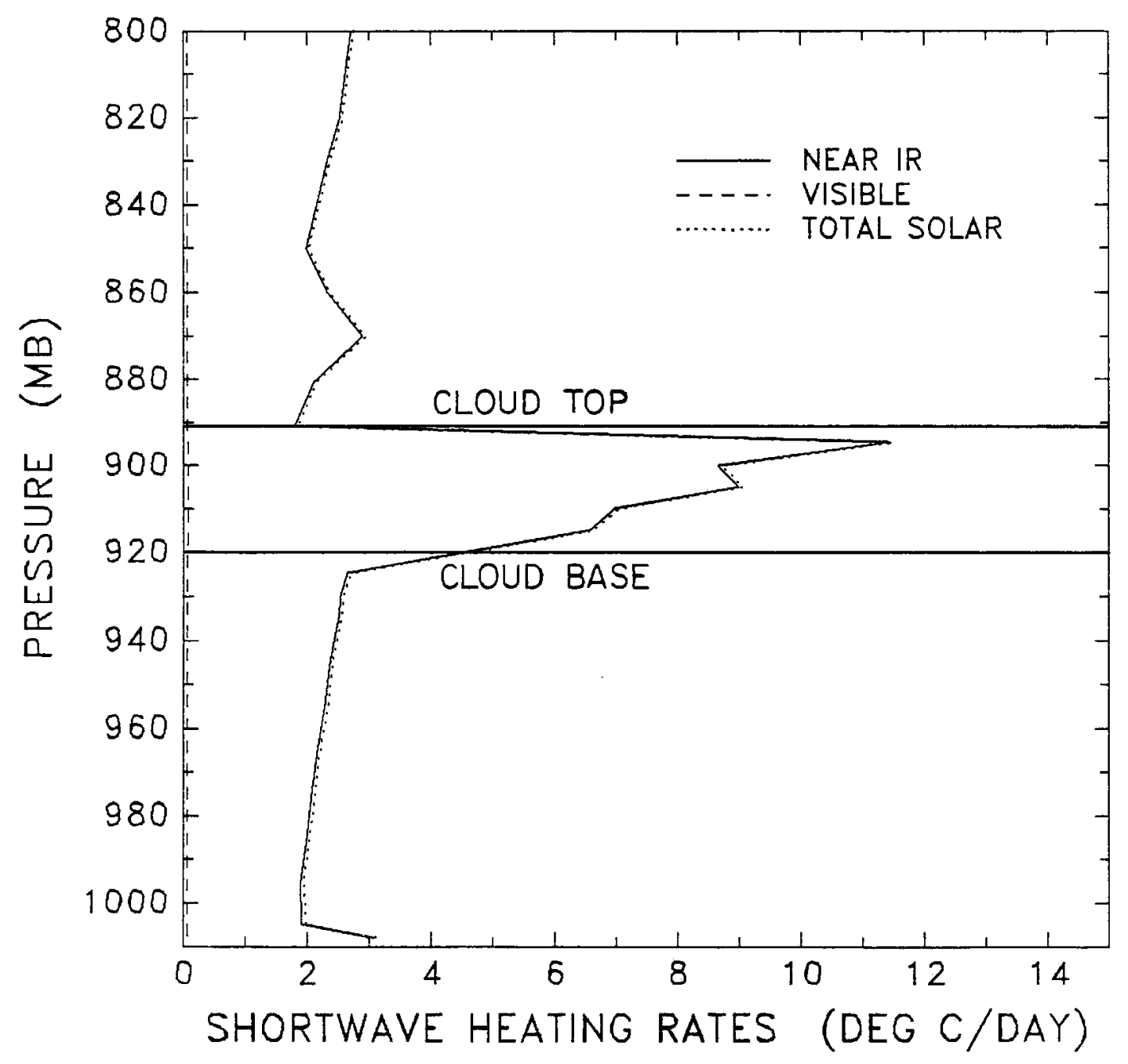

Figure 5.12: Calculated shortwave heating rates for Case 2. 


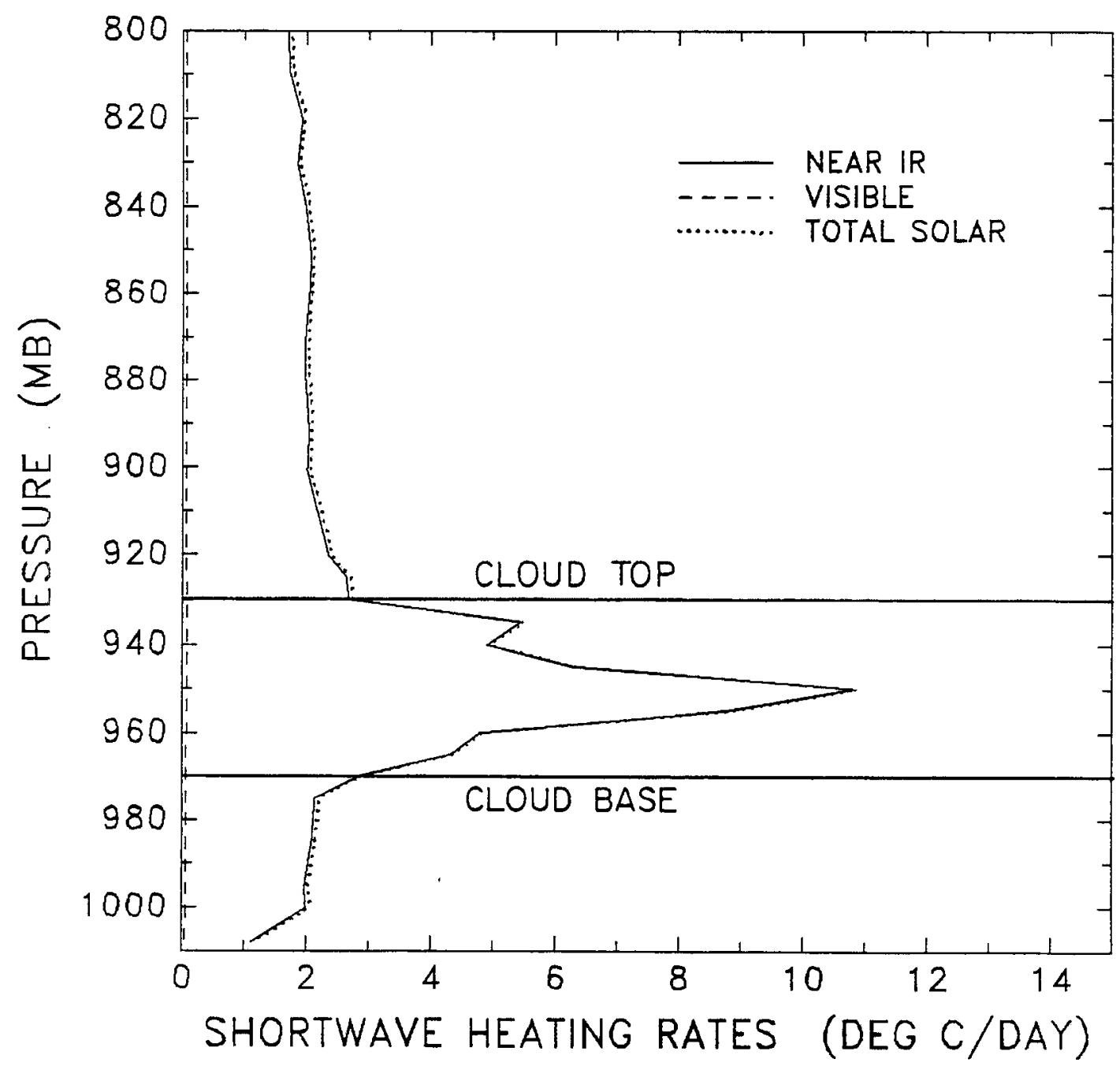

Figure 5.13: Calculated shortwave heating rates for Case 3. 
rates throughout the cloud were obtained by adding the longwave and shortwave heating rates at several levels in the cloud. In the theoretical simulation, the longwave cooling dominates the energy budget of the cloud in a manner that could lead to a destabilization of the boundary layer. By contrast, the observed solar heating rate is larger than the measured longwave cooling rate and produces a heating profile that would tend to stabilize the cloud layer.

\subsection{Solar Albedo Calculations}

The analysis of observed albedos in Chapter 4 indicated that the ratio between the measured cloud top near IR and visible albedos remained relatively uniform except for the very inhomogeneous cloud observed during Flight 5. In that flight, the measured visible albedo decreased relative to the near IR albedo. The clouds during that flight also had a much more marine-like size distribution than the other cases. The differing albedo ratios may have been caused by either the heterogeneities in the cloud or by the different microphysics. The radiative transfer model was used to investigate some the effects produced by the differences in the clouds between Flights 2 and 3 and those from Flight 5. Since the radiative transfer model assumes a horizontally homogeneous cloud, a comparison between the model and observed results may provide some information on the importance of heterogeneities on the cloud top albedo.

Tables 5.6-5.8 show the mean downwelling and upwelling fluxes at cloud top in $\mathrm{W} \cdot \mathrm{m}^{-2}$ and the near IR, visible and total solar albedos calculated for all three cases. The calculated albedos are highest for the high LWC cloud in Case 1, and higher in Case 2 than Case 3 since Case 2 is based on the microphysical properties of Flight 5, which contained more droplets than Flight 3. The calculated albedos, however, are lower than the albedos observed during the tethered balloon flights. This result is surprising since the cloud inhomogeneities in observed clouds would tend to lower the total solar albedo (McKee and Cox (1974)). In contrast to the model calculations, the albedo measured during Flight 5 (.5809) above a cloud with the largest LWP was lower than the albedos observed during Flight $2(.6355)$ and Flight $3(.7017)$. 
Table 5.5: Flight legs used to calculate the optical properties of the simulated clouds in Case 3.

\begin{tabular}{|c|c|c|}
\hline \multicolumn{3}{|c|}{ Case 3 } \\
\hline $\begin{array}{c}\text { Pressure } \\
(\mathrm{mb})\end{array}$ & $\begin{array}{c}\text { Height } \\
(\mathrm{m})\end{array}$ & Flight Leg \\
\hline $930.0-935.0$ & $650-604$ & Flt. 3, Leg 1 \\
$935.0-940.0$ & $604-559$ & Flt. 3, Leg 4 \\
$940.0-945.0$ & $559-514$ & Flt. 3, Leg 5 \\
$945.0-950.0$ & $514-470$ & Flt. 3, Leg 6 \\
$950.0-955.0$ & $470-426$ & Flt. 3, Leg 7 \\
$955.0-960.0$ & $426-382$ & Flt. 3, Leg 8 \\
$960.0-965.0$ & $382-339$ & Flt. 3, Leg 9 \\
$965.0-970.0$ & $339-296$ & Flt. 3, Leg 10 \\
\hline
\end{tabular}

Table 5.6: Calculated shortwave fluxes and the near IR, visible and total solar albedos for Case 1.

\begin{tabular}{|c|c|c|c|c|}
\hline Case 1 & & TOT & NIR & VIS \\
\hline & $\mathrm{F} \downarrow$ & 1103.0 & 538.1 & 564.9 \\
891.0 & $\mathrm{~F} \uparrow$ & 607.1 & 287.4 & 319.7 \\
$\mathrm{mb}$ & Albedo & .5504 & .5341 & .5659 \\
\hline NIR/VIS albedo & \multicolumn{3}{|c|}{.9438} \\
\hline
\end{tabular}

Table 5.7: Calculated shortwave fluxes and the near IR, visible and total solar albedos for Case 2.

\begin{tabular}{|c|c|c|c|c|}
\hline Case 2 & & TOT & NIR & VIS \\
\hline & $\mathrm{F} \downarrow$ & 1093.3 & 537.5 & 555.8 \\
891.0 & $\mathrm{~F} \uparrow$ & 475.5 & 228.5 & 247.0 \\
$\mathrm{mb}$ & Albedo & .4349 & .4251 & .4443 \\
\hline NIR/VIS albedo & \multicolumn{3}{|c|}{.9568} \\
\hline
\end{tabular}




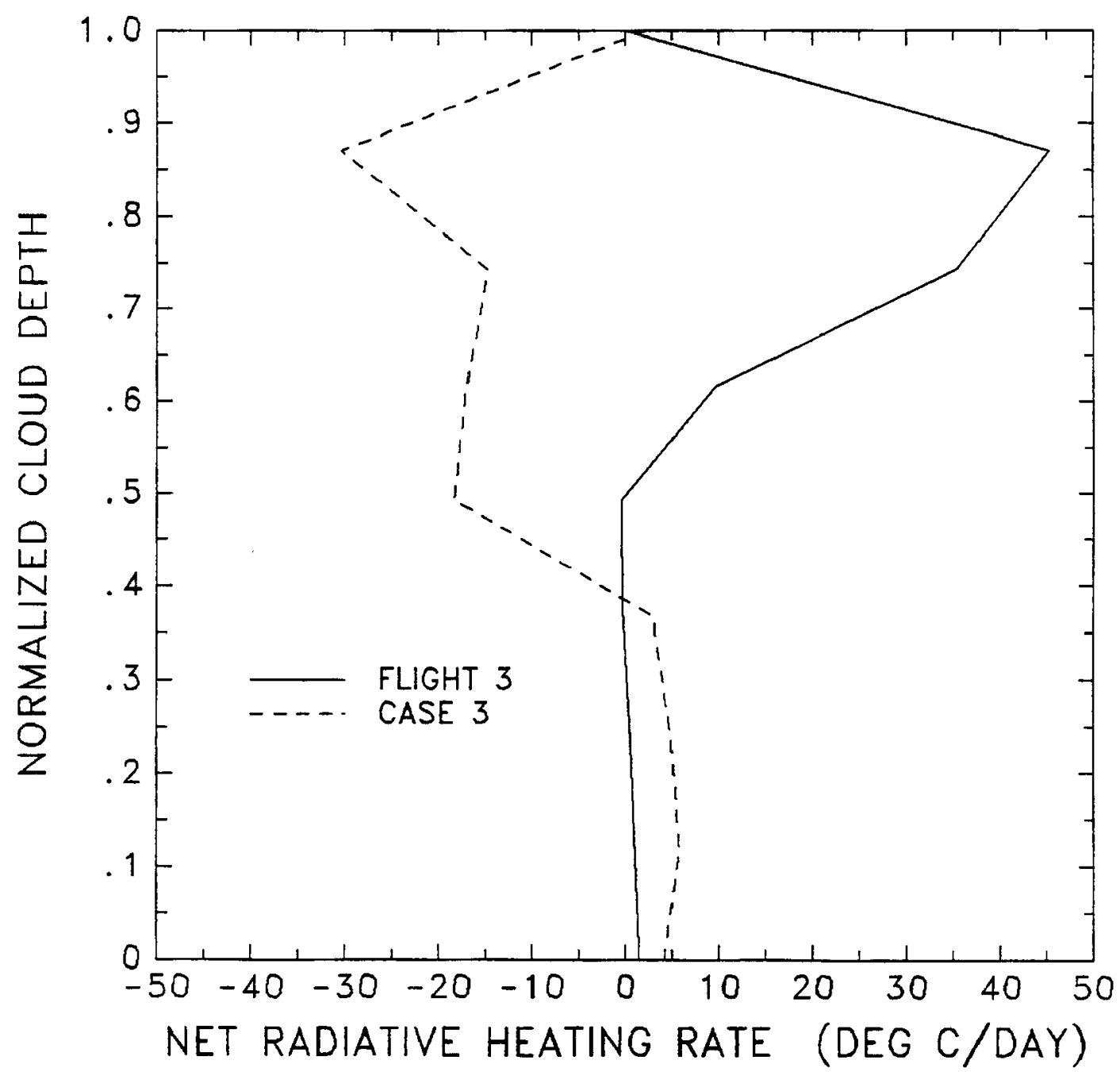

Figure 5.14: Observed (Flight 3 ) and calculated (Case 3) radiative energy balance inside the cloud on July 8,1987 . 
The discrepancies between and model and observed albedos and heating rates are consequently related to the differences between the calculated and observed transmissivities. In order to account for the large flux convergence values observed by the radiation instruments (despite the high albedo), the measured transmissivities below the cloud should be much lower than those calculated in the model. In order to relate the albedos and heating rates to cloud transmissivity, a set of definitions for cloud reflectance $(R)$, absorptivity $(A)$ and transmissivity $(T)$ are given below.

$$
\begin{aligned}
& A=\frac{F_{\text {top }}^{N}-F_{\text {bot }}^{N}}{F_{\text {top }}^{\dagger}+F_{\text {bot }}^{\dagger}} \\
& T=\frac{F_{\text {top }}^{\dagger}(1-A)-F_{\text {top }}^{\dagger}}{F_{\text {top }}^{\dagger}-F_{\text {bot }}^{\dagger}} \\
& R=\frac{F_{\text {top }}^{\dagger}(1-A)-F_{\text {bot }}^{\dagger}}{F_{\text {top }}^{\dagger}-F_{\text {bot }}^{\dagger}}
\end{aligned}
$$

$F_{\text {top }}^{\dagger}$ and $F_{\text {top }}^{\downarrow}$ are the upwelling and downwelling fluxes at cloud top, $F_{b o t}^{\dagger}$ and $F_{b o t}^{\downarrow}$ are the fluxes at cloud base and $F_{\text {top }}^{N}$ and $F_{b o t}^{N}$ are the net fluxes at cloud top and cloud base. These cloud properties are defined such that the sum of the three variables equals 1 .

Tables 5.9-5.11 present the mean cloud radiative properties for two flights and the corresponding simulations of those flights by the radiative transfer model. The radiative properties for the entire solar spectrum are shown in Table 5.9, while Tables 5.10 and 5.11 present the results for the near infrared and visible portions of the spectrum, respectively. In each table, the observed transmissivities are significantly lower than the corresponding calculated transmissivities and the observed values of cloud absorptivity are larger than the calculated values. This "anomalous" absorption in the solar spectrum has been observed by several investigators (see Stephens and Tsay, 1989) and it produces the discrepancies between the observed and calculated solar heating rates.

Table 5.12 presents the near IR to visible albedo ratios for the model results and the tethered balloon observations. The difference between the albedo ratios from Case 1 and Flight 5 are well within the uncertainties in the albedo ratio measurements and the albedo ratio from Flight 3 is only $4 \%$ lower than the ratio calculated from Case 3. This value is much less than the measured to observed ratio discrepancy presented by Hignett (1987) from aircraft observations of marine stratus clouds off the coast of Great Britain. 
Table 5.8: Calculated shortwave fluxes and the near IR, visible and total solar albedos for Case 3.

\begin{tabular}{|c|c|c|c|c|}
\hline Case 3 & & TOT & NIR & VIS \\
\hline & F $\downarrow$ & 1059.3 & 506.7 & 552.6 \\
930.0 & F & 437.8 & 204.7 & 233.1 \\
mb & Albedo & .4132 & .4040 & .4218 \\
\hline \multicolumn{2}{|c|}{ NIR/VIS albedo } & \multicolumn{3}{|c|}{.9578} \\
\hline
\end{tabular}

Table 5.9: Cloud radiative properties of the total solar spectrum.

\begin{tabular}{|c|l|l|l|}
\hline & Absorptivity (\%) & Transmissivity (\%) & Reflectivity (\%) \\
\hline \hline Flight 3 & $14.4 \pm 3.5$ & $14.1 \pm 0.3$ & $71.5 \pm 3.7$ \\
Case 3 & 2.3 & 69.1 & 28.6 \\
Flight 5 & $10.4 \pm 4.4$ & $29.4 \pm 0.5$ & $60.3 \pm 4.9$ \\
Case 1 & 3.5 & 47.8 & 48.7 \\
\hline
\end{tabular}

Table 5.10: Cloud radiative properties of the near infrared spectrum.

\begin{tabular}{|c|l|l|l|}
\hline & Absorptivity (\%) & Transmissivity (\%) & Reflectivity (\%) \\
\hline \hline Flight 3 & $19.4 \pm 3.6$ & $12.4 \pm 0.3$ & $68.3 \pm 3.9$ \\
Case 3 & 4.8 & 66.2 & 29.0 \\
Flight 5 & $12.9 \pm 4.5$ & $27.7 \pm 0.4$ & $59.4 \pm 4.8$ \\
Case 1 & 7.3 & 44.4 & 48.3 \\
\hline
\end{tabular}

Table 5.11: Cloud radiative properties of the visible spectrum.

\begin{tabular}{|c|l|l|l|}
\hline & Absorptivity (\%) & Transmissivity (\%) & Reflectivity (\%) \\
\hline \hline Flight 3 & $9.7 \pm 3.3$ & $15.7 \pm 0.2$ & $74.6 \pm 3.6$ \\
Case 3 & 0.05 & 71.84 & 28.11 \\
Flight 5 & $7.7 \pm 4.3$ & $31.2 \pm 0.6$ & $61.1 \pm 4.9$ \\
Case 1 & 0.05 & 51.09 & 48.86 \\
\hline
\end{tabular}




\subsection{Summary}

The formulation and structure of the two stream radiative transfer model developed by Stackhouse (1989) is outlined in this chapter. The matrix form of the two stream solution to the radiative transfer equation is given, along with the diffuse source terms in the shortwave and longwave regions of the model. The formulae used to calculate the increase optical depth due to various physical processes such are included as well as the scaling methods used to adjust the single scatter albedo, asymmetry parameter and direct backscattered fraction. The K-distribution method is used to calculate most of the gaseous absorption in the model and the adding method is used to join several layers of the model together. The heating rates are calculated inside each layer of the model.

In this chapter, the atmosphere and clouds used in the two stream radiative transfer model are described for each case, with an attempt to model the clouds observed during Flights 3 and 5 using the microphysical data from those flights. A comparison between the calculated and observed profiles of longwave fluxes and heating rates showed close agreement in both the depth and magnitude of the cooling inside the cloud. The depth of the longwave cooling however, appeared to be strongly influenced by the structure of the LWC in the cloud. The calculated shortwave heating rates were much less than the observed rates, which led to a discrepancy in the profiles of measured and calculated radiative energy balance inside the cloud. The computed solar albedos were lower than the albedos measured in the clouds, and the calculated cloud transmissivities are lower than the observed transmissivities, especially for Case 3. The near IR to visible albedo ratios measured during the flights compared well with the ratios computed during each corresponding numerical simulation by the two stream model. 
Table 5.12: Near IR to visible albedo ratios for the model results and the tethered balloon observations.

\begin{tabular}{|c|c|}
\hline Flight 3, Leg 2 & 0.92 \\
\hline Flight 5, Leg 13 & 0.97 \\
\hline Case 1 & 0.9438 \\
\hline Case 2 & 0.9568 \\
\hline Case 3 & 0.9578 \\
\hline
\end{tabular}




\section{Chapter 6}

\section{SUMMARY, CONCLUSIONS AND RECOMMENDATIONS}

In an effort to learn more about the influences of global cloudiness on the climate, several research programs have been recently developed to study the characteristics of large-scale cloud systems in greater detail. The International Satellite Cloud Climatology Project (ISCCP) is a program created to collect a climatological data base of global cloud cover from satellite imagery for the use of researchers in the study of cloud forcing on climate. Cirrus and marine stratocumulus clouds, however, are difficult to categorize and create several problems in the ISCCP algorithm. Project FIRE (First ISCCP Regional Experiment) is a field experiment and numerical modeling program designed to address these problems by developing a better understanding of these cloud systems.

One component of FIRE was an Intensive Field Observation (IFO) program designed to produce an improved set of observations of cirrus and stratocumulus clouds. The purpose of the observations was to study the various components of the cloud energy and moisture budgets, including cloud- top entrainment, radiative heating and surface heat and moisture fluxes. The stratocumulus IFO included satellite, aircraft, ship and surface measurements of the clouds near San Nicholas Island (SNI) in June-July 1987. In order to study the radiative balance in the cloud layer, an instrument platform was attached to a tethered balloon to make in situ measurements of the microphysical and radiative properties of the stratocumulus. Although tethered balloon instruments have not been often used to study stratocumulus clouds, they offer several advantages over the other systems in obtaining the complete, high resolution vertical profiles of radiation and microphysics data necessary for the study of the radiative transfer through the cloud. One objective of this thesis was to analyze this data and learn more about the balance between 
the solar and longwave radiative forcings inside of the cloud. More specifically, the analysis of the data was to provide estimates of the depth and intensity of the longwave cooling and shortwave heating at cloud top. The effects of cloud inhomogeneities on the radiative properties were examined and the influence of different air masses on the microphysical characteristics of the cloud (and consequently its radiative properties) were also considered. A two stream radiative transfer model was also used to simulate the observed clouds and the results were compared to measured fluxes in the cloud. The results of the analysis are summarized in the following sections.

\subsection{Analysis of Microphysical Data}

Microphysical data were analyzed for three flights. The results of the analysis showed:

1. The shape of the droplet size distributions remained constant throughout each flight and through all levels of the cloud. Flights 2 and 3 revealed clouds predominated by small droplets (2-8 $\mu \mathrm{m}$ in diameter), while Flight 5 had a more typical marine stratocumulus distribution.

2. The liquid water content profiles increased approximately linearly with height through the cloud layer. The observed values from Flights 2 and 3 were much less than the adiabatic LWC, and the liquid water path is considerably less than the LWP measured by the NOAA/WPL microwave radiometer on SNI. The measured LWC from Flight 5, however, was near the adiabatic value and the integrated LWC compared favorably with the liquid water path measured by the radiometer.

3. The total number densities varied with height inside the cloud for each flight. The maximum number densities for Flights 2 and 3 were near $50 \mathrm{~cm}^{-3}$ and near 100 $\mathrm{cm}^{-3}$ for Flight 5. The effective and mean radius slowly increased with height inside the cloud. Although the effective radius did not vary greatly between flights, the mean radii observed during Flight 5 were $45 \%$ larger than those measured during Flights 2 and 3. 


\subsection{Analysis of Radiation Data}

The analysis of the radiation data for the three flights showed:

1. The observed longwave cooling rates exhibited a sharp peak in the top $40 \mathrm{~m}$ of the cloud in each case with maximum cooling rates up to $5^{\circ} \mathrm{C} \cdot \mathrm{hr}{ }^{-1}$. The results compare favorably with other tethered balloon measurements and aircraft measurements of marine stratocumulus.

2. The solar heating rates increased with height inside the cloud. Although most of the heating in the early morning was in the top $50 \mathrm{~m}$ of the cloud, the heating extended through the entire depth of the cloud by noon. Nearly equal contributions to the shortwave heating rates came from the visible and near IR portions of the spectrum. The shortwave heating rates were equal to or greater in magnitude than the longwave cooling rates.

3. The solar albedo measured showed that the visible radiation tended to be reflected by the clouds more than the near IR radiation. The ratio of reflected visible to reflected near IR remained fairly uniform except for the very nonhomogeneous case of Flight 5. For this case, the visible albedo decreased relative to the near IR albedo.

\subsection{Comparison between Observed and Calculated Fluxes}

Three runs of the radiative transfer model were made using the optical properties derived from three different droplet size distributions. The first case simulated the clouds observed during Flight 5, while the third case modeled the clouds observed during Flight 3. The second case used a modified version of the droplet size distribution from Case 1 , which resulted in a cloud with a LWC profile similar in shape to Case 1 but with a LWP nearly equal to Case 3 .

The comparison between the calculated and observed radiative profiles is summarized below: 
1. The calculated and observed net longwave irradiance profiles agree closely in shape and in the magnitude of the cloud top flux divergence. The maximum cooling rates from all three model cases compare well with the cooling rates observed by the instrument platform.

2. The distribution of the calculated longwave cooling inside the cloud appears to be influenced mainly by the LWC structure inside of the cloud, rather than by the droplet size distribution.

3. The calculated shortwave heating rates are considerably smaller than the rates observed during the flights.

4. The computed solar albedos were lower than the albedos measured during the flights and the calculated transmissivity was higher than the observed transmissivity.

5. The near IR to visible albedo ratios measured during the flights compared well with the ratios computed during each corresponding numerical simulation by the two stream model.

\subsection{Conclusions and Recommendations for Future Research}

A tethered balloon platform was used to study the radiative and microphysical structure of marine stratocumulus clouds over San Nicholas Island. An analysis of the data was made in order to study the radiative heating profile inside of the cloud. From the results of the analysis and the comparison of the observations with radiative transfer model calculations, the following conclusions and recommendations were made:

1. The measured visible flux convergence was nearly equal to the near IR flux convergence measured in the clouds, while theoretical calculations show virtually no flux convergence in the visible wavelengths. The discrepancy between the model and observations appears too large to be reconciled by errors in either the measurements or the model. Although the observations of the visible and near-infrared albedos suggested that visible light is more strongly influenced by cloud heterogeneities than 
light at near IR wavelengths, it is not certain what was the exact cause of the discrepancy. More observations of stratocumulus clouds are necessary, preferably by instruments with finer spectral resolution in the visible and near IR wavelengths.

2. As a result of the visible absorption, the observations of solar heating rates in stratocumulus cloud were significantly greater than those calculated in the two stream radiative transfer model. Solar heating appeared to be much more important to the radiative energy balance of the cloud than previously expected.

3. Measurements of the cloud microphysics show that the droplet size distributions in marine stratocumulus were affected by the presence of maritime or continental air masses. More measurements of marine stratocumulus are needed to examine more thoroughly the variability of the microphysical structure in the stratocumulus cloud fields, especially when they are influenced by large-scale offshore air flows.

\subsection{Suggestions for observational approaches used in marine stratocumulus}

The use of tethered balloon instrumentation provides an excellent way to obtain high resolution, vertical profiles of thermodynamic, microphysical and radiative data throughout the marine boundary layer. From the analysis of the data, some suggestions on improving the quality of the data collected by the instrument platform are given below:

1. Although the winds in the marine boundary layer are generally strong and consistent enough to maintain an airflow through the FSSP probe, several problems arise in the computations of the microphysical data when only the wind is used to blow particles through the probe. Wind drag on the instrument platform causes the probe to twist on the tether line away from the wind, which can result in significant errors in the calculations of particle densities. It is suggested a fan be used in future observational programs in order to regulate the airflow through the probe.

2. Profiles of the radiative fluxes throughout the cloud can be made quickly by continuously raising or lowering the balloon through the boundary layer. Profiles of the microphysics require prolonged stepped profiles through the cloud which may take 
several hours to complete. It appears the sampling time through the cloud may be reduced by shortening the time at each constant level leg to five or ten minutes. This would allow for a proper sampling of the cloud microphysics in a shorter period of time. The use of a series of continuous and short step profiles during the day would allow for better study of the changes in the cloud microphysical and radiative properties during the day. 


\section{REFERENCES}

Albrecht, B., and S. K. Cox, 1977: Procedures for improving pyrgeometer performance. J. Appl. Meteor., 16, 188-197.

Chou, M. -D., 1984: Broadband water vapor transmission functions for atmospheric IR flux computations. J. Atmos. Sci., 41, 1775-1778.

- , and A. Arking, 1980: Computation of infrared cooling rates in the water vapor bands. J. Atmos. Sci., 37, 855-867.

- - and A. Arking, 1981: An efficient method for computing the absorption of solar radiation by water vapor. J. Atmos. Sci., 38, 798-807.

- , and L. Peng, 1983: A parameterization of the absorption in the $15 \mu \mathrm{m}$ spectral region with application to climate sensitivity studies. J. Atmos. Sci., 40, 2183-2192.

Davies, R. and M. Blaskovic, 1988: Diurnal variation of marine stratocumulus over San Nicholas Island during the FIRE IFO. Preprint Volume, FIRE Science Team Workshop, 11-15 July, Vail, Colorado, 209-213.

Gerber, H., 1986: Tethered balloon measurements at San Nicholas Island (Oct. 1984): Instrumentation, data summary, preliminary data interpretation. NRL Report 8972, $77 \mathrm{pp}$.

S. Gathman, J. James, M. Smith, I. Consterdine and S. Brandeki, 1988: NRL tethered balloon measurements at San Nicholas Island during FIRE IFO. Preprint Volume, FIRE Science Team Workshop, 11-15 July, Vail, Colorado, 293-297.

Hansen, J. E., G. Russel, D. Rind, P. Stone, A. Lacis, S. Lebedeff, R. Ruedy and L. Travis, 1983: Efficient three-dimensional global models for climate studies: Models I and II. Mon. Wea. Rev., bf 111, 609-662.

Hignett, P., 1987: A study of the short-wave radiative properties of marine stratus: aircraft measurements and model comparisons. Quart. J. Roy. Meteor. Soc., 113, 10111024.

Hogg, D. C., F. O. Guiraud, J. B. Snider, M. T. Decker, and E. R. Westwater, 1983: A steerable dual-channel microwave radiometer for measurement of water vapor and liquid in the troposphere. J. Clim. Appl. Meteor., 22, 789-806.

Hudson, J. G., 1988: Aerosol measurements in the stratocumulus project. Preprint Volume, FIRE Science Team Workshop, 11-15 July, Vail, Colorado, 281-284.

Iqbal, M., 1983: An Introduction to Solar Radiation, Academic Press, 390 pp. 
King, M. D., and Harshvardhan, 1986: Comparative accuracy of selected multiple scattering approximations. J. Atmos. Sci., 43, 784-801.

McClatchey, R. A., R. W. Fenn, J. E. A. Selby, F. E. Voltz, and J. S. Garing, 1972: Optical properties of the atmosphere, 3rd ed. AFCRL-72-0497, 108 pp.

Meador, W. E., and W. R. Weaver, 1980: Two stream approximations to radiative transfer in planetary atmospheres: A unified description of existing methods and a new improvement. J. Atmos. Sci., 37, 630-643.

Nakajima, T., and M. D. King, 1988: Cloud optical parameters as derived from the multispectral cloud radiometer. Preprint Volume, FIRE Science Team Workshop, 11-15 July, Vail, Colorado, 321-326.

Paltridge, G. W., and C. M. R. Platt, 1976: Radiative Processes in Meteorology and Climatology, Elsevier, $318 \mathrm{pp}$.

Particle Measuring Systems, Inc, 1984: Forward scattering spectrometer probe PMS model FSSP-100, Operating and servicing manual, $58 \mathrm{pp}$.

Radke, L. F., J. H. Lyons, P. V. Hobbs, and J. E. Coakley, 1988: In situ measurements of "ship tracks". Preprint Volume, FIRE Science Team Workshop, 11-15 July, Vail, Colorado, 285-287.

Roberts, R. E., J. E. A. Selby and L. M. Biberman, 1976: Infrared continuum absorption by atmospheric water vapour in the 8-12 $\mu \mathrm{m}$ window. Appl. Opt., 15, 2085-2090.

Sagan, C., and J. B. Pollack, 1967: Anisotropic nonconservative scattering and the clouds of Venus. J. Geophys. Res., 72, 469-477.

Slingo, A., R. Brown and C. L. Wrench, 1982: A field study of nocturnal stratocumulus; III. high resolution radiative and microphysical observations. Quart. J. Roy. Meteor. Soc., 108, 145-165.

- , and H. M. Schrecker, 1982: On the shortwave properties of stratiform water clouds. Quart. J. Roy. Meteor. Soc.; 108, 407-426.

Snider, J. B., 1988: Estimated accuracy of ground-based liquid water measurements during FIRE. Preprint Volume, FIRE Science Team Workshop, 11-15 July, Vail, Colorado, 289-292.

Stackhouse, P. W., 1989: A theoretical and observational comparison of cirrus cloud radiative properties. M. S. Thesis, Colo. State Univ., Dept. of Atmos. Sci., Fort Collins. pp. 120.

Stephens, G. L., 1978: Radiation profiles in extended water clouds. I: Theory. J. Atmos. Sci., 35, 2111-2122.

- 1984: The parameterization of radiation for numerical weather prediction and climate models. Mon. Wea, Rev., 112, 826-867.

—, G. W. Paltridge and C. M. R. Platt, 1978: Radiation profiles in extended water clouds. III: Observations. J. Atmos. Sci., 35, 2133-2141. 
- , and P. J. Webster, 1979: Sensitivity of radiative forcing to variable cloud and moisture. J. Atmos. Sci., 36, 1542-1556.

- - and S. -C. Tsay, 1989: On the cloud absorption anomaly. Submitted to Quart. J. Roy. Meteo. Soc..

Twomey. S., and T. Cocks, 1982: Spectral reflectance of clouds in the near- infrared: comparison of measurements and calculations. J. Meteor. Soc. Japan, 60, 583-592. 